\title{
Surveillance for Cancers Associated with Tobacco Use — United States, 2010-2014
}




\section{CONTENTS}

Introduction .

The MMWR series of publications is published by the Center for Surveillance, Epidemiology, and Laboratory Services, Centers for Disease Control and Prevention (CDC), U.S. Department of Health and Human Services, Atlanta, GA 30329-4027.

Suggested citation: [Author names; first three, then et al., if more than six.] [Title]. MMWR Surveill Summ 2018;67(No. SS-\#):[inclusive page numbers].

\section{Centers for Disease Control and Prevention \\ Robert R. Redfield, MD, Director}

Anne Schuchat, MD, Principal Deputy Director

Chesley L. Richards, MD, MPH, Deputy Director for Public Health Scientific Services

Leslie Dauphin, PhD, Acting Director, Office of Science

Barbara A. Ellis, MS, PhD, Acting Director, Office of Science Quality

William R. Mac Kenzie, MD, Acting Director, Center for Surveillance, Epidemiology, and Laboratory Services

MMWR Editorial and Production Staff (Serials)

Charlotte K. Kent, PhD, MPH, Acting Editor in Chief, Executive Editor Christine G. Casey, MD, Editor

Mary Dott, MD, MPH, Online Editor

Teresa F. Rutledge, Managing Editor

David C. Johnson, Lead Technical Writer-Editor

Catherine B. Lansdowne, MS, Project Editor

Matthew L. Boulton, MD, MPH

Virginia A. Caine, MD

Katherine Lyon Daniel, $\mathrm{PhD}$

Jonathan E. Fielding, MD, MPH, MBA

David W. Fleming, MD
MMWR Editorial Board

Timothy F. Jones, MD, Chairman

William E. Halperin, MD, DrPH, MPH

Robin Ikeda, MD, MPH

Phyllis Meadows, PhD, MSN, RN

Jewel Mullen, MD, MPH, MPA

Jeff Niederdeppe, $\mathrm{PhD}$
Martha F. Boyd, Lead Visual Information Specialist

Maureen A. Leahy, Julia C. Martinroe, Stephen R. Spriggs, Tong Yang, Visual Information Specialists

Quang M. Doan, MBA, Phyllis H. King, Terraye M. Starr, Moua Yang, Information Technology Specialists

Patricia Quinlisk, MD, MPH

Patrick L. Remington, MD, MPH

Carlos Roig, MS, MA

William Schaffner, MD 


\title{
Surveillance for Cancers Associated with Tobacco Use - United States, 2010-2014
}

\author{
M. Shayne Gallaway, $\mathrm{PhD}^{1,2}$ \\ S. Jane Henley, $\mathrm{MSPH}^{1}$ \\ C. Brooke Steele, $\mathrm{DO}^{1}$ \\ Behnoosh Momin, DrPH${ }^{1}$ \\ Cheryll C. Thomas, $\mathrm{MSPH}^{1}$ \\ Ahmed Jamal, MBBS 3 \\ Katrina F. Trivers, $\mathrm{PhD}^{3}$ \\ Simple D. Singh, $\mathrm{MD}^{1}$ \\ Sherri L. Stewart, $\mathrm{PhD}^{1}$ \\ ${ }^{1}$ Division of Cancer Prevention and Control, National Center for Chronic Disease Prevention and Health Promotion, CDC \\ ${ }^{2}$ Commissioned Corps, U.S. Public Health Service, Rockville, Maryland \\ ${ }^{3}$ Office on Smoking and Health, National Center for Chronic Disease and Prevention and Health Promotion, CDC
}

\begin{abstract}
Problem/Condition: Tobacco use is the leading preventable cause of cancer, contributing to at least 12 types of cancer, including acute myeloid leukemia (AML) and cancers of the oral cavity and pharynx; esophagus; stomach; colon and rectum; liver; pancreas; larynx; lung, bronchus, and trachea; kidney and renal pelvis; urinary bladder; and cervix. This report provides a comprehensive assessment of recent tobacco-associated cancer incidence for each cancer type by sex, age, race/ethnicity, metropolitan county classification, tumor characteristics, U.S. census region, and state. These data are important for initiation, monitoring, and evaluation of tobacco prevention and control measures.
\end{abstract}

Period Covered: 2010-2014.

Description of System: Cancer incidence data from CDC's National Program of Cancer Registries and the National Cancer Institute's Surveillance, Epidemiology, and End Results program were used to calculate average annual age-adjusted incidence rates for 2010-2014 and trends in annual age-adjusted incidence rates for 2010-2014. These cancer incidence data cover approximately $99 \%$ of the U.S. population. This report provides age-adjusted cancer incidence rates for each of the 12 cancer types known to be causally associated with tobacco use, including liver and colorectal cancer, which were deemed to be causally associated with tobacco use by the U.S. Surgeon General in 2014. Findings are reported by demographic and geographic characteristics, percentage distributions for tumor characteristics, and trends in cancer incidence by sex.

Results: During 2010-2014, approximately 3.3 million new tobacco-associated cancer cases were reported in the United States, approximately 667,000 per year. Age-adjusted incidence rates ranged from 4.2 AML cases per 100,000 persons to 61.3 lung cancer cases per 100,000 persons. By cancer type, incidence rates were higher among men than women (excluding cervical cancer), higher among non-Hispanics than Hispanics (for all cancers except stomach, liver, kidney, and cervical), higher among persons in nonmetropolitan counties than those in metropolitan counties (for all cancers except stomach, liver, pancreatic, and AML), and lower in the West than in other U.S. census regions (all except stomach, liver, bladder, and AML). Compared with other racial/ethnic groups, certain cancer rates were highest among whites (oral cavity and pharyngeal, esophageal, bladder, and AML), blacks (colon and rectal, pancreatic, laryngeal, lung and bronchial, cervical, and kidney), and Asians/Pacific Islanders (stomach and liver). During 2010-2014, the rate of all tobacco-associated cancers combined decreased $1.2 \%$ per year, influenced largely by decreases in cancers of the larynx (3.0\%), lung $(2.2 \%)$, colon and rectum $(2.1 \%)$, and bladder $(1.3 \%)$.

Interpretation: Although tobacco-associated cancer incidence decreased overall during 2010-2014, the incidence remains high in several states and subgroups, including among men, whites, blacks, non-Hispanics, and persons in nonmetropolitan counties. These disproportionately high rates of tobacco-related cancer incidence reflect overall demographic patterns of cancer incidence in the United States and also reflect patterns of tobacco use.

Public Health Action: Tobacco-associated cancer incidence can be reduced through prevention and control of tobacco use and

Corresponding author: M. Shayne Gallaway, PhD; Telephone: 404498-0491; Email: mgallaway@cdc.gov. comprehensive cancer-control efforts focused on reducing cancer risk, detecting cancer early, and better assisting communities disproportionately affected by cancer. Ongoing surveillance 
to monitor cancer incidence can identify populations with a high incidence of tobacco-associated cancers and evaluate the effectiveness of tobacco control programs and policies. Implementation research can be conducted to achieve wider adoption of existing evidence-based cancer prevention and screening programs and tobacco control measures, especially to reach groups with the largest disparities in cancer rates.

\section{Introduction}

Tobacco use is the leading cause of preventable disease and death in the United States, and approximately 480,000 deaths per year are caused by cigarette smoking and secondhand smoke exposure, or nearly one in five deaths annually $(1,2)$. This includes approximately 41,000 deaths among adults and 400 deaths among infants resulting from secondhand smoke exposure $(1,3,4)$. Tobacco smoke contains approximately 7,000 chemicals, including hundreds that are toxic. Approximately 70 of these chemicals can cause cancer $(1,5)$. Forms of tobacco used in the United States include cigarettes, cigars, smokeless tobacco (i.e., chewing tobacco, snuff, dip, snus, and dissolvable tobacco), pipes, hookah (water pipes), bidis, and electronic cigarettes. In addition, smoking accounts for approximately $\$ 300$ billion annually in direct health care expenditures ( $\$ 170$ billion) and lost productivity ( $\$ 156$ billion) $(1,6)$.

The relation between smoking and lung cancer was first classified as causal in a landmark report released by the U.S. Surgeon General in 1964 (7). Subsequent Surgeon General reports have concluded that smoking causes acute myeloid leukemia (AML) and cancer in many other organ sites, including the cervix, esophagus, kidney and renal pelvis, larynx, trachea, lung and bronchus, oral cavity and pharynx (OCP), pancreas, stomach, and urinary bladder (2,7-18). Surgeon General reports also have concluded that the use of smokeless tobacco (i.e., snuff and chewing tobacco) causes cancers of the OCP and esophagus; cigar use causes cancers of the oral cavity, esophagus, larynx, and lung; and secondhand smoke exposure causes lung cancer (19). During 1999-2004, approximately 2.4 million new cases of tobacco-associated cancer were reported in the United States (19). In 2014, the Surgeon General expanded the list of cancer sites to include the liver, colon, and rectum (1). Approximately $30 \%$ of cancer deaths in the United States, including approximately $80 \%$ of lung cancer deaths, are attributable to tobacco $(1,2,20-23)$. The International Agency for Research on Cancer has drawn conclusions (24-28) similar to the findings in the Surgeon General's reports on tobacco and health.

When the first Surgeon General's report on the health hazards of smoking was released in 1964, the prevalence of cigarette smoking in the United States was $42 \%$ but has since decreased (1). During 2005-2016, the prevalence of cigarette smoking among U.S. adults decreased from $20.9 \%$ to $15.5 \%$, and the proportion of ever smokers (i.e., persons who have smoked at least 100 cigarettes during their lifetime) who quit increased from $50.8 \%$ to $59.0 \%$ (29). Despite this progress, the United States has not yet achieved the Healthy People 2020 target of reducing the proportion of U.S. adults aged $\geq 18$ years who smoke cigarettes to $\leq 12.0 \%(1,30)$. Moreover, large disparities in tobacco use remain across populations defined by race/ethnicity, sociodemographic status, U.S. census region, disability or limitation status, sexual orientation, and presence of serious psychological distress $(1,29,31)$.

Furthermore, increases have occurred in the use of other tobacco products and the use of multiple products among youths. In 2016, among current tobacco product users, $47.2 \%$ of high school students and $42.4 \%$ of middle school students used two or more tobacco products, and electronic cigarettes were the most commonly used tobacco products among high school (11.3\%) and middle school (4.3\%) students (32). Since 2000, the prevalence of smokeless tobacco use in the United States has increased among adult males $(6.7 \%)(1,33)$ and males in high school $(8.3 \%)(1,32)$.

At least half of persons who smoke cigarettes for 20 years are expected to die from a tobacco-related disease, although tobacco cessation significantly decreases this risk (34-36). Therefore, among the 37.8 million persons in the United States who were current cigarette smokers in 2016 (29), approximately 18.9 million persons might die prematurely from a tobacco-related disease, including 6 million from cancer. Many tobacco-associated cancers could be prevented by population-level reduction of tobacco use through sustained, comprehensive state tobacco control programs. Proven population-based interventions, including increased tobacco prices, comprehensive smoke-free laws, antitobacco mass media campaigns, and barrier-free access to cessation assistance are critical to reduce cigarette smoking and smoking-related disease and deaths among U.S. adults (29). To help evaluate the effectiveness of tobacco control programs and policies and identify populations at greatest risk for developing cancers associated with tobacco use, ongoing surveillance of these cancers is essential.

This report describes the incidence of tobacco-associated cancers in the United States by cancer type, demographic and tumor characteristics, and state and U.S. census region. In addition, recent trends in cancer incidence are described. Cancer incidence data enable public health professionals to more effectively identify needs for cancer prevention and control 
at the national, state, and local levels (37-39). These data can be used to develop public health actions to reduce disparities in cancer outcomes (40) and to help measure the effectiveness of state-level tobacco control strategies such as tobacco-price increase implementation and smoke-free laws (41).

\section{Methods}

To describe the incidence of tobacco-associated cancers in the United States, cancer incidence data from CDC's National Program of Cancer Registries (NPCR) and the National Cancer Institute's (NCI's) Surveillance, Epidemiology, and End Results (SEER) program (39) were analyzed. Each year, NPCR- and SEER-funded central registries submit data on cancer diagnosed during the most recent year to the respective program. Rigorous quality-control edits, data completeness evaluations, and data quality assessment are performed on all data, and a registry's data must meet multiple criteria (i.e., case ascertainment, missing information, and required fields) to be included in U.S. Cancer Statistics. The average annual age-adjusted rates and trends in rates for the most recent 5-year period with available data (2010-2014) are presented and cover $100 \%$ of the U.S. population. Combined data from the NPCR and SEER programs provide the best source of information on population-based cancer incidence for the United States (42).

\section{Incidence Data}

Data on new cases of cancer diagnosed during 2010-2014 were obtained from 51 population-based cancer registries affiliated with NPCR and SEER programs in each state, the District of Columbia (DC), and Puerto Rico. Data from all registries except Nevada met U.S. Cancer Statistics publication criteria (43) for all years during 2010-2014. Data for Nevada were excluded from all analyses. Data for Puerto Rico are included in state-specific analyses but not in U.S. census region analyses. Cases were first classified by anatomic site according to the International Classification of Diseases for Oncology, Third Edition (ICD-O-3) (44), and cases with hematopoietic histologies were classified further using the 2008 WHO Classification of Tumours of Haematopoietic and Lymphoid Tissues (45). Only cases of invasive cancer were included for all analyses, except for urinary bladder cancer, for which in situ tumors also were included.

Tobacco-associated cancers were defined as those classified by the U.S. Surgeon General as causally related to cigarette smoking (1). These include AML (ICD-O-3 histology codes: 9840, 9861, 9865-9867, 9869, 9871-9874, 9895-9898, 9910-9911, and 9920) and cancers of the OCP (C00.0C14.8); esophagus (C15.0-C15.9); stomach (C16.0-16.9); colon and rectum (C18.0-20.9 and C26.0); liver (C22.0); pancreas (C25.0-25.9); larynx (C32.0-32.9); trachea, lung, and bronchus (C33.9-34.9); cervix (C53.0-53.9); kidney and renal pelvis (C64.9-65.9); and urinary bladder (C67.0-67.9). Anatomic sites were restricted to cancers with histology codes 8000-9049, 9056-9139, and 9141-9589 (excluding mesothelioma, Kaposi sarcoma, and hematopoietic cancers). Because information on tobacco use was not routinely collected by all cancer registries, cases of all cancer classified as causal by the U.S. Surgeon General (1) are reported. Therefore, cases of cancer included in this report might or might not be in persons who used tobacco.

\section{Demographic and Tumor Characteristics}

Incidence rates were estimated by several demographic characteristics including sex, age, race/ethnicity, and U.S. census region. Age was categorized as <40, 40-49, 50-59, $60-69,70-79$, and $\geq 80$ years. Information about race/ethnicity was collected from medical records; race was classified as white, black, American Indian/Alaska Native (AI/AN), and Asian/ Pacific Islander (A/PI) and ethnicity as Hispanic or nonHispanic. Cases among persons with other or unknown race $(2 \%)$ or unknown ethnicity $(2 \%)$ were included in overall rates but were not included as separate categories because population denominators were not available. U.S. census regions included the Northeast (Connecticut, Maine, Massachusetts, New Hampshire, New Jersey, New York, Pennsylvania, Rhode Island, and Vermont); Midwest (Illinois, Indiana, Iowa, Kansas, Michigan, Minnesota, Missouri, Nebraska, North Dakota, Ohio, South Dakota, and Wisconsin); South (Alabama, Arkansas, DC, Delaware, Florida, Georgia, Kentucky, Louisiana, Maryland, Mississippi, North Carolina, Oklahoma, South Carolina, Tennessee, Texas, Virginia, and West Virginia); and West (Alaska, Arizona, California, Colorado, Hawaii, Idaho, Montana, New Mexico, Oregon, Utah, Washington, and Wyoming).

For some cancer sites, several tumor characteristics are described, including histology, anatomic subsite (i.e., a specific location within a cancer site, such as the lip [subsite] for OCP [site]), and stage at diagnosis. Histologic groups for each cancer site were determined by incidence or clinical relevance. SEER Summary Stage 2000 was used to characterize stage at diagnosis as localized (cancer that is confined to the primary site), regional (cancer that has spread directly beyond the primary site or to regional lymph nodes), distant (cancer that has spread to other organs), or unknown stage using clinical and pathologic tumor characteristics, such as tumor size, depth of invasion and extension to regional or distant tissues, involvement of regional lymph nodes, and distant metastases 
(https://seer.cancer.gov/tools/ssm). Analyses by tumor characteristics excluded cases that were reported only by death certificate or autopsy and cases that were not microscopically confirmed (except for liver cancer because a large percentage of these cancers [29\%] were confirmed by radiography).

\section{Statistical Analysis}

Population estimates for incidence rate denominators were a modification of annual county population estimates by age, sex, bridged race, and ethnicity produced by the U.S. Census Bureau in collaboration with CDC and with support from the National Cancer Institute (https://seer.cancer.gov/popdata). Incidence rates per 100,000 population were age adjusted to the 2000 U.S. standard population; $95 \%$ confidence intervals were calculated as modified gamma intervals (46) and are presented to allow for informal comparison among rates, without defining a referent group. Although using the overlap between confidence intervals to determine significance is conservative, the confidence intervals provide a measure of the variability in the rates and perspective for making comparisons. Trends in age-adjusted incidence rates of invasive cancer were examined (by site and sex [men, women, and combined]), and the annual percentage change (APC) was used to quantify changes in rates during 2010-2014 by using least-squares regression. A t-test was used to determine whether an APC was significantly different from zero. The APC and associated $\mathrm{p}$ value corresponds to the overall increasing or decreasing trends observed during this time. Rates were considered to increase if the APC $>0(p<0.05)$ and to decrease if the APC $<0$ $(\mathrm{p}<0.05)$; otherwise, rates were considered stable. State-specific age-adjusted tobacco-associated cancer incidence rates were mapped using quartiles as cut points.

\section{Results}

\section{Lung Cancer}

A total of 1,070,504 new cases (61.3 per 100,000 persons) of cancers of the lung, bronchus, and trachea (lung cancer) were reported in the United States during 2010-2014 (Table 1). Incidence rates were substantially higher among men (72.7) than among women (52.7). Rates increased with increasing age and peaked among persons aged 70-79 years (390.0). Among men, blacks had the highest rates (85.9), followed by whites (72.4), AI/ANs (52.2), and A/PIs (45.1). Among women, whites had the highest rates (54.3), followed by blacks (49.2), AI/ANs (39.0), and A/PIs (27.9). Rates were two times higher among non-Hispanics than among Hispanics (64.1 versus 31.9, respectively). Among those with known tumor characteristics $(88.1 \%)$, approximately $81 \%$ of all lung cancer cases were non-small cell carcinomas. Adenocarcinoma was the most common histologic subtype, although women had greater percentages of adenocarcinomas than men $(52.4 \%$ and $43.2 \%$, respectively). Men had greater percentages of squamous cell carcinoma than women $(28.9 \%$ and $19.4 \%$, respectively). More than half $(52.6 \%)$ of lung cancer cases were diagnosed at the distant stage. During 2010-2014, lung cancer incidence rates were higher in nonmetropolitan counties (69.4) than in metropolitan counties (59.8). Among men, rates were highest in the South (80.8) and lowest in the West (53.5). Among women, rates were highest in the Midwest (57.4) and lowest in the West (42.7). Kentucky and West Virginia had some of the highest rates both among men (98.8-116.3) and women (66.3-79.7) (Figures 1 and 2).

\section{Laryngeal Cancer}

A total of 62,479 new cases (3.5 per 100,000 persons) of laryngeal cancer were reported in the United States during 2010-2014 (Table 2). Incidence rates were substantially higher among men (6.0) than among women (1.3). Rates increased with increasing age and peaked among persons aged 70-79 years (16.2). Among men, blacks had the highest rates (8.5), followed by whites (5.9), AI/ANs (3.6), and A/PIs (2.2). Rates were higher among non-Hispanics than among Hispanics (3.6 and 2.5, respectively). Among those with known tumor characteristics $(97.1 \%)$, almost all (96.9\%) laryngeal cancers were squamous cell carcinomas. The majority (53.6\%) were diagnosed at a localized stage; however, a smaller percentage of localized cases occurred among women $(47.1 \%)$ than men $(55.3 \%)$. Women had a greater percentage of regional stage laryngeal cancer diagnoses than men $(32.2 \%$ and $22.0 \%$, respectively), whereas men had slightly greater percentages of distant stage diagnoses than women $(17.9 \%$ for men and $16.5 \%$ for women). During 2010-2014, laryngeal cancer incidence rates were higher in nonmetropolitan counties (4.2) than in metropolitan counties (3.3). Among men, rates were highest in the South region of the United States (6.8) and lowest in the West (4.0). Among women, rates were similar in the South, Midwest, and Northeast (1.4-1.6) and were lower in the West (0.8). Kentucky, Louisiana, Mississippi, and West Virginia had some of the highest rates both among men (8.3-9.4) and women (1.9-2.6) (Figures 3 and 4).

\section{Oral Cavity and Pharyngeal Cancer}

A total of 204,537 new cases (11.5 per 100,000 persons) of OCP cancer were reported in the United States during 2010-2014 (Table 3). Incidence rates were substantially higher among men (17.4) than among women (6.4). Rates increased 
with age and peaked among men aged $70-79$ years (63.6) and women aged $\geq 80$ years (29.4). Among men, whites had the highest rates (17.8), followed by blacks (14.5), A/PIs (11.2), and AI/ANs (10.9). Among women, whites had the highest rates (6.5), followed by blacks (5.1), A/PIs (5.0), and AI/ANs (4.1). Rates were higher among non-Hispanics than Hispanics (12.0 and 7.1, respectively). The most common subsites were the oral cavity (7.9) and tonsils (3.6) among men and the oral cavity (3.5) and salivary glands (1.0) among women. Among those with known tumor characteristics $(97.5 \%)$, the majority of OCP cancers were squamous cell carcinomas (85.9\%). Most were diagnosed at the localized (31.7\%) and regional (45.3\%) stages. However, a greater percentage of cases were diagnosed at the localized stage among women than men $(43.0 \%$ and $27.1 \%$, respectively), and a greater percentage of cases were diagnosed at the regional stage among men than women (49.0\% and 36.3\%, respectively). During 2010-2014, OCP cancer incidence rates were higher in nonmetropolitan counties (12.5) than in metropolitan counties (11.3). Among men, rates were highest in the South region of the United States (18.6) and lowest in the West (15.5). Among women, rates of OCP cancers were similar in the South, Midwest, and Northeast (6.5) and were lower in the West (5.9). Alabama, Arkansas, Florida, Kentucky, Louisiana, Mississippi, and Oklahoma had some of the highest rates both among men (19.9-21.8) and women (6.6-7.4) (Figures 5 and 6).

\section{Esophageal Cancer}

A total of 81,608 new cases (4.6 per 100,000 persons) of esophageal cancer were reported in the United States during 2010-2014 (Table 4). Incidence rates were higher among men (8.0) than among women (1.8). Rates increased with age and peaked among those aged $\geq 80$ years ( 45.0 among men and 12.6 among women). Among men, rates were highest among whites (8.2), followed by blacks (7.1), AI/ANs (5.3), and A/PIs (3.7). Among women, rates were highest among blacks (2.3), followed by whites (1.7), AI/ANs (1.4), and A/PIs (1.0). Rates were higher among non-Hispanics (4.8) than Hispanics (2.8). Among those with known tumor characteristics (94.7\%), approximately two thirds (65.4\%) of all esophageal cancer cases were adenocarcinomas, and slightly less than one third were squamous cell carcinomas (29.6\%). This pattern was consistent among men (71.1\% adenocarcinomas and 24.2\% squamous cell carcinomas). However, the pattern differed among women, who had greater percentages of squamous cell carcinomas $(50.1 \%)$ than adenocarcinomas (43.9\%). More esophageal cancers were diagnosed at regional (32.9\%) and distant (36.6\%) stages than at the localized stage (19.4\%). Men had slightly smaller percentages of localized disease (18.9\%) than women $(21.6 \%)$ and slightly greater percentages of distant disease (38.3\%) than women (30.1\%). During 2010-2014, esophageal cancer rates were higher in nonmetropolitan counties (5.1) than in metropolitan counties (4.5). Rates among men were highest in the Midwest (8.9) and lowest in the West (6.9). Rates among women were highest in the Northeast and Midwest (1.9-2.0) and lowest in the South and West (1.6-1.7). Vermont, Maine, and New Hampshire had some of the highest rates among men (10.2-11.7) and women (2.3-2.4) (Figures 7 and 8).

\section{Stomach Cancer}

A total of 115,147 new cases (6.7 per 100,000 persons) of stomach cancer were reported in the United States during 20102014 (Table 5). Incidence rates were higher among men than among women (9.2 and 4.6, respectively). Rates increased with increasing age and peaked among adults aged $\geq 80$ years (43.6). A/PIs had the highest rate (10.7), followed by blacks (10.3), AI/ ANs (6.3), and whites (6.0). Hispanics had higher rates than non-Hispanics (9.9 and 6.3, respectively). Among those with known tumor characteristics $(96.2 \%)$, approximately $86.3 \%$ of stomach cancers were adenocarcinomas; gastrointestinal stromal tumors accounted for $8.9 \%$. Approximately $60 \%$ of stomach cancers were diagnosed at the regional $(26.3 \%)$ or distant stage (33.6\%), with women having greater percentages of localized disease than men (34.2\% and $26.7 \%$, respectively). During 2010-2014, stomach cancer rates were higher in metropolitan counties (6.9) than in nonmetropolitan counties (5.8). Among men, rates were highest in the Northeast (10.7) and lowest in the Midwest and South (8.7). Among women, rates were highest in the Northeast (5.2) and lowest in the Midwest (4.0). DC, Hawaii, New Jersey, New York, Puerto Rico, and Rhode Island had some of the highest rates among men and women (Figures 9 and 10).

\section{Colon and Rectal Cancers}

A total of 689,738 new cases (39.8 per 100,000 persons) of colon and rectal cancers were reported in the United States during 2010-2014 (Table 6). Incidence rates were substantially higher among men (45.8) than among women (34.8). Rates increased with age and peaked in women and men aged $\geq 80$ years. Rates were highest among blacks (46.7), followed by whites (38.9), A/PIs (31.4), and AI/ANs (30.9). NonHispanics had higher rates than Hispanics (40.3 and 35.0, respectively). Among those with known tumor characteristics (96.1\%), approximately two thirds $(67.9 \%)$ of all colon and rectal cancers were adenocarcinomas; adenomas accounted for $17.5 \%$. Approximately $60 \%$ of colon and rectal cancers were diagnosed at the regional or distant stage (55.8\%), 
with similar distributions among women and men. During 2010-2014, colon and rectal cancer rates were slightly higher in nonmetropolitan counties (43.1) than in metropolitan counties (39.1). Rates among men and women were highest in the Midwest (48.0 and 36.4, respectively) and lowest in the West (41.4 and 32.0, respectively). Louisiana, Mississippi, and Kentucky had the highest rates both among men (56.0-59.3) and women (41.4-42.4) (Figures 11 and 12).

\section{Liver Cancer}

A total of 126,165 new cases (6.9 per 100,000 persons) of liver cancer were reported in the United States during 2010 2014 (Table 7). Incidence rates were higher among men than among women (11.0 and 3.3, respectively). Among persons aged $<80$ years, rates increased with increasing age and peaked among adults aged $70-79$ years (27.2). Among men, rates were highest among A/PIs (18.5), followed by blacks (16.0), AI/ANs (12.8), and whites (9.8). Among women, rates were highest among A/PIs (6.6), followed by AI/ANs (5.6), blacks (4.3), and whites (2.9). Hispanics had higher rates than non-Hispanics (12.1 and 6.4, respectively). Among those with known tumor characteristics (94.2\%), 86.4\% of cases of liver cancer were hepatocellular carcinoma, and $7.2 \%$ were adenocarcinoma. Men had greater percentages of hepatocellular carcinomas than women $(89.1 \%$ and $78.3 \%$, respectively), whereas women had greater percentages of adenocarcinomas than men $(12.4 \%$ and $5.5 \%$, respectively). The majority of liver cancer cases $(44.8 \%)$ were diagnosed at the localized stage. Women had greater percentages of localized stage liver cancer diagnoses than men $(47.5 \%$ and $43.9 \%$, respectively), whereas men had greater percentages of regional stage liver cancer diagnoses $(28.0 \%$ and $24.2 \%$, respectively). During 2010-2014, liver cancer rates were higher in metropolitan counties (7.2) than in nonmetropolitan counties (5.8). Among men and women, liver cancer cases were highest in the West (12.2 and 4.0, respectively) and lowest in the Midwest (8.8 and 2.8, respectively). California, DC, Hawaii, New Mexico, and Texas had some of the highest rates of liver cancer among men (13.6-19.5) and women (3.9-5.3) (Figures 13 and 14).

\section{Pancreatic Cancer}

A total of 218,919 new cases (12.5 per 100,000 persons) of pancreatic cancer were reported in the United States during 2010-2014 (Table 8). Incidence rates were higher among men than among women (14.2 and 11.0, respectively). Rates increased with increasing age and peaked among adults aged $\geq 80$ years (93.1). Blacks had the highest rates (15.5), followed by whites (12.3), A/PIs (9.3), and AI/ANs (8.2). Non-Hispanics had higher rates than Hispanics (12.6 and 11.1, respectively).
Among those with known tumor characteristics (81.9\%), 79.7\% of pancreatic cancer cases were adenocarcinomas, and 3.3\% were mucinous adenocarcinomas. Ductal carcinomas accounted for $9.8 \%$ of pancreatic cancer diagnoses. Approximately half (51.5\%) of pancreatic cancer cases were diagnosed at the distant stage; $33.8 \%$ of pancreatic cancers were diagnosed at the regional stage, and $10.5 \%$ were diagnosed at the localized stage. During 2010-2014, pancreatic cancer rates were slightly higher in metropolitan counties (12.6) than in nonmetropolitan counties (12.1). Among men and women, pancreatic cancer rates were highest in the Northeast (15.4 and 12.0, respectively) and lowest in the West (13.2 and 10.4, respectively). DC, Delaware, Hawaii, Louisiana, Mississippi, New Jersey, New York, and Pennsylvania had some of the highest rates of pancreatic cancer among men (15.4-18.0) and women (11.9-13.8) (Figures 15 and 16).

\section{Kidney and Renal Pelvis Cancers}

A total of 280,883 new cases (16.1 per 100,000 persons) of kidney and renal pelvis cancers were reported in the United States during 2010-2014 (Table 9). Incidence rates were almost twice as high among men (21.8) than among women (11.3). In persons aged $<80$ years, rates increased with increasing age and peaked among men and women aged 70-79 years (97.5 and 48.5, respectively). Blacks had the highest rates (17.6), followed by whites (16.3), AI/ANs (15.7), and A/PIs (7.5). Rates were similar among non-Hispanics (16.2) and Hispanics (16.0). Among those with known tumor characteristics $(89.7 \%)$, the majority $(87.9 \%)$ of cases of kidney cancer were renal cell carcinomas. Transitional cell carcinoma accounted for $6.7 \%$ of cases, and other adenocarcinomas accounted for $2.5 \%$ of cases. At diagnosis, $67.2 \%$ of cases of kidney cancer were at a localized stage. During 2010-2014, kidney cancer rates were higher in nonmetropolitan counties (17.1) than in metropolitan counties (15.9). Among men, kidney cancer incidence rates were highest in the South, Northeast, and Midwest (22.2-22.9) and lowest in the West (19.7). Among women, rates were highest in the Midwest (12.1) and lowest in the West (9.9). Kentucky, Louisiana, and Mississippi had some of the highest rates of kidney cancer among men (26.2-28.4) and women (14.4-15.8) (Figures 17 and 18).

\section{Urinary Bladder Cancer}

A total of 354,478 new urinary bladder cancer cases (20.5 per 100,000 persons) were reported in the United States during 2010-2014 (Table 10). Incidence rates were approximately four times higher among men (35.8) than among women (8.8). Rates increased with increasing age and peaked among adults aged $\geq 80$ years (340.8 and 73.2 among men and women aged $\geq 80$ years, respectively). Whites had the highest rates (21.8), 
followed by blacks (11.7), AI/ANs (9.0), and A/PIs (8.5). Rates were higher among non-Hispanics (21.3) than Hispanics (11.2). Among those with known tumor characteristics $(97.8 \%)$, the majority of cases of urinary bladder cancer were transitional cell carcinomas (94.9\%) and were diagnosed at a localized stage (85.6\%). Among men during 2010-2014, urinary bladder cancer incidence rates were higher in nonmetropolitan counties (36.2) than in metropolitan counties (35.7). Among women, bladder cancer incidence rates did not differ between nonmetropolitan and metropolitan counties. Among men and women, bladder cancer incidence rates were highest in the Northeast ( 42.5 and 11.0, respectively) and lowest in the West (32.5 and 7.8, respectively). Connecticut, Delaware, Maine, Massachusetts, New Hampshire, New Jersey, New York, Pennsylvania, and Rhode Island had the highest rates of urinary bladder cancer among men (40.5-48.1) and women (10.5-12.8) (Figures 19 and 20).

\section{Cervical Cancer}

A total of 61,499 new cervical cancer cases ( 7.5 per 100,000 women) were reported in the United States during 2010-2014 (Table 11). Women aged 40-49 years had the highest rates of cervical cancer (14.3). Rates were highest among blacks (9.3), followed by whites (7.3), AI/ANs (6.5), and A/PIs (6.1). Rates were higher among Hispanics (9.7) than among non-Hispanics (7.3). Among those with known tumor characteristics (97.1\%), the majority of cervical cancer cases were squamous cell carcinomas (66.1\%); adenocarcinomas accounted for $27.6 \%$. Most cervical cancer cases were diagnosed at the localized (43.8\%) or regional (36.2\%) stage. During 2010-2014, cervical cancer rates were higher in nonmetropolitan counties (8.4) than in metropolitan counties (7.4). Cervical cancer cases were highest in the South (8.3) and lowest in the Northeast, Midwest, and West (6.9-7.1). Alabama, Arkansas, DC, Florida, Kentucky, Louisiana, Mississippi, Oklahoma, Puerto Rico, Texas, and West Virginia had the highest rates of cervical cancers (8.6-12.9) (Figure 21).

\section{Acute Myeloid Leukemia}

A total of 70,960 new AML cases (4.2 per 100,000 persons) were reported in the United States during 2010-2014 (Table 12). Incidence rates were higher among men than among women (5.2 and 3.5, respectively). Rates increased with increasing age and peaked among adults aged $\geq 80$ years (26.3). Whites had the highest rates (4.3), followed by blacks (3.5), A/PIs (3.4), and AI/ANs (2.7). Non-Hispanics had higher rates than Hispanics (4.3 and 3.6, respectively). During 2010-2014, AML incidence rates were similar between metropolitan and nonmetropolitan counties (4.2). Among men and women, AML incidence rates were highest in the Northeast and Midwest (5.5 among men and 3.7 among women) and lowest in the South and West (4.9-5.0 among men and 3.4 among women). Hawaii, Illinois, Indiana, Iowa, Kentucky, Maine, Pennsylvania, South Dakota, and Wisconsin had some of the highest rates among men (5.6-6.3) and women (3.7-4.1) (Figures 22 and 23).

\section{Estimated Annual Percentage Change in Incidence Rates of Tobacco-Associated Cancers}

During 2010-2014, APCs in incidence rates of tobaccoassociated cancers varied by site, sex, and men and women combined (Table 13) (Supplementary Table 1, https://stacks. cdc.gov/view/cdc/59431; Supplementary Table 2, https:// stacks.cdc.gov/view/cdc/59432). Significant decreases in cancers of the lung $(2.17 \%$ per year), larynx $(3.00 \%)$, esophagus $(0.86 \%)$, stomach $(1.01 \%)$, urinary bladder $(1.28 \%)$, and colon and rectum $(2.07 \%)$ occurred among men and women combined (Table 13). Although esophageal and stomach cancer rates decreased overall, rates remained stable among women. The decrease in lung cancer rates was significantly greater among men $(2.88 \%)$ than among women $(1.47 \%)$. Significant increases in liver $(1.98 \%$ per year) and kidney $(0.54 \%)$ cancer and AML $(0.34 \%)$ occurred in men and women combined. Rates for OCP, pancreatic, and cervical cancers were stable during 2010-2014.

\section{Discussion}

\section{Interpretation of Tobacco-Associated Cancer Incidence}

Approximately 3.3 million cases of tobacco-associated cancer were reported in the United States during 2010-2014 (approximately 667,000 each year), with lung cancer accounting for about a third of these diagnoses. The incidence of tobacco-associated cancers was higher among men than women. Black, white, and non-Hispanic populations had consistently higher incidence rates than other racial/ethnic populations, with a few exceptions. The majority of tobaccoassociated cancers occurred among persons aged $\geq 70$ years. Except for AML and cancers of the stomach, liver, and pancreas, tobacco-associated cancer rates were higher among nonmetropolitan counties than in metropolitan counties. The high rates among men, whites, blacks, non-Hispanics, older adults, and nonmetropolitan county residents reflect overall demographic patterns of cancer incidence in the United States 
(39) and patterns of tobacco use. In 2016, an estimated 15.5\% of adults in the United States (37.8 million persons) smoked cigarettes, with smoking being more common among men (17.5\%) than among women (13.5\%) (29). The prevalence of cigarette smoking in 2016 varied among racial/ethnic groups; the highest prevalence was among AI/ANs (31.8\%), followed by persons of multiple races $(25.2 \%)$, whites $(16.6 \%)$, blacks (16.5\%), Hispanics (10.7\%), and A/PIs (9.0\%) (29). Smoking prevalence among AI/ANs varies by region of the country, and cancer rates tend to parallel these differences (47). Blacks and whites had the highest tobacco-associated cancer incidence rates in this report and the second-and third-highest smoking prevalence, respectively, among racial/ethnic populations.

Substantial variation in tobacco use prevalence exists by state among adults in the United States (48). During 2014-2015, nine of the 10 states with the highest prevalence of current use of any tobacco product were in either the South (West Virginia [26.9\%], Kentucky [26.2\%], Arkansas [24.0\%], Oklahoma [23.8\%], Alabama [23.1\%], and Tennessee [22.7\%]) or in the Midwest (Ohio [23.8\%], South Dakota [23.0\%], and North Dakota [22.6\%]) (47). States with the lowest prevalence of current use of any tobacco product were in the West (California [10.2\%] and Utah [10.9\%]) (48). In this report, lung, laryngeal, OCP, kidney, and cervical cancer incidence rates were highest in the South and the Midwest. Cancer incidence rates were consistently lowest in the West for all the cancers in this report, with the exception of kidney and stomach cancers.

Cancers of the lung and bronchus, larynx, and OCP have the greatest average relative risks $(1,22,49)$ associated with tobacco use. Lung cancer is the second most commonly diagnosed cancer among men (after prostate cancer) and women (after breast cancer) and is the leading cause of cancer death both among men and women in the United States (39). The average tobacco-associated lung cancer relative risk ranges from 15.0 to $30.0(1,22,49)$. Tobacco use causes all histologic types of lung cancer $(1,50)$. Similar to previous studies, this study demonstrates that the percentage of squamous cell carcinoma of the lung is higher among men than among women, whereas the percentage of adenocarcinoma of the lung is higher among women than among men $(19,51)$. In the United States, the decrease in squamous cell carcinoma followed the trend of decreasing smoking prevalence (1). Adenocarcinoma rates in the United States increased in the 1980s and 1990s before decreasing through 2004 and reportedly increasing again during 2006-2010; however, much of this latter increase reflects improved classification of tumors previously designated as "other non-small cell lung cancer" $(1,52)$. The proportion of lung cancers classified as adenocarcinoma has increased over time and adenocarcinoma is now the most common type of lung cancer both among men and women smokers $(1,27)$.

In 2013, the U.S. Preventive Services Task Force recommended annual screening with low-dose computed tomography (LDCT) for persons at high risk for lung cancer (i.e., adults aged 55-80 years who have a history of smoking 30 packs per year and currently smoke or have quit within the past 15 years) (53). However, the percentage of persons screened has been low, with $3.3 \%$ of eligible smokers reporting LDCT screening in the past 12 months in 2010 and 3.9\% in 2015 (54). The reasons for underuse of screening might include smokers' lack of awareness about this test and limited health care access, as well as physicians' lack of knowledge about screening recommendations and concerns about false-positive results (55). Some studies have reported that eligible patients who benefit most from screening are those with chronic obstructive pulmonary disease (COPD) $(56,57)$. Compared with patients with normal baseline spirometry who receive annual screening with LDCT, patients with COPD have a greater incidence of lung cancer and are more likely to be detected with early stage disease $(56,57)$. Additional research is needed to determine whether current screening recommendations can be modified to include COPD status.

Laryngeal cancer is relatively rare in the United States (39). The average tobacco-associated relative risk for laryngeal cancer ranges from 10.0 to $17.0(1,22,49)$. Tobacco use is the single most important risk factor for developing laryngeal cancer $(1,2,7)$. The decrease in laryngeal cancer incidence rates observed in this study among men and women is consistent with decreasing incidence rates reported outside the United States (58). The decrease might be partially explained by changes in tobacco use (1). Alcohol use also is a risk factor for laryngeal cancer, and when used together, alcohol and tobacco have a synergistic effect on laryngeal cancer development $(26,59)$. However, the prevalence of alcohol consumption among U.S. adults has not decreased substantially in recent years $(60)$. Decreased dietary fiber intake also might be associated with risk for laryngeal cancer, particularly among women (61-63).

OCP cancer is the ninth most common cancer in the United States among men but is less common among women (39). This type of cancer includes tumors with origins in several anatomic organs of the head and neck. The average relative risk for tobacco-associated OCP cancer is 4.0-5.0 $(1,22,49)$. Use of all tobacco products, including cigarettes, cigars, pipes, and smokeless tobacco, are linked to head and neck cancer $(2,7,28)$. Strong evidence implicates tobacco as a carcinogenic factor in squamous cell cancers of the head and neck $(1,28)$. The predominant histologic tumor type of OCP cancer observed in this study was squamous cell carcinoma. Previous studies 
have demonstrated that cessation of tobacco use leads to a decrease in the risk for OCP cancer (64). Alcohol use is a risk factor for the development of OCP cancer, independent of the effects of tobacco use (65-67). The use of both alcohol and tobacco have a synergistic effect on the development of OCP cancers (26), accounting for as many as $64 \%$ of oral cavity and $72 \%$ of pharyngeal cancers $(59,65,68)$. Infection with human papillomavirus (HPV), particularly HPV16, increases the risk for cancer at certain OCP sites, including the oropharynx, base of the tongue, and tonsils $(69,70)$.

Cancers of the pancreas, urinary bladder, and colon and rectum have similar relative risks associated with tobacco use (pancreas, 2.0-4.0; urinary bladder, 3.0; colon and rectum, $1.9-2.5)(1,22,49,71)$. Pancreatic cancer is among the 10 most common cancers diagnosed in the United States and is the fifth leading cause of cancer death among men and women in the United States (39). Although recent increases in pancreatic cancer incidence might be due to increases in the prevalence of excess body weight (72), previous decreases were attributed to decreases in smoking prevalence (1). One study indicated that cigarette smoke increased tumor growth and metastases in pancreatic cancer cells (73). Human and animal studies have found that functional nicotinic receptors are present on pancreatic islet and beta cells, and nicotine can reduce the release of insulin through neuronal nicotinic acetylcholine receptors on islet cells (74). The collection of multiple studies in animals and humans strongly supports the hypothesis that cigarette smoking and exposure to nicotine can adversely affect insulin action and the function of pancreatic cells, both of which play fundamental roles in the pathogenesis of diabetes (75). Being overweight or having obesity, having a personal history of diabetes or chronic pancreatitis, and several genetic syndromes also are associated with increased risk for pancreatic cancer $(76,77)$. Findings from a recent meta-analysis show that increased fruit and vegetable intake is associated with decreased risk for pancreatic cancer (78).

Urinary bladder cancer is the fourth most commonly diagnosed cancer and the seventh leading cause of cancer death among men in the United States (39). Among women, urinary bladder cancer is much less common. The average tobacco-associated bladder cancer relative risk is $4.0(22,49)$. The decrease in bladder cancer incidence rates reported in this study among men and women is consistent with findings from other studies $(19,79)$. The incidence of urinary bladder cancer has decreased among men and women in the United States since 1999 (79). The strongest risk factor for bladder cancer in the United States is cigarette smoking. Approximately half of all bladder cancers are caused by cigarette smoking (80-82). Quitting smoking decreases the risk for bladder cancer by approximately $40 \%$ within $1-4$ years $(80,81,83)$. Pipe and cigar use (among noncigarette smokers) also is associated with increased risk for bladder cancer among men (81).

Colorectal cancer (i.e., cancer of the colon and rectum) is the second most common cancer diagnosed and the second leading cause of cancer death among men and women combined in the United States (39). Colorectal cancer is one of two additional cancers (including liver cancer) that were causally linked to tobacco use in the 2014 Surgeon General's report (1). The incidence of colorectal cancer has decreased steadily since 2001; most recently, incidence decreased an average of 3\% annually during 2005-2014 (84). This decrease might be due to increased colorectal cancer screening through the detection of precancerous polyps, which can then be removed before becoming cancerous, thus decreasing cancer incidence (72,85). Risk for colorectal cancer has been reported to increase with increased daily cigarette consumption and duration of smoking $(86,87)$. Long-term cigarette smoking is associated with increased incidence of colorectal cancer and risk for death from colorectal cancer in men and women $(1,27)$. In a study examining metabolites of tobacco smoking and colorectal cancer risk, persons with detectable levels of serum hydroxycotinine were reported to have a greater risk than those with undetectable levels (88). Additional research using biomarkers for smoking behaviors might help refine estimates of the association between cigarette smoking and colorectal cancer risk. An increased risk for colorectal cancer is associated with excessive alcohol use (89), being overweight or having obesity (90), consumption of processed or red meat (91), and certain genetic factors. Physical activity and fiber consumption might reduce the risk for colorectal cancer (92).

AML, esophageal, kidney, stomach, liver, and cervical cancers have similar relative risks associated with tobacco use (1.5-2.5) $(1,22,49)$. Esophageal cancer is not as commonly diagnosed in the United States as other cancers included in this report; however, esophageal cancer is one of the top 10 leading causes of cancer death among most racial/ethnic male populations (39). Squamous cell carcinoma of the esophagus was the more prevalent histologic subtype in the United States until the mid-1990s, when the incidence of squamous cell carcinoma decreased while the incidence of adenocarcinoma increased, resulting in adenocarcinoma becoming the most common histologic subtype (93-95). Current smokers have a three to five times higher risk for developing squamous cell carcinoma compared with never smokers, and former smokers have a significantly lower risk for developing this subtype compared with current smokers $(96,97)$. Increased time since quitting smoking is associated with decreased risk for squamous cell carcinomas $(96,97)$. The incidence of squamous cell carcinoma of the esophagus has decreased sharply in North America since the early 1970s, which is likely due to lower rates of smoking 
$(96,98,99)$. In contrast, during this same period, the incidence of adenocarcinoma of the esophagus has increased (95). Both current and former smokers have approximately twice the risk for developing this subtype as never smokers $(96,97)$. Esophageal adenocarcinoma also is associated with obesity and alcohol use (96). The prevalence of obesity among U.S. adults aged $\geq 20$ years increased from 1999-2000 through 2015-2016 (100). Obesity has been most strongly associated with early onset (among persons aged $\leq 50$ years) esophageal adenocarcinoma (101). In 2016, 55.0\% of adults in the United States reported drinking alcohol in the past month, a slight increase from 1997 (53.5\%) (102).

Kidney cancer is among the 10 most common cancers diagnosed both among men and women in the United States (39). Smoking is an important risk factor for kidney cancers (103). Cohort studies have reported positive associations between smoking and kidney cancer incidence $(104,105)$ and death $(106,107)$. In addition to smoking, excess body weight, and hypertension are risk factors for kidney cancer $(104,108,109)$. Both for men and women, incidence rates of kidney cancer during 2010-2014 were higher compared with previously published estimates for 1999-2004 (19). Certain studies suggest that these increases might have resulted from increased detection of kidney cancer through recent increased use of ultrasound and computed tomography for non-cancer-related conditions (110-112) or from increases in the prevalence of overweight and obesity (42).

Stomach cancer is common among certain racial/ethnic populations in the United States (39). Among current smokers, risk for stomach cancer increases with the number of cigarettes smoked per day and duration of smoking (113). The risk for stomach cancer decreases as time since stopping smoking increases (113). Tobacco use is related to both cardia and noncardia stomach cancer (96). Former, light, and moderate cigarette smokers have slightly higher risks for developing gastric cardia cancer than noncardia cancer (113). The incidence rate of stomach cancer in this report was higher among A/PIs, non-Hispanic blacks, and Hispanics compared with non-Hispanic whites. The finding in this report that stomach cancer incidence has been decreasing in recent years is consistent with a decrease that has been occurring since the middle of the 20th century in high-income countries in North America and Western Europe and also more recently in areas with historically high rates of stomach cancer (e.g., Asia and Latin America) (114). Trends in decreasing stomach cancer rates might be attributable to decreased prevalence of Helicobacter pylori infection resulting from improved sanitation and use of antibiotics, increased availability of fresh produce, and lower consumption of salt-preserved and smoked food $(92,115)$. In addition, decreases in smoking (in countries with high rates of tobacco use) might have contributed to the decreasing trends of stomach cancer incidence (116). H. pylori is a major risk factor for noncardia gastric cancer; therefore, the decrease in stomach cancer incidence largely reflects decreasing occurrence at this anatomic subsite $(114,117)$. In contrast to noncardia gastric cancer, rates of cardia gastric cancer are increasing in the United States and other high-income countries (114). This increase might be associated with increases in obesity or improvements in classification of stomach tumors (118).

Liver cancer is among the 10 most common cancers diagnosed among nonwhite men in the United States and the fifth leading cause of cancer death among all men in the United States (39). Although liver cancer occurs more frequently in less developed regions of the world $(1,119)$, this cancer type is still a substantial health concern in the United States. Liver cancer is one of two additional cancers (including colorectal) that was causally linked to tobacco use in the 2014 Surgeon General's report (1). Approximately 30,000 new cases of liver cancer are diagnosed every year in the United States, with approximately 20,000 associated deaths $(1,39)$. In addition to cigarette smoking, metabolic disorders (including obesity), infection with hepatitis $\mathrm{B}$ virus or hepatitis $\mathrm{C}$ virus, and alcohol use are risk factors for developing liver cancer (120). Long-term exposure to carcinogens in smoke might cause cellular damage in the liver and contribute to the development of cancer (1). Smoking has also been recognized as a risk factor for primary biliary cirrhosis, a condition that can progress to hepatocellular carcinoma, or primary liver cancer (121-123), and smoking cessation has benefitted patients with chronic liver diseases (122). A 2009 meta-analysis (124) showed an estimated 50\% increased risk for liver cancer among current smokers compared with never smokers (i.e., adults who have never smoked or who have smoked $<100$ cigarettes in their lifetime).

Although the overall incidence of cervical cancer is low in the United States, black and Hispanic women continue to have a higher incidence than white women (39). Smoking has been consistently associated with an increased risk for cervical cancer, and risk increases with increased daily cigarette smoking and duration of smoking (125-127). Although tobacco use is associated with cervical cancer, the primary risk factor is HPV infection, which is thought to be responsible for approximately $90 \%$ of cervical cancers (128). In this report, HPV infection likely contributed to the lower incidence rate among women aged 40-49 years, as well as the high rate among black and Hispanic women $(128,129)$. The combination of smoking and HPV infection might increase the risk, such that women who are HPV-positive and smoke have a twofold increased risk for cervical cancer compared with women who are HPVpositive and have never smoked $(126,127)$. Women who have quit smoking cigarettes for long periods have a decreased risk 
for cervical cancer compared with current smokers, even after adjusting for the presence of an HPV infection (126). Cervical cancer is largely preventable with the HPV vaccine, current recommendations are to routinely vaccinate girls and boys aged 11-12 years; women up to age 26 years and men up age 21 years also might be vaccinated if they were not previously (130). Routine screening remains an important part of cervical cancer prevention $(131,132)$. Two tests can be used for cervical cancer screening: a Papanicolaou (Pap) test and an HPV test; one or both of these tests is recommended, depending on the age of the woman (132). Special outreach efforts to increase cervical cancer screening among black and Hispanic women are underway (131). Targeted education about the dangers of tobacco use in these populations might also be warranted.

AML is a relatively rare cancer in the United States (39). Cigarette smoking is an established risk factor for AML in adults $(133,134)$. One of the carcinogens contained in cigarette smoke is benzene, which is strongly associated with increased risk for AML (3). Current smokers have a 40\% increased risk for developing AML compared with nonsmokers (134). AML risk also increases with higher intensity (i.e., number of cigarettes smoked daily) and longer duration (i.e., number of years) of smoking (134). Smoking cessation might decrease AML risk (135). In this report, AML incidence rates were highest among white men and women, and the Midwest and Northeast had the highest incidence rates among men. A previous report noted U.S. state incidence rates of AML were inconsistent with smoking patterns (19). In this report, many states with the highest observed AML incidence rates among men (i.e., Connecticut, Hawaii, Illinois, Iowa, Maine, New York, Pennsylvania, and Wisconsin) also were not those with the highest rates of smoking in the United States (48). The etiology for most cases of AML is unclear. Other environmental exposures and genetic risk factors might play a role (136).

\section{Public Health Implications}

Implementing tobacco control policies and programs as recommended by Ending the Tobacco Epidemic: A Tobacco Control Strategic Action Plan by the U.S. Department of Health and Human Service (137) and Ending the Tobacco Problem: A Blueprint for the Nation by the National Academy of Medicine (NAM, formerly the Institute of Medicine) (138) would accelerate the decrease of tobacco use among youths and adults and accelerate progress toward achieving the Healthy People 2020 objectives to reduce cigarette smoking (1). The NAM report presented a blueprint for action to reduce tobacco use to a level that would eliminate smoking as a public health problem. The two-pronged strategy for achieving this goal included 1) strengthening and fully implementing traditional tobacco control measures and 2) changing the legal framework to permit policy innovations. Sustained implementation of comprehensive state tobacco control programs can accelerate progress toward reducing adult smoking prevalence $(32,139)$.

CDC recommends that each state establish and sustain a comprehensive tobacco control program that contains the following overarching components: state and community interventions; health communication interventions that reach large audiences (i.e., mass-reach interventions); cessation interventions; surveillance and evaluation; and infrastructure, administration, and management (139). Evidence-based statewide tobacco control programs that are comprehensive, sustained, and accountable have decreased smoking rates and tobacco-associated diseases and deaths (139). A comprehensive statewide tobacco control program is a coordinated effort to establish smoke-free policies and social norms, promote and assist with cessation of tobacco, and prevent initiation of tobacco use. CDC's Best Practices for Comprehensive Tobacco Control Programs - 2014 is an evidence-based guide to help states plan and establish comprehensive tobacco control programs (139). The report describes an integrated programmatic structure for implementing effective interventions and estimates the recommended level of state investment to reach these goals and to reduce tobacco use in each state. Additional support for tobacco prevention and control is available from CDC's National Comprehensive Cancer Control Program (NCCCP), which in 1998 began providing financial support and technical assistance to states, tribes, and territories to create, implement, and evaluate cancer control plans (140). A 2013 analysis of 69 NCCCP cancer plans showed that every plan contained at least one CDC-recommended, evidence-based tobacco control strategy (141). Strategies incorporated were consistent with CDC's Best Practices for Comprehensive Tobacco Control Programs or The Guide to Community Preventive Services (141). CDC also funds the Consortium of National Networks to Impact Populations Experiencing Tobacco-Related and Cancer Health Disparities and the National Tobacco Control Program, which both promote tobacco use prevention and cancer prevention among persons at highest risk for tobacco use $(140,142)$.

Increased state investments in tobacco control programs, compared with the overall U.S. investments, are more positively correlated with decreases in cigarette sales and the prevalence of smoking (143-145). For example, during 2001-2010, decreases in smoking prevalence among adults and youths in New York (as reported by the New York State Tobacco Control Program) were higher than overall U.S. decreases in smoking prevalence (146). As a result, smoking-attributable personal health care expenditures in New York in 2010 were $\$ 4.1$ billion less than they would have been had the prevalence of smoking 
remained at 2001 levels (146). In addition to benefits of larger investments in tobacco control programs on smoking rates, research also shows that the longer states invest in such programs, the greater and more rapid the impact $(138,139)$. For example, in California, which has the nation's first and longest-running comprehensive tobacco control program, the prevalence of smoking among adults decreased from $22.7 \%$ in 1988 to $10.5 \%$ in 2015 (147). Correspondingly, lung cancer incidence has decreased nearly four times faster in California than in the rest of the United States (148). Other states such as Colorado (149), Florida (150), Massachusetts (151), and Minnesota (152) also have decreased smoking among adults and youths through various approaches. Data from continued monitoring of cancer incidence rates and death rates at the local, state, and national levels can be used to evaluate the impact of these and other public health successes in reducing the effects of tobacco use.

Preventive services recommended by the U.S. Preventive Services Task Force for decreasing tobacco-associated cancers include tobacco cessation counseling and treatment as well as screening for cervical, colorectal, and lung cancers to help detect the diseases at an early, often treatable, stage (153). The Advisory Committee for Immunization Practices recommends hepatitis $B$ virus and HPV vaccinations to prevent infection with these viruses that are also known to cause tobaccoassociated cancers (liver, cervical, and OCP). NCCCP funds states, DC, tribes, and territories to work through state and local level cancer coalitions to ensure access to these early detection and treatment services, implement evidence-based programs to prevent cancer, and support cancer survivorship activities. Federal initiatives also can help reduce tobacco use and tobacco-associated cancers. For example, a 1997 executive order established a smoke-free environment for federal employees and members of the public visiting or using federal facilities by prohibiting smoking of tobacco products in all interior spaces owned, rented, or leased by the executive branch of the federal government (154).

Continued research is important to identify additional types of cancer that might be associated with tobacco use as well as to enhance understanding of how tobacco exposure affects the cellular processes responsible for promotion and progression of the cancers examined in this report. In 2014, the Surgeon General's report reviewed the evidence on smoking and cancers of prostate and breast; however, evidence to establish causality was inadequate or insufficient (1). Among men in the United States, prostate cancer is the most commonly diagnosed cancer and the second leading cause of cancer death (39). Evidence suggests that smoking, especially current or recent smoking, is a risk factor for death from prostate cancer but not for incidence, indicating that continued smoking might lead to higher risk for disease progression (1). Evidence of a positive association between smoking and prostate cancer deaths but no association with incidence is consistent across prospective cohort studies conducted in various settings and decades (1). Prostate cancer mortality is higher among smokers than nonsmokers (1). However, the mortality rates in former smokers who quit years in the past suggests that quitting smoking might reduce prostate cancer mortality (1). The Surgeon General's report recommended future research needs to refine the temporal relation between smoking, cessation, and prostate cancer diagnoses and related mortality (1).

Breast cancer is the most frequently diagnosed type of cancer (other than nonmelanoma skin cancers) and the second leading cause of cancer death among women in the United States (39). The Surgeon General concluded that the evidence suggests but is not sufficient to infer a causal relation between active smoking or secondhand tobacco smoke exposure and breast cancer (1). Evidence (including several large cohort studies) suggests a person with a history of ever smoking has a $10 \%$ increased likelihood of receiving a breast cancer diagnosis, an association that although significant, is weak (1). The International Agency for Research on Cancer similarly concluded that the overall association between smoking and breast cancer is weaker than the association between smoking and other cancers and that the dose-response relations (i.e., pack years, cigarettes smoked per day, and age at initiation) are correspondingly small (27). As stated in the 2014 Surgeon General's report, because breast cancer is the most common cancer type among women, decreases in smoking might have a substantial impact on the overall incidence of breast cancer (1).

\section{Future Directions}

This report examines the incidence of tobacco-associated cancers by demographic and tumor characteristics and by state and U.S. census region. Examination of county-level patterns within states might be helpful in determining areas with disproportionately high cancer incidence or death rates. Using tools such as State Cancer Profiles (https://statecancerprofiles. cancer.gov) could help identify prevalence of risk factors and use of screening tests that might affect these rates. Additional research and data evaluation are needed to determine whether a causal relation exists between smoking and cancers of the prostate and breast.

\section{Limitations}

The findings in this report are subject to at least four limitations. First, because information about tobacco use and other risk factors for cancer is not available in all cancer registry data, these results should not be used to describe 
cancer rates among smokers. Rather, the incidence rates are limited to cancers that are known to be associated with tobacco use. Second, cancer has many different risk factors and combinations of factors, including tobacco use; therefore, the number of cases and trends in tobacco-associated cancers also might be affected by changes in these other risk factors or cancer screening trends. Third, although this report includes estimates of tobacco-associated cancers, it does not estimate what proportion of these cancers are attributable to tobacco use. Although the 2014 Surgeon General's report was used to define tobacco-associated cancers, not all incident cancers for each cancer site are necessarily caused by smoking; likewise, using this definition might underestimate the true incidence because evidence that tobacco use might cause additional cancers is still accumulating (1). Finally, findings related to race/ethnicity might have been affected if race/ethnicity information was incorrectly collected or recorded in the medical record; ongoing procedures are used to ensure that this information is as accurate as possible (155). For example, to minimize misclassification of AI/ANs, some previous studies have restricted analyses to Contract Health Service Delivery Area (CHSDA) counties and have found that rates for AI/ ANs in CHSDA counties are generally higher than for AI/ ANs in all U.S. counties (156). In general, CHSDA counties contain federally recognized tribal lands or are adjacent to tribal lands; however, rates restricted to these counties might not be generalizable to all AI/ANs because only $64 \%$ of AI/ANs live in a CHSDA county and because CHSDA counties tend to be in more rural areas and in Western states (156).

\section{Conclusion}

Tobacco-associated cancer incidence can be reduced through efforts to prevent and control tobacco use and other comprehensive cancer control efforts focused on reducing cancer risk, detecting cancer early, and better assisting communities disproportionately impacted by cancer. Continued surveillance to measure characteristics within states can help identify populations with tobacco-associated disparities (157). Continued monitoring of cancer incidence rates at the local, state, and national levels can identify populations with high rates of tobacco-associated cancers and help evaluate the effectiveness of targeted tobacco control programs and policies.

\section{Conflict of Interest}

No conflicts of interest were reported.

\section{References}

1. US Department of Health and Human Services. The health consequences of smoking - 50 years of progress: a report of the Surgeon General. Atlanta, GA: US Department of Health and Human Services, CDC; 2014. https:// www.surgeongeneral.gov/library/reports/50-years-of-progress/index.html

2. US Department of Health and Human Services. The health consequences of smoking. a report of the Surgeon General. Atlanta, GA: US Department of Health and Human Services, CDC; 2004. https://www.cdc.gov/ tobacco/data_statistics/sgr/2004/complete_report/index.htm

3. National Toxicology Program. Benzene. In: Report on carcinogens. 14th ed. Research Triangle Park, NC: US Department of Health and Human Services, US Public Health Service, National Toxicology Program; 2016. https://ntp.niehs.nih.gov/pubhealth/roc/index-1.html

4. Max W, Sung HY, Shi Y. Deaths from secondhand smoke exposure in the United States: economic implications. Am J Public Health 2012;102:2173-80. https://doi.org/10.2105/AJPH.2012.300805

5. National Toxicology Program. Tobacco-related exposures. In: Report on carcinogens. 14th ed. Research Triangle Park, NC: US Department of Health and Human Services, US Public Health Service, National Toxicology Program; 2016. https://ntp.niehs.nih.gov/pubhealth/roc/ index-1.html

6. Xu X, Bishop EE, Kennedy SM, Simpson SA, Pechacek TF. Annual healthcare spending attributable to cigarette smoking: an update. Am J Prev Med 2015;48:326-33. https://doi.org/10.1016/j.amepre.2014.10.012

7. US Department of Health Education and Welfare. Smoking and health: report of the Advisory Committee to the Surgeon General of the Public Health Service. Washington, DC: US Department of Health, Education, and Welfare, US Public Health Service; 1964.

8. US Department of Health and Human Services. How tobacco smoke causes disease- the biology and behavioral basis for smoking-attributable disease: a report of the Surgeon General. Atlanta, GA: US Department of Health and Human Services, CDC; 2010.

9. US Department of Health and Human Services. The health consequences of smoking for women: a report of the Surgeon General. Washington, DC: US Department of Health and Human Services, US Public Health Service; 1980.

10. US Department of Health and Human Services. The health consequences of smoking: cancer: a report of the Surgeon General. Washington, DC: US Department of Health and Human Services, US Public Health Service; 1982.

11. US Department of Health and Human Services. The health benefits of smoking cessation: a report of the Surgeon General. Atlanta, GA: US Department of Health and Human Services, US Public Health Service; 1990.

12. US Department of Health Education and Welfare. The health consequences of smoking: a Public Health Service review. Washington, DC: US Department of Health, Education, and Welfare; 1967.

13. US Department of Health Education and Welfare. The health consequences of smoking: 1968 Supplement to the 1967 Public Health Service Review. Washington, DC: US Department of Health, Education, and Welfare; 1968.

14. US Department of Health Education and Welfare. The health consequences of smoking. Washington, DC: US Department of Health, Education, and Welfare; 1971.

15. US Department of Health Education and Welfare. The health consequences of smoking. Washington, DC: US Department of Health, Education, and Welfare; 1972.

16. US Department of Health Education and Welfare. The health consequences of smoking. Washington, DC: US Department of Health, Education, and Welfare; 1974.

17. US Department of Health Education and Welfare. Smoking and health: a report of the Surgeon General. Washington, DC: US Department of Health, Education, and Welfare; 1979. 
18. US Department of Health Education and Welfare. The health consequences of smoking: nicotine addiction: a report of the Surgeon General. Washington, DC: US Department of Health, Education, and Welfare; 1988.

19. Stewart SL, Cardinez CJ, Richardson LC, et al; CDC. Surveillance for cancers associated with tobacco use-United States, 1999-2004. MMWR Surveill Summ 2008;57(No. SS-8).

20. Doll R, Hill AB. The mortality of doctors in relation to their smoking habits; a preliminary report. BMJ 1954;1:1451-5. https://doi. org/10.1136/bmj.1.4877.1451

21. Doll R, Hill AB. Lung cancer and other causes of death in relation to smoking; a second report on the mortality of British doctors. BMJ 1956;2:1071-81. https://doi.org/10.1136/bmj.2.5001.1071

22. Islami F, Goding Sauer A, Miller KD, et al. Proportion and number of cancer cases and deaths attributable to potentially modifiable risk factors in the United States. CA Cancer J Clin 2018;68:31-54. https:// doi.org/10.3322/caac. 21440

23. Lortet-Tieulent J, Goding Sauer A, Siegel RL, et al. State-Level Cancer Mortality Attributable to Cigarette Smoking in the United States. JAMA Intern Med 2016;176:1792-8. https://doi.org/10.1001/ jamainternmed.2016.6530

24. International Agency for Research on Cancer. Tobacco smoking. IARC Monogr Eval Carcinog Risks Hum 1986;38:1-421.

25. International Agency for Research on Cancer. Overall evaluations of carcinogenicity: an updating of IARC Monographs volumes 1 to 42. IARC Monogr Eval Carcinog Risks Hum Suppl 1987;7:1-440.

26. International Agency for Research on Cancer Working Group on the Evaluation of Carcinogenic Risks to Humans. Tobacco smoke and involuntary smoking. IARC Monogr Eval Carcinog Risks Hum 2004;83:1-1438.

27. International Agency for Research on Cancer. Personal habits and indoor combustions: a review of human carcinogens. IARC Monogr Eval Carcinog Risks Hum 2012;100(Part E):1-598.

28. International Agency for Research on Cancer. Smokeless tobacco and some tobacco-specific N-nitrosamines. Monographs on the evaluation of carcinogenic risks to humans. IARC Monogr Eval Carcinog Risks Hum 2007;89:1-641.

29. Jamal A, Phillips E, Gentzke AS, et al. Current cigarette smoking among adults-United States, 2016. MMWR Morb Mortal Wkly Rep 2018;67:53-9. https://doi.org/10.15585/mmwr.mm6702a1

30. US Department of Health and Human Services. Tobacco use. In: Healthy people 2020. Washington, DC: US Department of Health and Human Services; 2012. https://www.healthypeople.gov/2020/topics-objectives/ topic/tobacco-use/objectives?topicId=41

31. Berkowitz Z, Zhang X, Richards TB, Peipins L, Henley SJ, Holt J. Multilevel small-area estimation of multiple cigarette smoking status categories using the 2012 Behavioral Risk Factor Surveillance System. Cancer Epidemiol Biomarkers Prev 2016;25:1402-10. https://doi. org/10.1158/1055-9965.EPI-16-0244

32. Jamal A, Gentzke A, Hu SS, et al. Tobacco use among middle and high school students-United States, 2011-2016. MMWR Morb Mortal Wkly Rep 2017;66:597-603. https://doi.org/10.15585/mmwr. mm6623a1

33. Center for Behavioral Health Statistics and Quality. Results from the 2014 National Survey on Drug Use and Health: detailed tables. Rockville, MD: Center for Behavioral Health Statistics and Quality; 2015. https://www.samhsa.gov/data/sites/default/files/NSDUHDetTabs2014/NSDUH-DetTabs2014.pdf

34. Banks E, Joshy G, Weber MF, et al. Tobacco smoking and all-cause mortality in a large Australian cohort study: findings from a mature epidemic with current low smoking prevalence. BMC Med 2015;13:38. https://doi.org/10.1186/s12916-015-0281-z

35. Doll R, Peto R. Mortality in relation to smoking: 20 years' observations on male British doctors. BMJ 1976;2:1525-36. https://doi.org/10.1136/ bmj.2.6051.1525
36. Doll R, Peto R, Boreham J, Sutherland I. Mortality in relation to smoking: 50 years' observations on male British doctors. BMJ 2004;328:1519. https://doi.org/10.1136/bmj.38142.554479.AE

37. Glaser SL, Clarke CA, Gomez SL, O’Malley CD, Purdie DM, West DW. Cancer surveillance research: a vital subdiscipline of cancer epidemiology. Cancer Causes Control 2005;16:1009-19. https://doi.org/10.1007/ s10552-005-4501-2

38. Parkin DM. The evolution of the population-based cancer registry. Nat Rev Cancer 2006;6:603-12. https://doi.org/10.1038/nrc1948

39. US Cancer Statistics Working Group. U.S. cancer statistics: 1999-2014 incidence and mortality web-based report. Atlanta, GA; 2017. https:// www.cdc.gov/cancer/npcr/pdf/uscs_factsheet.pdf

40. White MC, Babcock F, Hayes NS, et al. The history and use of cancer registry data by public health cancer control programs in the United States. Cancer 2017;123(Suppl 24):4969-76. https://doi.org/10.1002/ cncr.30905

41. Black BL, Cowens-Alvarado R, Gershman S, Weir HK. Using data to motivate action: the need for high quality, an effective presentation, and an action context for decision-making. Cancer Causes Control 2005;16(Suppl 1):15-25. https://doi.org/10.1007/s10552-005-0457-5

42. Jemal A, Ward EM, Johnson CJ, et al. Annual report to the nation on the status of cancer, 1975-2014, featuring survival. J Natl Cancer Inst 2017;109:109. https://doi.org/10.1093/jnci/djx030

43. US Cancer Statistics Working Group. U.S. cancer statistics publication criteria. Atlanta, GA; 2017. https://www.cdc.gov/cancer/npcr/uscs/ technical_notes/criteria.htm

44. Fritz A, Percy C, Jack A, et al. International classification of diseases for oncology (ICD-O-3). 3rd ed. Geneva, Switzerland: World Health Organization; 2000.

45. National Cancer Institute. Hematopoietic codes based on WHO classification of tumours of haematopoietic and lymphoid tissues. Rockville, MD: US Department of Health and Human Services, National Cancer Institute; 2008.

46. Tiwari RC, Clegg LX, Zou Z. Efficient interval estimation for ageadjusted cancer rates. Stat Methods Med Res 2006;15:547-69. https:// doi.org/10.1177/0962280206070621

47. Plescia M, Henley SJ, Pate A, Underwood JM, Rhodes K. Lung cancer deaths among American Indians and Alaska Natives, 1990-2009. Am J Public Health 2014;104(Suppl 3):S388-95. https://doi.org/10.2105/ AJPH.2013.301609

48. Odani S, Armour BS, Graffunder CM, Willis G, Hartman AM, Agaku IT. State-specific prevalence of tobacco product use among adults-United States, 2014-2015. MMWR Morb Mortal Wkly Rep 2018;67:97-102. https://doi.org/10.15585/mmwr.mm6703a3

49. Vineis P, Alavanja M, Buffler P, et al. Tobacco and cancer: recent epidemiological evidence. J Natl Cancer Inst 2004;96:99-106. https:// doi.org/10.1093/jnci/djh014

50. Khuder SA. Effect of cigarette smoking on major histological types of lung cancer: a meta-analysis. Lung Cancer 2001;31:139-48. https:// doi.org/10.1016/S0169-5002(00)00181-1

51. Houston KA, Henley SJ, Li J, White MC, Richards TB. Patterns in lung cancer incidence rates and trends by histologic type in the United States, 2004-2009. Lung Cancer 2014;86:22-8. https://doi.org/10.1016/j. lungcan.2014.08.001

52. Lewis DR, Check DP, Caporaso NE, Travis WD, Devesa SS. U.S. lung cancer trends by histologic type. Cancer 2014;120:2883-92. https:// doi.org/10.1002/cncr.28749

53. Moyer VA; US Preventive Services Task Force. Screening for lung cancer: U.S. Preventive Services Task Force recommendation statement. Ann Intern Med 2014;160:330-8. https://doi.org/10.7326/M13-2771

54. Jemal A, Fedewa SA. Lung cancer screening with low-dose computed tomography in the United States-2010 to 2015. JAMA Oncol 2017;3:1278-81. https://doi.org/10.1001/jamaoncol.2016.6416 
55. Ersek JL, Eberth JM, McDonnell KK, et al. Knowledge of, attitudes toward, and use of low-dose computed tomography for lung cancer screening among family physicians. Cancer 2016;122:2324-31. https:// doi.org/10.1002/cncr.29944

56. de-Torres JP, Casanova C, Marín JM, et al. Exploring the impact of screening with low-dose CT on lung cancer mortality in mild to moderate COPD patients: a pilot study. Respir Med 2013;107:702-7. https://doi. org/10.1016/j.rmed.2013.01.013

57. Young RP, Duan F, Chiles C, et al. Airflow limitation and histology shift in the National Lung Screening Trial. The NLST-ACRIN Cohort Substudy. Am J Respir Crit Care Med 2015;192:1060-7. https://doi. org/10.1164/rccm.201505-0894OC

58. Chatenoud L, Garavello W, Pagan E, et al. Laryngeal cancer mortality trends in European countries. Int J Cancer 2016;138:833-42. https:// doi.org/10.1002/ijc.29833

59. Hashibe M, Brennan P, Chuang SC, et al. Interaction between tobacco and alcohol use and the risk of head and neck cancer: pooled analysis in the International Head and Neck Cancer Epidemiology Consortium. Cancer Epidemiol Biomarkers Prev 2009;18:541-50. https://doi. org/10.1158/1055-9965.EPI-08-0347

60. Dwyer-Lindgren L, Flaxman AD, Ng M, Hansen GM, Murray CJ, Mokdad AH. Drinking patterns in U.S. counties from 2002 to 2012. Am J Public Health 2015;105:1120-7. https://doi.org/10.2105/ AJPH.2014.302313

61. Kawakita D, Lee YA, Turati F, et al. Dietary fiber intake and head and neck cancer risk: a pooled analysis in the International Head and Neck Cancer Epidemiology consortium. Int J Cancer 2017;141:1811-21. https://doi.org/10.1002/ijc.30886

62. Lam TK, Cross AJ, Freedman N, et al. Dietary fiber and grain consumption in relation to head and neck cancer in the NIH-AARP Diet and Health Study. Cancer Causes Control 2011;22:1405-14. https:// doi.org/10.1007/s10552-011-9813-9

63. Pelucchi C, Talamini R, Levi F, et al. Fibre intake and laryngeal cancer risk. Ann Oncol 2003;14:162-7. https://doi.org/10.1093/annonc/mdg032

64. Marron M, Boffetta P, Zhang ZF, et al. Cessation of alcohol drinking, tobacco smoking and the reversal of head and neck cancer risk. Int J Epidemiol 2010;39:182-96. https://doi.org/10.1093/ije/dyp291

65. Blot WJ, McLaughlin JK, Winn DM, et al. Smoking and drinking in relation to oral and pharyngeal cancer. Cancer Res 1988;48:3282-7.

66. Lubin JH, Muscat J, Gaudet MM, et al. An examination of male and female odds ratios by BMI, cigarette smoking, and alcohol consumption for cancers of the oral cavity, pharynx, and larynx in pooled data from 15 case-control studies. Cancer Causes Control 2011;22:1217-31. https:// doi.org/10.1007/s10552-011-9792-x

67. Talamini R, La Vecchia C, Levi F, Conti E, Favero A, Franceschi S. Cancer of the oral cavity and pharynx in nonsmokers who drink alcohol and in nondrinkers who smoke tobacco. J Natl Cancer Inst 1998;90:1901-3. https://doi.org/10.1093/jnci/90.24.1901

68. Hashibe M, Sturgis EM. Epidemiology of oral-cavity and oropharyngeal carcinomas: controlling a tobacco epidemic while a human papillomavirus epidemic emerges. Otolaryngol Clin North Am 2013;46:507-20. https://doi.org/10.1016/j.otc.2013.05.001

69. Gillison ML, Koch WM, Capone RB, et al. Evidence for a causal association between human papillomavirus and a subset of head and neck cancers. J Natl Cancer Inst 2000;92:709-20. https://doi.org/10.1093/ jnci/92.9.709

70. IARC Working Group on the Evaluation of Carcinogenic Risks to Humans. Human papillomaviruses. IARC Monogr Eval Carcinog Risks Hum 2007;90:1-636.

71. Botteri E, Iodice S, Raimondi S, Maisonneuve P, Lowenfels AB. Cigarette smoking and adenomatous polyps: a meta-analysis. Gastroenterology 2008;134:388-95.e3. https://doi.org/10.1053/j.gastro.2007.11.007
72. Steele CB, Thomas CC, Henley SJ, et al. Vital signs: trends in incidence of cancers associated with overweight and obesity-United States, 2005-2014. MMWR Morb Mortal Wkly Rep 2017;66:1052-8. https:// doi.org/10.15585/mmwr.mm6639e1

73. Momi N, Ponnusamy MP, Kaur S, et al. Nicotine/cigarette smoke promotes metastasis of pancreatic cancer through $\alpha 7 \mathrm{nAChR}$-mediated MUC4 upregulation. Oncogene 2013;32:1384-95. https://doi. org/10.1038/onc.2012.163

74. Yoshikawa H, Hellström-Lindahl E, Grill V. Evidence for functional nicotinic receptors on pancreatic beta cells. Metabolism 2005;54:247-54. https://doi.org/10.1016/j.metabol.2004.08.020

75. Xie XT, Liu Q, Wu J, Wakui M. Impact of cigarette smoking in type 2 diabetes development. Acta Pharmacol Sin 2009;30:784-7. https://doi. org/10.1038/aps.2009.49

76. Nöthlings U, Wilkens LR, Murphy SP, Hankin JH, Henderson BE, Kolonel LN. Meat and fat intake as risk factors for pancreatic cancer: the multiethnic cohort study. J Natl Cancer Inst 2005;97:1458-65. https://doi.org/10.1093/jnci/dji292

77. Tersmette AC, Petersen GM, Offerhaus GJ, et al. Increased risk of incident pancreatic cancer among first-degree relatives of patients with familial pancreatic cancer. Clin Cancer Res 2001;7:738-44.

78. Wu QJ, Wu L, Zheng LQ, Xu X, Ji C, Gong TT. Consumption of fruit and vegetables reduces risk of pancreatic cancer: evidence from epidemiological studies. Eur J Cancer Prev 2016;25:196-205. https:// doi.org/10.1097/CEJ.0000000000000171

79. Espey DK, Wu XC, Swan J, et al. Annual report to the nation on the status of cancer, 1975-2004, featuring cancer in American Indians and Alaska Natives. Cancer 2007;110:2119-52. https://doi.org/10.1002/ cncr.23044

80. Brennan P, Bogillot O, Greiser E, et al. The contribution of cigarette smoking to bladder cancer in women (pooled European data). Cancer Causes Control 2001;12:411-7. https://doi. org/10.1023/A:1011214222810

81. Freedman ND, Silverman DT, Hollenbeck AR, Schatzkin A, Abnet CC. Association between smoking and risk of bladder cancer among men and women. JAMA 2011;306:737-45. https://doi.org/10.1001/ jama.2011.1142

82. Kirkali Z, Chan T, Manoharan M, et al. Bladder cancer: epidemiology, staging and grading, and diagnosis. Urology 2005;66(Suppl 1):4-34. https://doi.org/10.1016/j.urology.2005.07.062

83. Burger M, Catto JW, Dalbagni G, et al. Epidemiology and risk factors of urothelial bladder cancer. Eur Urol 2013;63:234-41. https://doi. org/10.1016/j.eururo.2012.07.033

84. Howlander N, Noone AM, Krapcho M, et al. SEER cancer statistics review, 1975-2014. Bethesda, MD: National Cancer Institute; 2017. https://seer.cancer.gov/archive/csr/1975_2014

85. White A, Thompson TD, White MC, et al. Cancer screening test useUnited States, 2015. MMWR Morb Mortal Wkly Rep 2017;66:201-6. https://doi.org/10.15585/mmwr.mm6608a1

86. Liang PS, Chen TY, Giovannucci E. Cigarette smoking and colorectal cancer incidence and mortality: systematic review and meta-analysis. Int J Cancer 2009;124:2406-15. https://doi.org/10.1002/ijc.24191

87. Tsoi KK, Pau CY, Wu WK, Chan FK, Griffiths S, Sung JJ. Cigarette smoking and the risk of colorectal cancer: a meta-analysis of prospective cohort studies. Clin Gastroenterol Hepatol 2009;7:682-688.e5, 688. e1-5. https://doi.org/10.1016/j.cgh.2009.02.016

88. Cross AJ, Boca S, Freedman ND, et al. Metabolites of tobacco smoking and colorectal cancer risk. Carcinogenesis 2014;35:1516-22. https:// doi.org/10.1093/carcin/bgu071

89. Fedirko V, Tramacere I, Bagnardi V, et al. Alcohol drinking and colorectal cancer risk: an overall and dose-response meta-analysis of published studies. Ann Oncol 2011;22:1958-72. https://doi.org/10.1093/annonc/mdq653 
90. Ma Y, Yang Y, Wang F, et al. Obesity and risk of colorectal cancer: a systematic review of prospective studies. PLoS One 2013;8:e53916. https://doi.org/10.1371/journal.pone.0053916

91. International Agency for Research on Cancer. Red meat and processed meat. IARC Monogr Eval Carcinog Risks Hum 2018;114.

92. World Cancer Research Fund; American Institute for Cancer Research. Diet, nutrition, physical activity and cancer: A global perspective. Continuous update project expert report 2018. London, England: World Cancer Research Fund International; 2018. https://www.wcrf. org/dietandcancer/resources-and-toolkit

93. Blot WJ, McLaughlin JK. The changing epidemiology of esophageal cancer. Semin Oncol 1999;26(Suppl 15):2-8.

94. Brown LM, Devesa SS, Chow WH. Incidence of adenocarcinoma of the esophagus among white Americans by sex, stage, and age. J Natl Cancer Inst 2008;100:1184-7. https://doi.org/10.1093/jnci/djn211

95. Trivers KF, Sabatino SA, Stewart SL. Trends in esophageal cancer incidence by histology, United States, 1998-2003. Int J Cancer 2008;123:1422-8. https://doi.org/10.1002/ijc.23691

96. Dong J, Thrift AP. Alcohol, smoking and risk of oesophago-gastric cancer. Best Pract Res Clin Gastroenterol 2017;31:509-17. https://doi. org/10.1016/j.bpg.2017.09.002

97. Wang QL, Xie SH, Li WT, Lagergren J. Smoking cessation and risk of esophageal cancer by histological type: Systematic review and meta-analysis. J Natl Cancer Inst 2017;109. https://doi.org/10.1093/jnci/djx115

98. Lubin JH, Cook MB, Pandeya N, et al. The importance of exposure rate on odds ratios by cigarette smoking and alcohol consumption for esophageal adenocarcinoma and squamous cell carcinoma in the Barrett's Esophagus and Esophageal Adenocarcinoma Consortium. Cancer Epidemiol 2012;36:306-16. https://doi.org/10.1016/j. canep.2012.03.001

99. Pandeya N, Williams GM, Sadhegi S, Green AC, Webb PM, Whiteman DC. Associations of duration, intensity, and quantity of smoking with adenocarcinoma and squamous cell carcinoma of the esophagus. Am J Epidemiol 2008;168:105-14. https://doi.org/10.1093/aje/kwn091

100. Hales CM, Carroll MD, Fryar CD, Ogden CL. Prevalence of obesity among adults and youth: United States, 2015-2016. Hyattsville, MD: National Center for Health Statistics, CDC; 2017.

101. Drahos J, Xiao Q, Risch HA, et al. Age-specific risk factor profiles of adenocarcinomas of the esophagus: A pooled analysis from the international BEACON consortium. Int J Cancer 2016;138:55-64. https://doi.org/10.1002/ijc.29688

102. CDC. BRFSS prevalence and trends data. Atlanta, GA: CDC; 2016. https://www.cdc.gov/brfss/brfssprevalence

103. CDC. Kidney cancer. Atlanta, GA: CDC; 2018. https://www.cdc.gov/ cancer/kidney/index.htm

104. Flaherty KT, Fuchs CS, Colditz GA, et al. A prospective study of body mass index, hypertension, and smoking and the risk of renal cell carcinoma (United States). Cancer Causes Control 2005;16:1099-106. https://doi.org/10.1007/s10552-005-0349-8

105. McLaughlin JK, Hrubec Z, Heineman EF, Blot WJ, Fraumeni JF Jr. Renal cancer and cigarette smoking in a 26-year followup of U.S. veterans. Public Health Rep 1990;105:535-7.

106. Coughlin SS, Neaton JD, Randall B, Sengupta A. Predictors of mortality from kidney cancer in 332,547 men screened for the multiple risk factor intervention trial. Cancer 1997;79:2171-7. https://doi.org/10.1002/ (SICI) 1097-0142(19970601)79:11<2171::AID-CNCR15>3.0.CO;2-T

107. Weir JM, Dunn JE Jr. Smoking and mortality: a prospective study. Cancer 1970;25:105-12. https://doi.org/10.1002/10970142(197001)25:1<105::AID-CNCR2820250115>3.0.CO;2-Z
108. Chow WH, Gridley G, Fraumeni JF Jr, Järvholm B. Obesity, hypertension, and the risk of kidney cancer in men. N Engl J Med 2000;343:1305-11. https://doi.org/10.1056/NEJM200011023431804

109. Liss M, Natarajan L, Hasan A, Noguchi JL, White M, Parsons JK. Physical activity decreases kidney cancer mortality. Curr Urol 2017;10:193-8. https://doi.org/10.1159/000447180

110. Jayson M, Sanders H. Increased incidence of serendipitously discovered renal cell carcinoma. Urology 1998;51:203-5. https://doi.org/10.1016/ S0090-4295(97)00506-2

111. Miller DC, Ruterbusch J, Colt JS, et al. Contemporary clinical epidemiology of renal cell carcinoma: insight from a population based case-control study. J Urol 2010;184:2254-8. https://doi.org/10.1016/j. juro.2010.08.018

112. Stafford HS, Saltzstein SL, Shimasaki S, Sanders C, Downs TM, Sadler GR. Racial/ethnic and gender disparities in renal cell carcinoma incidence and survival. J Urol 2008;179:1704-8. https://doi.org/10.1016/j. juro.2008.01.027

113. Praud D, Rota M, Pelucchi C, et al. Cigarette smoking and gastric cancer in the Stomach Cancer Pooling (StoP) Project. Eur J Cancer Prev 2018;27:124-33. https://doi.org/10.1097/CEJ.0000000000000290

114. Torre LA, Siegel RL, Ward EM, Jemal A. Global cancer incidence and mortality rates and trends - an update. Cancer Epidemiol Biomarkers Prev 2016;25:16-27. https://doi.org/10.1158/1055-9965.EPI-15-0578

115. Blaser MJ, Falkow S. What are the consequences of the disappearing human microbiota? Nat Rev Microbiol 2009;7:887-94. https://doi. org/10.1038/nrmicro2245

116. Bertuccio P, Chatenoud L, Levi F, et al. Recent patterns in gastric cancer: a global overview. Int J Cancer 2009;125:666-73. https://doi.org/10.1002/ ijc. 24290

117. Plummer M, de Martel C, Vignat J, Ferlay J, Bray F, Franceschi S. Global burden of cancers attributable to infections in 2012: a synthetic analysis. Lancet Glob Health 2016;4:e609-16. https://doi.org/10.1016/ S2214-109X(16)30143-7

118. Corley DA, Kubo A. Influence of site classification on cancer incidence rates: an analysis of gastric cardia carcinomas. J Natl Cancer Inst 2004;96:1383-7. https://doi.org/10.1093/jnci/djh265

119. Ferlay J, Soerjomataram I, Dikshit R, et al. Cancer incidence and mortality worldwide: sources, methods and major patterns in GLOBOCAN 2012. Int J Cancer 2015;136:E359-86. https://doi.org/10.1002/ijc.29210

120. Makarova-Rusher OV, Altekruse SF, McNeel TS, et al. Population attributable fractions of risk factors for hepatocellular carcinoma in the United States. Cancer 2016;122:1757-65. https://doi.org/10.1002/ cncr.29971

121. Corpechot C, Gaouar F, Chrétien Y, Johanet C, Chazouillères O, Poupon R. Smoking as an independent risk factor of liver fibrosis in primary biliary cirrhosis. J Hepatol 2012;56:218-24. https://doi. org/10.1016/j.jhep.2011.03.031

122. Smyk DS, Rigopoulou EI, Muratori L, Burroughs AK, Bogdanos DP. Smoking as a risk factor for autoimmune liver disease: what we can learn from primary biliary cirrhosis. Ann Hepatol 2012;11:7-14.

123. Zein CO, Beatty K, Post AB, Logan L, Debanne S, McCullough AJ. Smoking and increased severity of hepatic fibrosis in primary biliary cirrhosis: a cross validated retrospective assessment. Hepatology 2006;44:1564-71. https://doi.org/10.1002/hep.21423

124. Lee YC, Cohet C, Yang YC, Stayner L, Hashibe M, Straif K. Metaanalysis of epidemiologic studies on cigarette smoking and liver cancer. Int J Epidemiol 2009;38:1497-511. https://doi.org/10.1093/ije/dyp280 
125. US Department of Health and Human Services. Women and smoking. Atlanta, GA: US Department of Health and Human Services, CDC, 2001.

126. Roura E, Castellsagué X, Pawlita M, et al. Smoking as a major risk factor for cervical cancer and pre-cancer: results from the EPIC cohort. Int J Cancer 2014;135:453-66. https://doi.org/10.1002/ijc.28666

127. Plummer M, Herrero R, Franceschi S, et al; IARC MultiCentre Cervical Cancer Study Group. Smoking and cervical cancer: pooled analysis of the IARC multi-centric case-control study. Cancer Causes Control 2003;14:805-14. https://doi. org/10.1023/B:CACO.0000003811.98261.3e

128. Saraiya M, Unger ER, Thompson TD, et al; HPV Typing of Cancers Workgroup. U.S. assessment of HPV types in cancers: implications for current and 9-valent HPV vaccines. J Natl Cancer Inst 2015;107:djv086. https://doi.org/10.1093/jnci/djv086

129. McQuillan G, Kruszon-Moran D, Markowitz LE, Unger ER, PauloseRam R. Prevalence of HPV in adults aged 18-69: United States, 2011-2014. NCHS Data Brief 2017; (280):1-8.

130. Petrosky E, Bocchini JA Jr, Hariri S, et al; CDC. Use of 9-valent human papillomavirus (HPV) vaccine: updated HPV vaccination recommendations of the advisory committee on immunization practices. MMWR Morb Mortal Wkly Rep 2015;64:300-4.

131. Benard VB, Watson M, Saraiya M, et al. Cervical cancer survival in the United States by race and stage (2001-2009): Findings from the CONCORD-2 study. Cancer 2017;123(Suppl 24):5119-37. https:// doi.org/10.1002/cncr.30906

132. US Preventive Services Task Force. Final recommendation statement: cervical cancer: screening. Rockville, MD: US Preventive Services Task Force; 2018. https://www.uspreventiveservicestaskforce.org/Page/ Document/RecommendationStatementFinal/cervical-cancer-screening2

133. Brownson RC, Novotny TE, Perry MC. Cigarette smoking and adult leukemia. A meta-analysis. Arch Intern Med 1993;153:469-75. https:// doi.org/10.1001/archinte.1993.00410040037006

134. Fircanis S, Merriam P, Khan N, Castillo JJ. The relation between cigarette smoking and risk of acute myeloid leukemia: an updated meta-analysis of epidemiological studies. Am J Hematol 2014;89:E125-32. https:// doi.org/10.1002/ajh.23744

135. Musselman JR, Blair CK, Cerhan JR, Nguyen P, Hirsch B, Ross JA. Risk of adult acute and chronic myeloid leukemia with cigarette smoking and cessation. Cancer Epidemiol 2013;37:410-6. https://doi.org/10.1016/j. canep.2013.03.012

136. Deschler B, Lübbert M. Acute myeloid leukemia: epidemiology and etiology. Cancer 2006;107:2099-107. https://doi.org/10.1002/ cncr.22233

137. US Department of Health and Human Services. Ending the tobacco epidemic: a tobacco control strategic action plan for the U.S. Department of Health and Human Services. Washington, DC: Office of the Assistant Secretary for Health, US Department of Health and Human Services; 2010.

138. Institute of Medicine. Ending the tobacco problem: a blueprint for the nation. Washington, DC: National Academies Press; 2007.

139. CDC. Best practices for comprehensive tobacco control programs - 2014. Atlanta, GA: US Department of Health and Human Services, CDC, National Center for Chronic Disease Prevention and Health Promotion, Office on Smoking and Health; 2014.

140. CDC. National Comprehensive Cancer Control Program. Atlanta, GA: US Department of Health and Human Services, CDC; 2017. https:// www.cdc.gov/cancer/ncccp
141. Dunne K, Henderson S, Stewart SL, et al. An update on tobacco control initiatives in comprehensive cancer control plans. Prev Chronic Dis 2013;10:E107. https://doi.org/10.5888/pcd10.120331

142. CDC, Office on Smoking and Health. National Tobacco Control Program. Atlanta, GA: US Department of Health and Human Services, CDC; 2018. https://www.cdc.gov/tobacco/stateandcommunity/ tobacco_control_programs/ntcp/index.htm.

143. Farrelly MC, Pechacek TF, Chaloupka FJ. The impact of tobacco control program expenditures on aggregate cigarette sales: 19812000. J Health Econ 2003;22:843-59. https://doi.org/10.1016/ S0167-6296(03)00057-2

144. Farrelly MC, Pechacek TF, Thomas KY, Nelson D. The impact of tobacco control programs on adult smoking. Am J Public Health 2008;98:304-9. https://doi.org/10.2105/AJPH.2006.106377

145. Tauras JA, Chaloupka FJ, Farrelly MC, et al. State tobacco control spending and youth smoking. Am J Public Health 2005;95:338-44. https://doi.org/10.2105/AJPH.2004.039727

146. RTI International. 2011 independent evaluation report on the New York tobacco control program. Albany, NY: New York State Department of Health; 2011.

147. California Department of Public Health. Smoking prevalence among California adults, 1984-2015. Appendix Table 1.3. Sacramento, CA: California Department of Public Health. https://www.cdph.ca.gov/ Programs/CCDPHP/DCDIC/CTCB/CDPH\%20Document\%20 Library/ResearchandEvaluation/FactsandFigures/2016FactsFigures Web.pdf

148. CDC. State-specific trends in lung cancer incidence and smokingUnited States, 1999-2008. MMWR Morb Mortal Wkly Rep 2011;60:1243-7.

149. Partnership for Prevention. Colorado Tobacco Cessation and Sustainability Partnership: a case study: a collaborative approach to meeting the U.S. Preventive Services Task Force Recommendations on Tobacco Cessation Screening and Intervention. Washington, DC: Partnership for Prevention; 2011.

150. Bauer UE, Johnson TM, Hopkins RS, Brooks RG. Changes in youth cigarette use and intentions following implementation of a tobacco control program: findings from the Florida Youth Tobacco Survey, 19982000. JAMA 2000;284:723-8. https://doi.org/10.1001/jama.284.6.723

151. Land T, Rigotti NA, Levy DE, et al. A longitudinal study of Medicaid coverage for tobacco dependence treatments in Massachusetts and associated decreases in hospitalizations for cardiovascular disease. PLoS Med 2010;7:e1000375. https://doi.org/10.1371/journal.pmed.1000375

152. Schillo BA, Wendling A, Saul J, et al. Expanding access to nicotine replacement therapy through Minnesota's QUITLINE partnership. Tob Control 2007;16(Suppl 1):i37-41. https://doi.org/10.1136/ tc. 2007.020180

153. CDC. Cancer prevention and control screening tests. Atlanta, GA: US Department of Health and Human Services, CDC; 2018. https://www. cdc.gov/cancer/dcpc/prevention/screening.htm

154. Clinton WJ. Executive Order 13058: Protecting federal employees and the public from exposure to tobacco smoke in the federal workplace. Fed Regist 1997;62:1224-5.

155. Singh SD, Henley SJ, Ryerson AB. Summary of notifiable noninfectious conditions and disease outbreaks: surveillance for cancer incidence and mortality-United States, 2011. MMWR Morb Mortal Wkly Rep 2015;62:11-51. https://doi.org/10.15585/mmwr.mm6254a3 
156. Espey DK, Jim MA, Richards TB, Begay C, Haverkamp D, Roberts D. Methods for improving the quality and completeness of mortality data for American Indians and Alaska Natives. Am J Public Health 2014;104(Suppl 3):S286-94. https://doi.org/10.2105/ AJPH.2013.301716
157. Starr G, Rogers T, Schooley M, Porter S, Wiesen E, Jamison N. Key outcome indicators for evaluating comprehensive tobacco control programs. Atlanta, GA: CDC; 2005. 
TABLE 1. Incidence rates* and percentages ${ }^{\dagger}$ of invasive lung, bronchial, and tracheal cancers, by demographic and tumor characteristics United States, $\$$ 2010-2014

\begin{tabular}{|c|c|c|c|c|c|c|}
\hline \multirow[b]{2}{*}{ Demographic characteristic } & \multicolumn{2}{|c|}{ Total } & \multicolumn{2}{|c|}{ Male } & \multicolumn{2}{|c|}{ Female } \\
\hline & No. & Rate $(95 \% \mathrm{Cl})$ & No. & Rate $(95 \% \mathrm{CI})$ & No. & Rate $(95 \% \mathrm{Cl})$ \\
\hline Total & $1,070,504$ & $61.3(61.2-61.4)$ & 566,713 & 72.7 (72.5-72.9) & 503,791 & $52.7(52.5-52.8)$ \\
\hline \multicolumn{7}{|l|}{ Age group at diagnosis (yrs) } \\
\hline$<40$ & 5,413 & $0.7(0.7-0.7)$ & 2,624 & $0.7(0.7-0.7)$ & 2,789 & $0.7(0.7-0.8)$ \\
\hline $40-49$ & 34,419 & $15.6(15.5-15.8)$ & 16,262 & $14.9(14.7-15.2)$ & 18,157 & $16.4(16.1-16.6)$ \\
\hline $50-59$ & 163,296 & $74.3(74.0-74.7)$ & 87,194 & $81.3(80.7-81.8)$ & 76,102 & $67.8(67.3-68.3)$ \\
\hline $60-69$ & 313,543 & $202.8(202.1-203.5)$ & 172,045 & $234.2(233.1-235.3)$ & 141,498 & $174.4(173.5-175.3)$ \\
\hline $70-79$ & 340,129 & $390.0(388.7-391.3)$ & 180,917 & $461.9(459.8-464.0)$ & 159,212 & $331.6(330.0-333.3)$ \\
\hline$\geq 80$ & 213,704 & $374.5(372.9-376.1)$ & 107,671 & $502.7(499.7-505.7)$ & 106,033 & $298.6(296.7-300.4)$ \\
\hline \multicolumn{7}{|l|}{ Race } \\
\hline White & 920,427 & $62.1(61.9-62.2)$ & 483,499 & $72.4(72.2-72.6)$ & 436,928 & $54.3(54.1-54.4)$ \\
\hline Black & 113,633 & $64.0(63.6-64.4)$ & 63,233 & $85.9(85.2-86.7)$ & 50,400 & $49.2(48.7-49.6)$ \\
\hline American Indian/Alaska Native & 6,000 & $44.7(43.5-45.9)$ & 3,111 & $52.2(50.2-54.2)$ & 2,889 & $39.0(37.6-40.6)$ \\
\hline Asian/Pacific Islander & 25,905 & $35.2(34.8-35.6)$ & 14,286 & $45.1(44.3-45.9)$ & 11,619 & $27.9(27.4-28.4)$ \\
\hline \multicolumn{7}{|l|}{ Ethnicity } \\
\hline Hispanic & 44,500 & $31.9(31.6-32.2)$ & 24,297 & $40.8(40.2-41.3)$ & 20,203 & $25.5(25.2-25.9)$ \\
\hline Non-Hispanic & $1,025,933$ & $64.1(64.0-64.2)$ & 542,388 & 75.7 (75.5-75.9) & 483,545 & $55.3(55.1-55.4)$ \\
\hline \multicolumn{7}{|l|}{ County classification } \\
\hline Metropolitan & 841,631 & $59.8(59.7-59.9)$ & 438,447 & $70.4(70.1-70.6)$ & 403,184 & $51.9(51.8-52.1)$ \\
\hline Nonmetropolitan & 178,536 & $69.4(69.0-69.7)$ & 100,611 & $84.9(84.4-85.4)$ & 77,925 & $57.0(56.6-57.4)$ \\
\hline \multicolumn{7}{|l|}{ Census region } \\
\hline Northeast & 208,137 & $62.6(62.3-62.9)$ & 104,465 & $72.0(71.5-72.4)$ & 103,672 & $56.0(55.7-56.4)$ \\
\hline Midwest & 258,247 & $66.5(66.2-66.7)$ & 136,591 & $78.6(78.2-79.0)$ & 121,656 & $57.4(57.1-57.7)$ \\
\hline South & 430,881 & $65.5(65.3-65.7)$ & 237,375 & $80.8(80.4-81.1)$ & 193,506 & $53.8(53.6-54.0)$ \\
\hline West & 173,239 & $47.4(47.2-47.6)$ & 88,282 & $53.5(53.1-53.8)$ & 84,957 & $42.7(42.4-43.0)$ \\
\hline Tumor characteristic** & No. & $\%$ & No. & $\%$ & No. & $\%$ \\
\hline Total & 942,919 & 100.0 & 498,902 & 100.0 & 444,017 & 100.0 \\
\hline \multicolumn{7}{|l|}{ Histology } \\
\hline Non-small cell carcinoma & 764,914 & 81.1 & 408,889 & 81.9 & 356,025 & 80.1 \\
\hline Adenocarcinoma & 448,320 & 47.5 & 215,628 & 43.2 & 232,692 & 52.4 \\
\hline Squamous cell carcinoma & 230,569 & 24.5 & 144,310 & 28.9 & 86,259 & 19.4 \\
\hline Non-small cell carcinoma, NOS & 70,142 & 7.4 & 39,900 & 8.0 & 30,242 & 6.8 \\
\hline Large cell carcinoma & 15,883 & 1.7 & 9,051 & 1.8 & 6,832 & 1.5 \\
\hline Small cell carcinoma & 133,192 & 14.1 & 65,925 & 13.2 & 67,267 & 15.1 \\
\hline Epithelial carcinoma & 23,319 & 2.5 & 13,540 & 2.7 & 9,779 & 2.2 \\
\hline All other histologies & 21,494 & 2.3 & 10,548 & 2.1 & 10,946 & 2.5 \\
\hline \multicolumn{7}{|l|}{ Stage $^{\dagger \dagger}$} \\
\hline Localized & 189,113 & 20.1 & 89,436 & 17.9 & 99,677 & 22.4 \\
\hline Regional & 227,876 & 24.2 & 120,567 & 24.2 & 107,309 & 24.2 \\
\hline Distant & 495,671 & 52.6 & 272,506 & 54.6 & 223,165 & 50.3 \\
\hline Unknown & 30,259 & 3.2 & 16,393 & 3.3 & 13,866 & 3.1 \\
\hline
\end{tabular}

Abbreviations: $\mathrm{Cl}=$ confidence interval; NOS = not otherwise specified.

* New cases diagnosed per 100,000 persons, age adjusted to the 2000 U.S. standard population.

† New cases diagnosed.

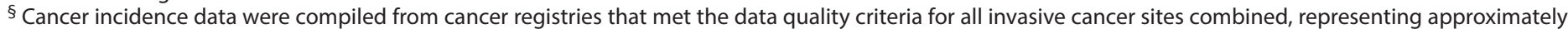

99\% of the U.S. population. (Data from Nevada did not meet U.S. Cancer Statistics publication criteria for 2010-2014.)

I Ethnicity is not mutually exclusive from race.

** Only includes microscopically confirmed cases; excludes cases identified only through death certificate or autopsy report.

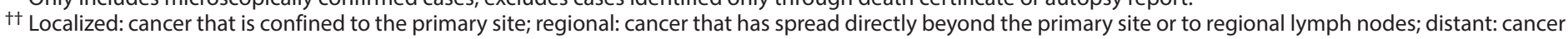
that has spread to other organs. 
TABLE 2. Incidence rates* and percentages ${ }^{\dagger}$ of invasive laryngeal cancer, by demographic and tumor characteristics - United States, ${ }^{\S}$ 2010-2014

\begin{tabular}{|c|c|c|c|c|c|c|}
\hline \multirow[b]{2}{*}{ Demographic characteristic } & \multicolumn{2}{|c|}{ Total } & \multicolumn{2}{|c|}{ Male } & \multicolumn{2}{|c|}{ Female } \\
\hline & No. & Rate $(95 \% \mathrm{Cl})$ & No. & Rate $(95 \% \mathrm{CI})$ & No. & Rate $(95 \% \mathrm{Cl})$ \\
\hline Total & 62,479 & $3.5(3.4-3.5)$ & 49,605 & $6.0(6.0-6.1)$ & 12,874 & $1.3(1.3-1.4)$ \\
\hline \multicolumn{7}{|l|}{ Age group at diagnosis (yrs) } \\
\hline$<40$ & 563 & $0.1(0.1-0.1)$ & 374 & $0.1(0.1-0.1)$ & 189 & $0.0(0.0-0.1)$ \\
\hline $40-49$ & 3,888 & $1.8(1.7-1.8)$ & 2,855 & $2.6(2.5-2.7)$ & 1,033 & $0.9(0.9-1.0)$ \\
\hline $50-59$ & 16,028 & $7.3(7.2-7.5)$ & 12,437 & $11.7(11.5-11.9)$ & 3,591 & $3.2(3.1-3.3)$ \\
\hline $60-69$ & 20,840 & $13.4(13.2-13.5)$ & 16,802 & $22.7(22.3-23.0)$ & 4,038 & $4.9(4.8-5.1)$ \\
\hline $70-79$ & 14,176 & $16.2(15.9-16.4)$ & 11,470 & $29.1(28.6-29.6)$ & 2,706 & $5.6(5.4-5.8)$ \\
\hline$\geq 80$ & 6,984 & $12.2(12.0-12.5)$ & 5,667 & $26.5(25.8-27.2)$ & 1,317 & $3.7(3.5-3.9)$ \\
\hline \multicolumn{7}{|l|}{ Race } \\
\hline White & 51,997 & $3.4(3.4-3.5)$ & 41,239 & $5.9(5.8-5.9)$ & 10,758 & $1.4(1.3-1.4)$ \\
\hline Black & 8,751 & $4.5(4.4-4.6)$ & 6,911 & $8.5(8.3-8.7)$ & 1,840 & $1.7(1.6-1.7)$ \\
\hline American Indian/Alaska Native & 331 & $2.1(1.8-2.3)$ & 260 & $3.6(3.1-4.1)$ & 71 & $0.8(0.6-1.0)$ \\
\hline Asian/Pacific Islander & 878 & $1.1(1.1-1.2)$ & 752 & $2.2(2.1-2.4)$ & 126 & $0.3(0.2-0.3)$ \\
\hline \multicolumn{7}{|l|}{ Ethnicity } \\
\hline Hispanic & 3,865 & $2.5(2.4-2.6)$ & 3,299 & $4.8(4.7-5.0)$ & 566 & $0.7(0.6-0.7)$ \\
\hline Non-Hispanic & 58,606 & $3.6(3.5-3.6)$ & 46,300 & $6.1(6.1-6.2)$ & 12,306 & $1.4(1.4-1.4)$ \\
\hline \multicolumn{7}{|l|}{ County classification } \\
\hline Metropolitan & 48,624 & $3.3(3.3-3.4)$ & 38,562 & $5.8(5.7-5.9)$ & 10,062 & $1.3(1.3-1.3)$ \\
\hline Nonmetropolitan & 10,920 & $4.2(4.2-4.3)$ & 8,685 & $7.1(6.9-7.3)$ & 2,235 & $1.7(1.6-1.8)$ \\
\hline \multicolumn{7}{|l|}{ Census region } \\
\hline Northeast & 11,835 & $3.5(3.4-3.5)$ & 9,320 & $6.1(6.0-6.2)$ & 2,515 & $1.4(1.3-1.4)$ \\
\hline Midwest & 15,154 & $3.8(3.7-3.9)$ & 11,845 & $6.4(6.3-6.5)$ & 3,309 & $1.6(1.5-1.6)$ \\
\hline South & 26,865 & $4.0(3.9-4.0)$ & 21,346 & $6.8(6.8-6.9)$ & 5,519 & $1.5(1.5-1.6)$ \\
\hline West & 8,625 & $2.3(2.2-2.3)$ & 7,094 & $4.0(3.9-4.1)$ & 1,531 & $0.8(0.7-0.8)$ \\
\hline Tumor characteristic** & No. & $\%$ & No. & $\%$ & No. & $\%$ \\
\hline Total & 60,676 & 100.0 & 48,165 & 100.0 & 12,511 & 100.0 \\
\hline \multicolumn{7}{|l|}{ Histology } \\
\hline Squamous cell carcinoma & 58,810 & 96.9 & 46,767 & 97.1 & 12,043 & 96.3 \\
\hline Adenocarcinoma & 381 & 0.6 & 238 & 0.5 & 143 & 1.1 \\
\hline Epithelial carcinoma, NOS & 881 & 1.5 & 687 & 1.4 & 194 & 1.6 \\
\hline All other histologies & 604 & 1.0 & 473 & 1.0 & 131 & 1.0 \\
\hline \multicolumn{7}{|l|}{ Stage ${ }^{\dagger \dagger}$} \\
\hline Localized & 32,534 & 53.6 & 26,646 & 55.3 & 5,888 & 47.1 \\
\hline Regional & 14,640 & 24.1 & 10,608 & 22.0 & 4,032 & 32.2 \\
\hline Distant & 10,702 & 17.6 & 8,632 & 17.9 & 2,070 & 16.5 \\
\hline Unknown & 2,800 & 4.6 & 2,279 & 4.7 & 521 & 4.2 \\
\hline
\end{tabular}

Abbreviations: $\mathrm{Cl}=$ confidence interval; $\mathrm{NOS}=$ not otherwise specified.

* New cases diagnosed per 100,000 persons, age adjusted to the 2000 U.S. standard population.

† New cases diagnosed.

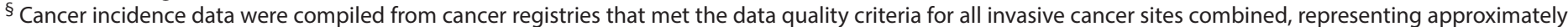

99\% of the U.S. population. (Data from Nevada did not meet U.S. Cancer Statistics publication criteria for 2010-2014.)

१ Ethnicity is not mutually exclusive from race.

** Only includes microscopically confirmed cases; excludes cases identified only through death certificate or autopsy report.

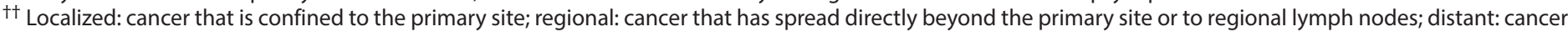
that has spread to other organs. 
TABLE 3. Incidence rates* and percentages ${ }^{\dagger}$ of invasive oral cavity and pharyngeal cancers, by demographic and tumor characteristics — United States, $\$$ 2010-2014

\begin{tabular}{|c|c|c|c|c|c|c|}
\hline \multirow[b]{2}{*}{ Demographic characteristic } & \multicolumn{2}{|c|}{ Total } & \multicolumn{2}{|c|}{ Male } & \multicolumn{2}{|c|}{ Female } \\
\hline & No. & Rate $(95 \% \mathrm{CI})$ & No. & Rate $(95 \% \mathrm{Cl})$ & No. & Rate $(95 \% \mathrm{Cl})$ \\
\hline Total & 204,537 & $11.5(11.4-11.5)$ & 144,851 & $17.4(17.3-17.4)$ & 59,686 & $6.4(6.3-6.4)$ \\
\hline \multicolumn{7}{|l|}{ Age group at diagnosis (yrs) } \\
\hline$<40$ & 7,562 & $1.0(0.9-1.0)$ & 4,153 & $1.1(1.0-1.1)$ & 3,409 & $0.9(0.8-0.9)$ \\
\hline $40-49$ & 19,866 & $9.1(9.0-9.3)$ & 14,391 & $13.3(13.1-13.6)$ & 5,475 & $5.0(4.9-5.1)$ \\
\hline $50-59$ & 56,098 & $25.8(25.6-26.0)$ & 42,834 & $40.3(40.0-40.7)$ & 13,264 & $11.9(11.7-12.1)$ \\
\hline $60-69$ & 60,210 & $38.4(38.1-38.7)$ & 45,247 & $60.7(60.1-61.2)$ & 14,963 & $18.3(18.0-18.6)$ \\
\hline $70-79$ & 37,022 & $42.3(41.8-42.7)$ & 25,140 & $63.6(62.8-64.4)$ & 11,882 & $24.7(24.3-25.2)$ \\
\hline$\geq 80$ & 23,779 & $41.3(40.8-41.8)$ & 13,086 & $61.2(60.1-62.3)$ & 10,693 & $29.4(28.8-29.9)$ \\
\hline \multicolumn{7}{|l|}{ Race } \\
\hline White & 176,221 & $11.8(11.8-11.9)$ & 125,496 & $17.8(17.7-17.9)$ & 50,725 & $6.5(6.4-6.5)$ \\
\hline Black & 18,089 & $9.2(9.0-9.3)$ & 12,574 & $14.5(14.3-14.8)$ & 5,515 & $5.1(5.0-5.2)$ \\
\hline American Indian/Alaska Native & 1,191 & $7.3(6.8-7.7)$ & 843 & $10.9(10.1-11.7)$ & 348 & $4.1(3.7-4.6)$ \\
\hline Asian/Pacific Islander & 6,519 & $7.8(7.6-8.0)$ & 4,257 & $11.2(10.9-11.6)$ & 2,262 & $5.0(4.8-5.2)$ \\
\hline \multicolumn{7}{|l|}{ Ethnicity } \\
\hline Hispanic & 11,854 & $7.1(6.9-7.2)$ & 8,096 & $10.5(10.3-10.8)$ & 3,758 & $4.2(4.1-4.3)$ \\
\hline Non-Hispanic & 192,676 & $12.0(12.0-12.1)$ & 136,750 & $18.2(18.1-18.3)$ & 55,926 & $6.6(6.6-6.7)$ \\
\hline \multicolumn{7}{|l|}{ County classification } \\
\hline Metropolitan & 163,768 & $11.3(11.2-11.3)$ & 115,587 & $17.1(17.0-17.2)$ & 48,181 & $6.3(6.2-6.3)$ \\
\hline Nonmetropolitan & 31,220 & $12.5(12.3-12.6)$ & 22,450 & $18.7(18.4-18.9)$ & 8,770 & $6.7(6.6-6.9)$ \\
\hline \multicolumn{7}{|l|}{ Census region } \\
\hline Northeast & 37,358 & $11.1(11.0-11.3)$ & 25,665 & $16.6(16.4-16.8)$ & 11,693 & $6.5(6.4-6.6)$ \\
\hline Midwest & 46,294 & $11.7(11.6-11.9)$ & 32,792 & $17.7(17.5-17.9)$ & 13,502 & $6.5(6.4-6.6)$ \\
\hline South & 80,910 & $12.1(12.0-12.2)$ & 58,190 & $18.6(18.5-18.8)$ & 22,720 & $6.5(6.4-6.6)$ \\
\hline West & 39,975 & $10.4(10.3-10.6)$ & 28,204 & $15.5(15.4-15.7)$ & 11,771 & $5.9(5.8-6.0)$ \\
\hline \multicolumn{7}{|l|}{ Anatomic subsite } \\
\hline Lip & 10,035 & $0.6(0.6-0.6)$ & 7,284 & $0.9(0.9-1.0)$ & 2,751 & $0.3(0.3-0.3)$ \\
\hline Oral cavity & 99,539 & $5.6(5.5-5.6)$ & 66,678 & $7.9(7.9-8.0)$ & 32,861 & $3.5(3.4-3.5)$ \\
\hline Salivary gland & 21,517 & $1.3(1.3-1.3)$ & 12,629 & $1.7(1.6-1.7)$ & 8,888 & $1.0(1.0-1.0)$ \\
\hline Tonsil & 38,061 & $2.1(2.1-2.1)$ & 31,175 & $3.6(3.5-3.6)$ & 6,886 & $0.7(0.7-0.7)$ \\
\hline Oropharynx & 9,428 & $0.5(0.5-0.5)$ & 7,189 & $0.8(0.8-0.9)$ & 2,239 & $0.2(0.2-0.2)$ \\
\hline Nasopharynx & 14,393 & $0.8(0.8-0.8)$ & 10,925 & $1.3(1.3-1.3)$ & 3,468 & $0.4(0.4-0.4)$ \\
\hline Hypopharynx & 6,004 & $0.3(0.3-0.3)$ & 4,700 & $0.6(0.5-0.6)$ & 1,304 & $0.1(0.1-0.1)$ \\
\hline Other oral cavity and pharynx & 5,560 & $0.3(0.3-0.3)$ & 4,271 & $0.5(0.5-0.5)$ & 1,289 & $0.1(0.1-0.1)$ \\
\hline Tumor characteristic** & No. & $\%$ & No. & $\%$ & No. & $\%$ \\
\hline Total & 199,496 & 100.0 & 141,383 & 100.0 & 58,113 & 100.0 \\
\hline \multicolumn{7}{|l|}{ Histology } \\
\hline Squamous cell carcinoma & 171,299 & 85.9 & 126,036 & 89.1 & 45,263 & 77.9 \\
\hline Adenocarcinoma & 7,579 & 3.8 & 4,014 & 2.8 & 3,565 & 6.1 \\
\hline Mucoepidermoid carcinoma & 6,259 & 3.1 & 2,802 & 2.0 & 3,457 & 5.9 \\
\hline Epithelial carcinoma, NOS & 5,711 & 2.9 & 4,094 & 2.9 & 1,617 & 2.8 \\
\hline All other histologies & 8,648 & 4.3 & 4,437 & 3.1 & 4,211 & 7.2 \\
\hline \multicolumn{7}{|l|}{ Stage $\mathrm{e}^{\dagger \dagger}$} \\
\hline Localized & 63,275 & 31.7 & 38,268 & 27.1 & 25,007 & 43.0 \\
\hline Regional & 90,347 & 45.3 & 69,275 & 49.0 & 21,072 & 36.3 \\
\hline Distant & 35,439 & 17.8 & 26,741 & 18.9 & 8,698 & 15.0 \\
\hline Unknown & 10,435 & 5.2 & 7,099 & 5.0 & 3,336 & 5.7 \\
\hline
\end{tabular}

Abbreviations: $\mathrm{Cl}=$ confidence interval; $\mathrm{NOS}=$ not otherwise specified.

* New cases diagnosed per 100,000 persons, age adjusted to the 2000 U.S. standard population.

$\dagger$ New cases diagnosed.

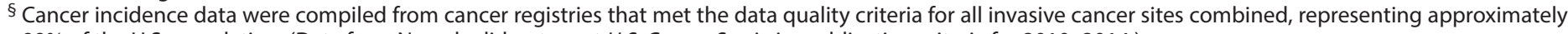
99\% of the U.S. population. (Data from Nevada did not meet U.S. Cancer Statistics publication criteria for 2010-2014.)

I Ethnicity is not mutually exclusive from race.

** Only includes microscopically confirmed cases; excludes cases identified only through death certificate or autopsy report.

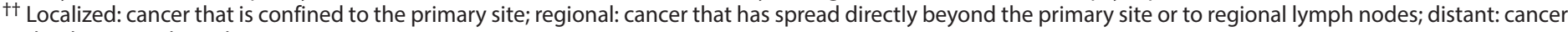
that has spread to other organs. 
TABLE 4. Incidence rates* and percentages ${ }^{\dagger}$ of invasive esophageal cancer, by demographic and tumor characteristics - United States, $\$$ 2010-2014

\begin{tabular}{|c|c|c|c|c|c|c|c|}
\hline \multirow[b]{2}{*}{ Demographic characteristic } & \multicolumn{2}{|c|}{ Total } & \multicolumn{3}{|c|}{ Male } & \multicolumn{2}{|c|}{ Female } \\
\hline & No. & Rate $(95 \% \mathrm{Cl})$ & No. & Rate & $(95 \% \mathrm{Cl})$ & No. & Rate $(95 \% \mathrm{Cl})$ \\
\hline Total & 81,608 & $4.6(4.6-4.6)$ & 64,311 & 8.0 & $(7.9-8.0)$ & 17,297 & $1.8(1.8-1.8)$ \\
\hline \multicolumn{8}{|l|}{ Age group at diagnosis (yrs) } \\
\hline$<40$ & 706 & $0.1(0.1-0.1)$ & 562 & 0.2 & $(0.1-0.2)$ & 144 & $0.0(0.0-0.0)$ \\
\hline $40-49$ & 3,951 & $1.8(1.8-1.9)$ & 3,223 & 3.0 & $(2.9-3.1)$ & 728 & $0.7(0.6-0.7)$ \\
\hline $50-59$ & 15,943 & $7.3(7.1-7.4)$ & 13,075 & 12.2 & $(12.0-12.4)$ & 2,868 & $2.6(2.5-2.7)$ \\
\hline $60-69$ & 25,765 & $16.5(16.3-16.7)$ & 21,335 & 28.8 & $(28.4-29.2)$ & 4,430 & $5.4(5.3-5.6)$ \\
\hline $70-79$ & 20,982 & $24.0(23.7-24.3)$ & 16,480 & 41.9 & $(41.3-42.6)$ & 4,502 & $9.4(9.1-9.7)$ \\
\hline$\geq 80$ & 14,261 & $24.8(24.4-25.2)$ & 9,636 & 45.0 & $(44.1-45.9)$ & 4,625 & $12.6(12.3-13.0)$ \\
\hline \multicolumn{8}{|l|}{ Race } \\
\hline White & 71,002 & $4.7(4.7-4.8)$ & 56,735 & 8.2 & $(8.2-8.3)$ & 14,267 & $1.7(1.7-1.8)$ \\
\hline Black & 7,984 & $4.3(4.2-4.4)$ & 5,581 & 7.1 & $(6.9-7.3)$ & 2,403 & $2.3(2.2-2.4)$ \\
\hline American Indian/Alaska Native & 460 & $3.2(2.8-3.5)$ & 357 & 5.3 & $(4.7-5.9)$ & 103 & $1.4(1.1-1.7)$ \\
\hline Asian/Pacific Islander & 1,659 & $2.2(2.1-2.3)$ & 1,257 & 3.7 & $(3.5-3.9)$ & 402 & $1.0(0.9-1.1)$ \\
\hline \multicolumn{8}{|l|}{ Ethnicity } \\
\hline Hispanic & 4,157 & $2.8(2.7-2.9)$ & 3,284 & 4.9 & $(4.7-5.1)$ & 873 & $1.1(1.0-1.2)$ \\
\hline Non-Hispanic & 77,446 & $4.8(4.7-4.8)$ & 61,025 & 8.3 & $(8.2-8.3)$ & 16,421 & $1.8(1.8-1.9)$ \\
\hline \multicolumn{8}{|l|}{ County classification } \\
\hline Metropolitan & 64,726 & $4.5(4.5-4.5)$ & 50,559 & 7.8 & $(7.7-7.9)$ & 14,167 & $1.8(1.8-1.8)$ \\
\hline Nonmetropolitan & 13,056 & $5.1(5.0-5.1)$ & 10,693 & 8.9 & $(8.7-9.1)$ & 2,363 & $1.7(1.6-1.8)$ \\
\hline \multicolumn{8}{|l|}{ Census region } \\
\hline Northeast & 16,751 & $4.9(4.9-5.0)$ & 12,913 & 8.6 & $(8.5-8.8)$ & 3,838 & $2.0(1.9-2.1)$ \\
\hline Midwest & 20,158 & $5.1(5.0-5.2)$ & 15,996 & 8.9 & $(8.8-9.1)$ & 4,162 & $1.9(1.8-2.0)$ \\
\hline South & 29,532 & $4.4(4.4-4.5)$ & 23,471 & 7.7 & $(7.6-7.8)$ & 6,061 & $1.7(1.6-1.7)$ \\
\hline West & 15,167 & $4.0(4.0-4.1)$ & 11,931 & 6.9 & $(6.8-7.0)$ & 3,236 & $1.6(1.6-1.7)$ \\
\hline Tumor characteristic** & No. & $\%$ & No. & & & No. & $\%$ \\
\hline Total & 77,252 & 100.0 & 61,024 & & & 16,228 & 100.0 \\
\hline \multicolumn{8}{|l|}{ Histology } \\
\hline Squamous cell carcinoma & 22,900 & 29.6 & 14,768 & & & 8,132 & 50.1 \\
\hline Adenocarcinoma & 50,492 & 65.4 & 43,361 & & & 7,131 & 43.9 \\
\hline Epithelial carcinoma, NOS & 2,853 & 3.7 & 2,173 & & & 680 & 4.2 \\
\hline All other histologies & 1,007 & 1.3 & 722 & & & 285 & 1.8 \\
\hline \multicolumn{8}{|l|}{ Stage $^{\dagger t}$} \\
\hline Localized & 15,021 & 19.4 & 11,522 & & & 3,499 & 21.6 \\
\hline Regional & 25,437 & 32.9 & 19,992 & & & 5,445 & 33.6 \\
\hline Distant & 28,248 & 36.6 & 23,359 & & & 4,889 & 30.1 \\
\hline Unknown & 8,546 & 11.1 & 6,151 & & & 2,395 & 14.8 \\
\hline
\end{tabular}

Abbreviations: $\mathrm{Cl}=$ confidence interval; $\mathrm{NOS}=$ not otherwise specified.

* New cases diagnosed per 100,000 persons, age adjusted to the 2000 U.S. standard population.

† New cases diagnosed.

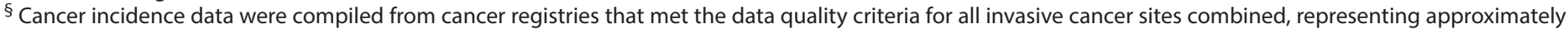
99\% of the U.S. population. (Data from Nevada did not meet U.S. Cancer Statistics publication criteria for 2010-2014.)

I Ethnicity is not mutually exclusive from race.

** Only includes microscopically confirmed cases; excludes cases identified only through death certificate or autopsy report.

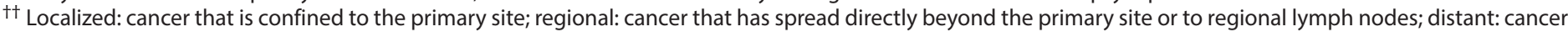
that has spread to other organs. 
TABLE 5. Incidence rates* and percentages ${ }^{\dagger}$ of invasive stomach cancer, by demographic and tumor characteristics - United States, ${ }^{\S}$ 2010-2014

\begin{tabular}{|c|c|c|c|c|c|c|}
\hline \multirow[b]{2}{*}{ Demographic characteristic } & \multicolumn{2}{|c|}{ Total } & \multicolumn{2}{|c|}{ Male } & \multicolumn{2}{|c|}{ Female } \\
\hline & No. & Rate $(95 \% \mathrm{Cl})$ & No. & Rate $(95 \% \mathrm{Cl})$ & No. & Rate $(95 \% \mathrm{Cl})$ \\
\hline Total & 115,147 & $6.7(6.6-6.7)$ & 71,429 & $9.2(9.1-9.3)$ & 43,718 & $4.6(4.6-4.7)$ \\
\hline \multicolumn{7}{|l|}{ Age group at diagnosis (yrs) } \\
\hline$<40$ & 3,543 & $0.5(0.4-0.5)$ & 1,812 & $0.5(0.4-0.5)$ & 1,731 & $0.4(0.4-0.5)$ \\
\hline $40-49$ & 8,145 & $3.8(3.7-3.9)$ & 4,733 & $4.4(4.3-4.6)$ & 3,412 & $3.2(3.1-3.3)$ \\
\hline $50-59$ & 19,704 & $9.0(8.9-9.2)$ & 12,852 & $12.1(11.9-12.3)$ & 6,852 & $6.2(6.0-6.3)$ \\
\hline $60-69$ & 29,093 & 18.7 (18.5-18.9) & 19,548 & $26.4(26.1-26.8)$ & 9,545 & $11.7(11.5-12.0)$ \\
\hline $70-79$ & 29,473 & $33.9(33.5-34.3)$ & 18,938 & $48.4(47.7-49.1)$ & 10,535 & $22.0(21.6-22.4)$ \\
\hline$\geq 80$ & 25,189 & $43.6(43.0-44.1)$ & 13,546 & $63.4(62.3-64.5)$ & 11,643 & $31.8(31.2-32.4)$ \\
\hline \multicolumn{7}{|l|}{ Race } \\
\hline White & 86,976 & $6.0(5.9-6.0)$ & 55,378 & $8.3(8.3-8.4)$ & 31,598 & $4.0(3.9-4.0)$ \\
\hline Black & 17,936 & $10.3(10.1-10.5)$ & 10,169 & $14.1(13.8-14.4)$ & 7,767 & $7.7(7.6-7.9)$ \\
\hline American Indian/Alaska Native & 877 & $6.3(5.8-6.7)$ & 521 & $8.3(7.6-9.2)$ & 356 & $4.7(4.2-5.2)$ \\
\hline Asian/Pacific Islander & 8,011 & 10.7 (10.4-10.9) & 4,596 & $14.1(13.6-14.5)$ & 3,415 & $8.1(7.8-8.4)$ \\
\hline \multicolumn{7}{|l|}{ Ethnicity } \\
\hline Hispanic & 15,364 & $9.9(9.8-10.1)$ & 8,722 & $12.8(12.5-13.1)$ & 6,642 & $7.7(7.6-7.9)$ \\
\hline Non-Hispanic & 99,765 & $6.3(6.3-6.4)$ & 62,697 & $8.8(8.8-8.9)$ & 37,068 & $4.3(4.2-4.3)$ \\
\hline \multicolumn{7}{|l|}{ County classification } \\
\hline Metropolitan & 96,346 & $6.9(6.8-6.9)$ & 59,281 & $9.5(9.4-9.5)$ & 37,065 & $4.8(4.8-4.9)$ \\
\hline Nonmetropolitan & 14,432 & $5.8(5.7-5.9)$ & 9,256 & $8.0(7.8-8.2)$ & 5,176 & $3.9(3.8-4.0)$ \\
\hline \multicolumn{7}{|l|}{ Census region } \\
\hline Northeast & 25,142 & $7.6(7.5-7.7)$ & 15,455 & $10.7(10.5-10.8)$ & 9,687 & $5.2(5.1-5.3)$ \\
\hline Midwest & 23,656 & $6.1(6.1-6.2)$ & 15,148 & $8.7(8.6-8.9)$ & 8,508 & $4.0(4.0-4.1)$ \\
\hline South & 41,502 & $6.4(6.4-6.5)$ & 25,497 & $8.7(8.6-8.9)$ & 16,005 & $4.6(4.5-4.6)$ \\
\hline West & 24,847 & $6.8(6.7-6.9)$ & 15,329 & $9.1(9.0-9.3)$ & 9,518 & $4.8(4.7-4.9)$ \\
\hline Tumor characteristic** & No. & $\%$ & No. & $\%$ & No. & $\%$ \\
\hline Total & 110,731 & 100.0 & 68,956 & 100.0 & 41,775 & 100.0 \\
\hline \multicolumn{7}{|l|}{ Histology } \\
\hline Squamous cell carcinoma & 1,091 & 1.0 & 772 & 1.1 & 319 & 0.8 \\
\hline Adenocarcinoma & 95,611 & 86.3 & 60,701 & 88.0 & 34,910 & 83.6 \\
\hline Epithelial carcinoma, NOS & 2,881 & 2.6 & 1,810 & 2.6 & 1,071 & 2.6 \\
\hline Gastrointestinal stromal tumor & 9,819 & 8.9 & 4,887 & 7.1 & 4,932 & 11.8 \\
\hline All other histologies & 1,329 & 1.2 & 786 & 1.1 & 543 & 1.3 \\
\hline \multicolumn{7}{|l|}{ Stage ${ }^{\dagger \dagger}$} \\
\hline Localized & 32,689 & 29.5 & 18,397 & 26.7 & 14,292 & 34.2 \\
\hline Regional & 29,104 & 26.3 & 19,554 & 28.4 & 9,550 & 22.9 \\
\hline Distant & 37,226 & 33.6 & 24,515 & 35.6 & 12,711 & 30.4 \\
\hline Unknown & 11,712 & 10.6 & 6,490 & 9.4 & 5,222 & 12.5 \\
\hline
\end{tabular}

Abbreviations: $\mathrm{Cl}=$ confidence interval; $\mathrm{NOS}=$ not otherwise specified.

* New cases diagnosed per 100,000 persons, age adjusted to the 2000 U.S. standard population.

† New cases diagnosed.

$\S$ Cancer incidence data were compiled from cancer registries that met the data quality criteria for all invasive cancer sites combined, representing approximately 99\% of the U.S. population. (Data from Nevada did not meet U.S. Cancer Statistics publication criteria for 2010-2014.)

" Ethnicity is not mutually exclusive from race.

** Only includes microscopically confirmed cases; excludes cases identified only through death certificate or autopsy report.

t+ Localized: cancer that is confined to the primary site; regional: cancer that has spread directly beyond the primary site or to regional lymph nodes; distant: cancer that has spread to other organs. 
TABLE 6. Incidence rates* and percentages ${ }^{\dagger}$ of invasive colon and rectal cancers, by demographic and tumor characteristics — United States, ${ }^{\S}$ 2010-2014

\begin{tabular}{|c|c|c|c|c|c|c|}
\hline \multirow[b]{2}{*}{ Demographic characteristic } & \multicolumn{2}{|c|}{ Total } & \multicolumn{2}{|c|}{ Male } & \multicolumn{2}{|c|}{ Female } \\
\hline & No. & Rate $(95 \% \mathrm{Cl})$ & No. & Rate $(95 \% \mathrm{Cl})$ & No. & Rate $(95 \% \mathrm{Cl})$ \\
\hline Total & 689,738 & $39.8(39.7-39.9)$ & 358,980 & $45.8(45.6-45.9)$ & 330,758 & $34.8(34.7-34.9)$ \\
\hline \multicolumn{7}{|l|}{ Age group at diagnosis (yrs) } \\
\hline$<40$ & 19,731 & $2.6(2.5-2.6)$ & 9,987 & $2.6(2.5-2.6)$ & 9,744 & $2.5(2.5-2.6)$ \\
\hline $40-49$ & 52,570 & $24.3(24.1-24.5)$ & 28,010 & $26.1(25.8-26.5)$ & 24,560 & $22.5(22.3-22.8)$ \\
\hline $50-59$ & 132,893 & $61.5(61.2-61.8)$ & 74,955 & $71.0(70.5-71.5)$ & 57,938 & $52.5(52.0-52.9)$ \\
\hline $60-69$ & 167,619 & $107.8(107.3-108.3)$ & 96,144 & $130.0(129.2-130.9)$ & 71,475 & $87.6(87.0-88.3)$ \\
\hline 70-79 & 162,100 & $186.3(185.4-187.3)$ & 85,303 & $218.0(216.6-219.5)$ & 76,797 & $160.5(159.3-161.6)$ \\
\hline$\geq 80$ & 154,825 & $267.2(265.9-268.5)$ & 64,581 & $302.4(300.0-304.7)$ & 90,244 & $246.3(244.7-248.0)$ \\
\hline \multicolumn{7}{|l|}{ Race } \\
\hline White & 568,027 & $38.9(38.8-39.0)$ & 297,149 & $44.7(44.5-44.8)$ & 270,878 & $33.9(33.8-34.1)$ \\
\hline Black & 84,797 & $46.7(46.4-47.1)$ & 42,304 & $55.1(54.6-55.7)$ & 42,493 & $40.9(40.5-41.3)$ \\
\hline American Indian/Alaska Native & 4,533 & $30.9(29.9-31.9)$ & 2,367 & $34.7(33.2-36.3)$ & 2,166 & $27.8(26.6-29.0)$ \\
\hline Asian/Pacific Islander & 24,651 & $31.4(31.0-31.8)$ & 12,927 & $37.0(36.3-37.6)$ & 11,724 & $27.0(26.5-27.5)$ \\
\hline \multicolumn{7}{|l|}{ Ethnicity } \\
\hline Hispanic & 54,664 & $35.0(34.7-35.3)$ & 29,604 & $42.0(41.5-42.6)$ & 25,060 & $29.4(29.0-29.8)$ \\
\hline Non-Hispanic & 635,010 & $40.3(40.2-40.4)$ & 329,348 & $46.3(46.2-46.5)$ & 305,662 & $35.4(35.3-35.5)$ \\
\hline \multicolumn{7}{|l|}{ County classification } \\
\hline Metropolitan & 550,090 & $39.1(39.0-39.2)$ & 284,709 & $45.0(44.8-45.2)$ & 265,381 & $34.2(34.1-34.3)$ \\
\hline Nonmetropolitan & 107,117 & $43.1(42.8-43.4)$ & 56,914 & $49.3(48.9-49.8)$ & 50,203 & $37.7(37.4-38.0)$ \\
\hline \multicolumn{7}{|l|}{ Census region } \\
\hline Northeast & 134,889 & $40.8(40.5-41.0)$ & 67,880 & $46.7(46.3-47.0)$ & 67,009 & $36.0(35.7-36.3)$ \\
\hline Midwest & 160,438 & $41.6(41.4-41.8)$ & 83,150 & $48.0(47.6-48.3)$ & 77,288 & $36.4(36.1-36.6)$ \\
\hline South & 259,826 & $40.0(39.9-40.2)$ & 137,204 & $46.6(46.3-46.8)$ & 122,622 & $34.7(34.5-34.9)$ \\
\hline West & 134,585 & $36.3(36.1-36.5)$ & 70,746 & $41.4(41.1-41.7)$ & 63,839 & $32.0(31.8-32.3)$ \\
\hline Tumor characteristic** & No. & $\%$ & No. & $\%$ & No. & $\%$ \\
\hline Total & 663,134 & 100.0 & 346,670 & 100.0 & 316,464 & 100.0 \\
\hline \multicolumn{7}{|l|}{ Histology } \\
\hline Adenocarcinoma & 450,086 & 67.9 & 237,862 & 68.6 & 212,224 & 67.1 \\
\hline Adenoma & 115,940 & 17.5 & 62,459 & 18.0 & 53,481 & 16.9 \\
\hline Mucinous carcinoma & 50,295 & 7.6 & 24,365 & 7.0 & 25,930 & 8.2 \\
\hline Carcinoid & 28,410 & 4.3 & 13,624 & 3.9 & 14,786 & 4.7 \\
\hline Epithelial carcinoma, NOS & 7,140 & 1.1 & 3,723 & 1.1 & 3,417 & 1.1 \\
\hline All other histologies & 11,263 & 1.7 & 4,637 & 1.3 & 6,626 & 2.1 \\
\hline \multicolumn{7}{|l|}{ Stage $\mathrm{e}^{\dagger \dagger}$} \\
\hline Localized & 260,739 & 39.3 & 135,705 & 39.1 & 125,034 & 39.5 \\
\hline Regional & 233,918 & 35.3 & 121,636 & 35.1 & 112,282 & 35.5 \\
\hline Distant & 135,731 & 20.5 & 72,393 & 20.9 & 63,338 & 20.0 \\
\hline Unknown & 32,746 & 4.9 & 16,936 & 4.9 & 15,810 & 5.0 \\
\hline
\end{tabular}

Abbreviations: $\mathrm{Cl}=$ confidence interval; $\mathrm{NOS}=$ not otherwise specified.

* New cases diagnosed per 100,000 persons, age adjusted to the 2000 U.S. standard population.

$\dagger$ New cases diagnosed.

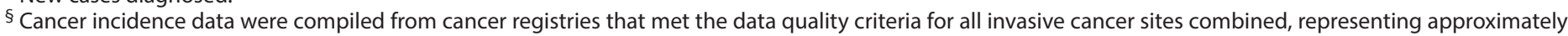
99\% of the U.S. population. (Data from Nevada did not meet U.S. Cancer Statistics publication criteria for 2010-2014.)

१ Ethnicity is not mutually exclusive from race.

** Only includes microscopically confirmed cases; excludes cases identified only through death certificate or autopsy report.

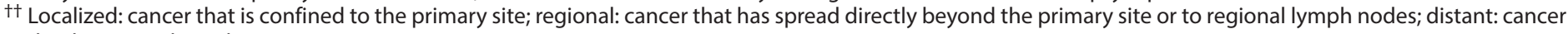
that has spread to other organs. 
TABLE 7. Incidence rates* and percentages ${ }^{\dagger}$ of invasive liver cancer, by demographic and tumor characteristics - United States, $\$$ 2010-2014

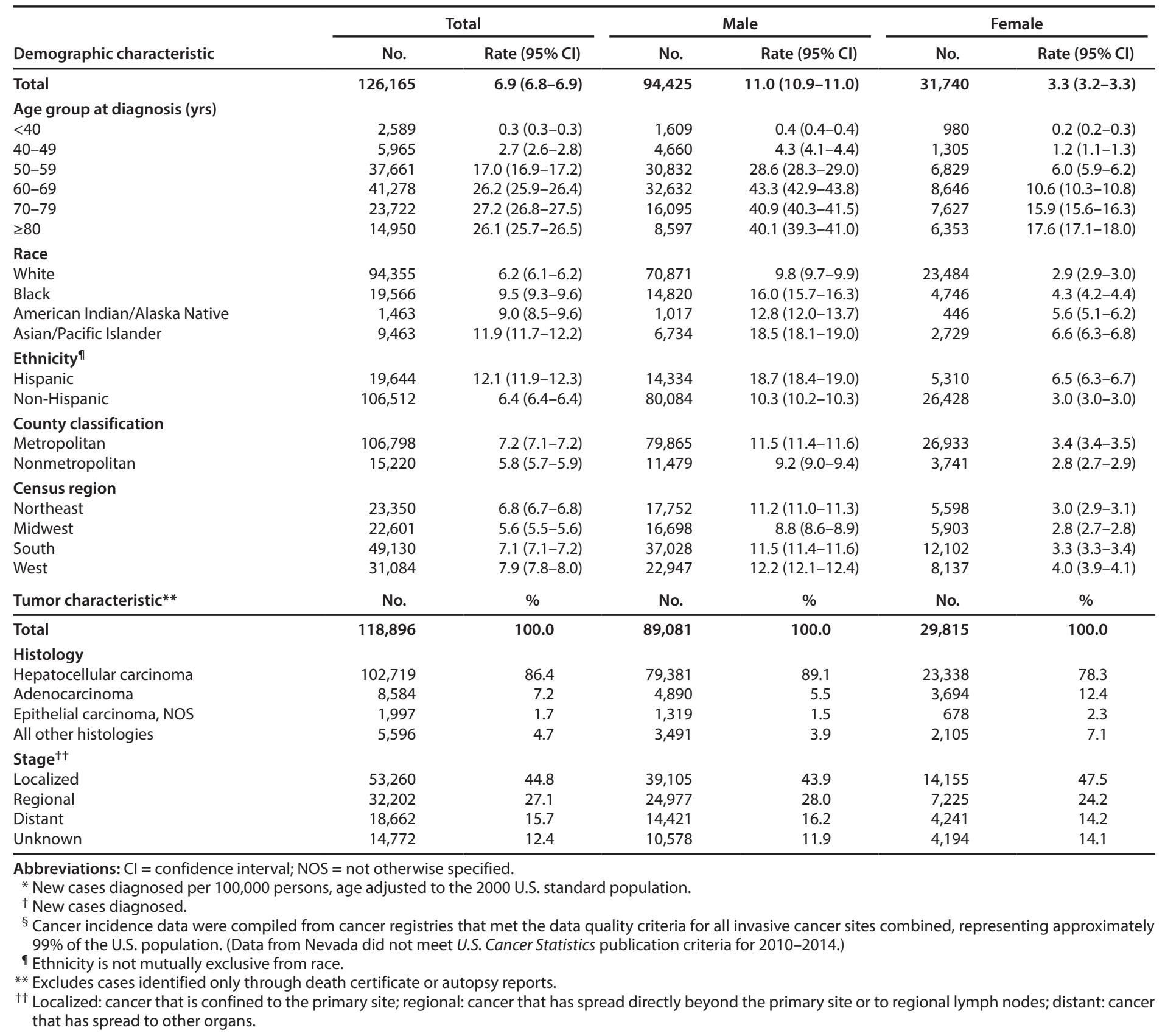




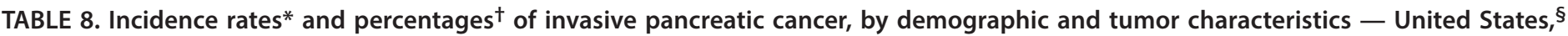
2010-2014

\begin{tabular}{|c|c|c|c|c|c|c|}
\hline \multirow[b]{2}{*}{ Demographic characteristic } & \multicolumn{2}{|c|}{ Total } & \multicolumn{2}{|c|}{ Male } & \multicolumn{2}{|c|}{ Female } \\
\hline & No. & Rate $(95 \% \mathrm{Cl})$ & No. & Rate $(95 \% \mathrm{Cl})$ & No. & Rate $(95 \% \mathrm{CI})$ \\
\hline Total & 218,919 & $12.5(12.4-12.6)$ & 111,730 & $14.2(14.1-14.3)$ & 107,189 & $11.0(11.0-11.1)$ \\
\hline \multicolumn{7}{|l|}{ Age group at diagnosis (yrs) } \\
\hline$<40$ & 2,502 & $0.3(0.3-0.3)$ & 1,182 & $0.3(0.3-0.3)$ & 1,320 & $0.3(0.3-0.4)$ \\
\hline $40-49$ & 9,445 & $4.3(4.2-4.4)$ & 5,345 & $5.0(4.8-5.1)$ & 4,100 & $3.7(3.6-3.8)$ \\
\hline $50-59$ & 34,179 & $15.6(15.4-15.7)$ & 19,892 & $18.6(18.3-18.8)$ & 14,287 & $12.7(12.5-12.9)$ \\
\hline $60-69$ & 59,397 & $38.2(37.9-38.6)$ & 33,373 & $45.2(44.7-45.7)$ & 26,024 & $32.0(31.6-32.4)$ \\
\hline $70-79$ & 59,506 & $68.4(67.8-68.9)$ & 30,244 & $77.3(76.4-78.1)$ & 29,262 & $61.1(60.4-61.8)$ \\
\hline$\geq 80$ & 53,890 & $93.1(92.3-93.9)$ & 21,694 & $101.5(100.2-102.9)$ & 32,196 & $87.9(86.9-88.9)$ \\
\hline \multicolumn{7}{|l|}{ Race } \\
\hline White & 182,531 & $12.3(12.2-12.3)$ & 94,557 & $14.1(14.0-14.2)$ & 87,974 & $10.7(10.6-10.8)$ \\
\hline Black & 27,174 & $15.5(15.3-15.7)$ & 12,671 & $16.9(16.6-17.2)$ & 14,503 & $14.4(14.2-14.6)$ \\
\hline American Indian/Alaska Native & 1,131 & $8.2(7.7-8.7)$ & 587 & $9.1(8.3-10.0)$ & 544 & $7.4(6.7-8.0)$ \\
\hline Asian/Pacific Islander & 6,787 & $9.3(9.1-9.5)$ & 3,227 & $10.0(9.6-10.4)$ & 3,560 & $8.7(8.4-9.0)$ \\
\hline \multicolumn{7}{|l|}{ Ethnicity } \\
\hline Hispanic & 16,048 & $11.1(10.9-11.3)$ & 7,854 & $12.0(11.7-12.3)$ & 8,194 & $10.3(10.1-10.6)$ \\
\hline Non-Hispanic & 202,859 & $12.6(12.6-12.7)$ & 103,870 & $14.5(14.4-14.5)$ & 98,989 & $11.1(11.0-11.2)$ \\
\hline \multicolumn{7}{|l|}{ County classification } \\
\hline Metropolitan & 178,483 & $12.6(12.5-12.7)$ & 90,388 & $14.3(14.2-14.4)$ & 88,095 & $11.2(11.1-11.2)$ \\
\hline Nonmetropolitan & 30,997 & $12.1(12.0-12.3)$ & 16,246 & $13.9(13.6-14.1)$ & 14,751 & $10.6(10.4-10.8)$ \\
\hline \multicolumn{7}{|l|}{ Census region } \\
\hline Northeast & 45,414 & $13.5(13.4-13.6)$ & 22,564 & $15.4(15.2-15.6)$ & 22,850 & $12.0(11.8-12.1)$ \\
\hline Midwest & 49,381 & $12.6(12.5-12.7)$ & 25,272 & $14.4(14.3-14.6)$ & 24,109 & $11.1(11.0-11.2)$ \\
\hline South & 80,688 & $12.4(12.3-12.4)$ & 41,527 & $14.1(14.0-14.3)$ & 39,161 & $10.9(10.7-11.0)$ \\
\hline West & 43,436 & $11.7(11.6-11.8)$ & 22,367 & $13.2(13.0-13.4)$ & 21,069 & $10.4(10.3-10.6)$ \\
\hline Tumor characteristic** & No. & $\%$ & No. & $\%$ & No. & $\%$ \\
\hline Total & 179,360 & 100.0 & 93,822 & 100.0 & 85,538 & 100.0 \\
\hline \multicolumn{7}{|l|}{ Histology } \\
\hline Mucinous adenocarcinoma & 5,874 & 3.3 & 2,943 & 3.1 & 2,931 & 3.4 \\
\hline Other adenocarcinomas & 142,872 & 79.7 & 74,884 & 79.8 & 67,988 & 79.5 \\
\hline Epithelial carcinoma, NOS & 8,105 & 4.5 & 4,427 & 4.7 & 3,678 & 4.3 \\
\hline Ductal carcinoma & 17,655 & 9.8 & 8,999 & 9.6 & 8,656 & 10.1 \\
\hline All other histologies & 4,854 & 2.7 & 2,569 & 2.7 & 2,285 & 2.7 \\
\hline \multicolumn{7}{|l|}{ Stage $^{\dagger \dagger}$} \\
\hline Localized & 18,904 & 10.5 & 9,114 & 9.7 & 9,790 & 11.4 \\
\hline Regional & 60,545 & 33.8 & 30,867 & 32.9 & 29,678 & 34.7 \\
\hline Distant & 92,435 & 51.5 & 50,179 & 53.5 & 42,256 & 49.4 \\
\hline Unknown & 7,476 & 4.2 & 3,662 & 3.9 & 3,814 & 4.5 \\
\hline
\end{tabular}

Abbreviations: $\mathrm{Cl}=$ confidence interval; $\mathrm{NOS}=$ not otherwise specified.

* New cases diagnosed per 100,000 persons, age adjusted to the 2000 U.S. standard population.

$\dagger$ New cases diagnosed.

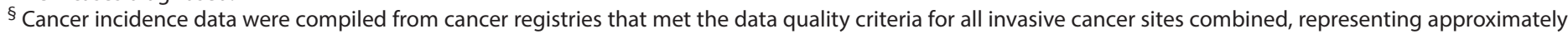
99\% of the U.S. population. (Data from Nevada did not meet U.S. Cancer Statistics publication criteria for 2010-2014.)

" Ethnicity is not mutually exclusive from race.

** Only includes microscopically confirmed cases; excludes cases identified only through death certificate or autopsy report.

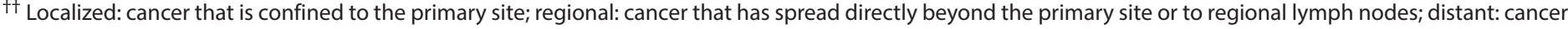
that has spread to other organs. 
TABLE 9. Incidence rates* and percentages ${ }^{\dagger}$ of invasive kidney and renal pelvis cancers, by demographic and tumor characteristics — United States, ${ }^{\S}$ 2010-2014

\begin{tabular}{|c|c|c|c|c|c|c|}
\hline \multirow[b]{2}{*}{ Demographic characteristic } & \multicolumn{2}{|c|}{ Total } & \multicolumn{2}{|c|}{ Male } & \multicolumn{2}{|c|}{ Female } \\
\hline & No. & Rate $(95 \% \mathrm{Cl})$ & No. & Rate $(95 \% \mathrm{Cl})$ & No. & Rate $(95 \% \mathrm{CI})$ \\
\hline Total & 280,883 & $16.1(16.1-16.2)$ & 176,108 & $21.8(21.7-21.9)$ & 104,775 & $11.3(11.2-11.4)$ \\
\hline \multicolumn{7}{|l|}{ Age group at diagnosis (yrs) } \\
\hline$<40$ & 13,898 & $1.8(1.8-1.8)$ & 7,650 & $2.0(1.9-2.0)$ & 6,248 & $1.6(1.6-1.7)$ \\
\hline $40-49$ & 27,897 & $13.0(12.8-13.1)$ & 17,920 & $16.8(16.5-17.0)$ & 9,977 & $9.2(9.0-9.4)$ \\
\hline $50-59$ & 61,403 & $28.2(28.0-28.4)$ & 40,198 & $37.9(37.5-38.2)$ & 21,205 & 19.0 (18.7-19.3) \\
\hline $60-69$ & 81,318 & $52.2(51.9-52.6)$ & 53,099 & $71.8(71.1-72.4)$ & 28,219 & $34.6(34.2-35.0)$ \\
\hline $70-79$ & 61,763 & $70.5(70.0-71.1)$ & 38,439 & $97.5(96.5-98.5)$ & 23,324 & $48.5(47.9-49.1)$ \\
\hline$\geq 80$ & 34,604 & $60.5(59.9-61.1)$ & 18,802 & $87.8(86.5-89.1)$ & 15,802 & $44.1(43.4-44.8)$ \\
\hline \multicolumn{7}{|l|}{ Race } \\
\hline White & 236,281 & $16.3(16.2-16.3)$ & 148,897 & $21.9(21.8-22.0)$ & 87,384 & $11.4(11.3-11.5)$ \\
\hline Black & 33,396 & $17.6(17.4-17.8)$ & 20,108 & $24.2(23.8-24.5)$ & 13,288 & $12.6(12.4-12.8)$ \\
\hline American Indian/Alaska Native & 2,526 & $15.7(15.1-16.4)$ & 1,510 & $20.1(19.0-21.3)$ & 1,016 & $11.9(11.2-12.7)$ \\
\hline Asian/Pacific Islander & 6,057 & $7.5(7.3-7.7)$ & 3,926 & $10.9(10.5-11.2)$ & 2,131 & $4.8(4.6-5.1)$ \\
\hline \multicolumn{7}{|l|}{ Ethnicity } \\
\hline Hispanic & 27,057 & $16.0(15.8-16.2)$ & 16,067 & $20.8(20.4-21.1)$ & 10,990 & $12.1(11.8-12.3)$ \\
\hline Non-Hispanic & 253,801 & $16.2(16.1-16.3)$ & 160,031 & $22.0(21.9-22.1)$ & 93,770 & $11.2(11.2-11.3)$ \\
\hline \multicolumn{7}{|l|}{ County classification } \\
\hline Metropolitan & 226,032 & $15.9(15.9-16.0)$ & 141,835 & $21.7(21.6-21.8)$ & 84,197 & $11.1(11.0-11.2)$ \\
\hline Nonmetropolitan & 41,830 & $17.1(16.9-17.2)$ & 25,957 & $22.2(21.9-22.5)$ & 15,873 & $12.5(12.3-12.7)$ \\
\hline \multicolumn{7}{|l|}{ Census region } \\
\hline Northeast & 52,819 & $16.1(16.0-16.3)$ & 33,417 & $22.3(22.1-22.6)$ & 19,402 & $10.9(10.8-11.1)$ \\
\hline Midwest & 65,551 & $17.1(16.9-17.2)$ & 40,907 & $22.9(22.7-23.1)$ & 24,644 & $12.1(11.9-12.2)$ \\
\hline South & 108,341 & $16.6(16.5-16.7)$ & 67,177 & $22.2(22.1-22.4)$ & 41,164 & $11.8(11.7-11.9)$ \\
\hline West & 54,172 & $14.5(14.3-14.6)$ & 34,607 & $19.7(19.5-19.9)$ & 19,565 & $9.9(9.8-10.1)$ \\
\hline Tumor characteristic** & No. & $\%$ & No. & $\%$ & No. & $\%$ \\
\hline Total & 251,844 & 100.0 & 158,949 & 100.0 & 92,895 & 100.0 \\
\hline \multicolumn{7}{|l|}{ Histology } \\
\hline Renal cell carcinoma & 221,417 & 87.9 & 140,989 & 88.7 & 80,428 & 86.6 \\
\hline Other adenocarcinomas & 6,286 & 2.5 & 4,060 & 2.6 & 2,226 & 2.4 \\
\hline Transitional cell carcinoma & 16,767 & 6.7 & 9,805 & 6.2 & 6,962 & 7.5 \\
\hline Epithelial carcinoma, NOS & 1,942 & 0.8 & 1,217 & 0.8 & 725 & 0.8 \\
\hline All other histologies & 5,432 & 2.2 & 2,878 & 1.8 & 2,554 & 2.7 \\
\hline \multicolumn{7}{|l|}{ Stage $^{\dagger \dagger}$} \\
\hline Localized & 169,202 & 67.2 & 104,164 & 65.5 & 65,038 & 70.0 \\
\hline Regional & 42,681 & 16.9 & 28,202 & 17.7 & 14,479 & 15.6 \\
\hline Distant & 34,681 & 13.8 & 23,306 & 14.7 & 11,375 & 12.2 \\
\hline Unknown & 5,280 & 2.1 & 3,277 & 2.1 & 2,003 & 2.2 \\
\hline
\end{tabular}

Abbreviations: $\mathrm{Cl}=$ confidence interval; $\mathrm{NOS}=$ not otherwise specified.

* New cases diagnosed per 100,000 persons, age adjusted to the 2000 U.S. standard population.

$\dagger$ New cases diagnosed.

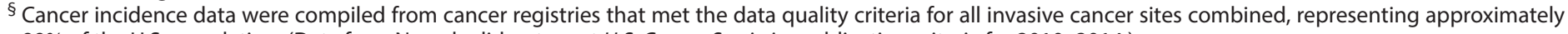
99\% of the U.S. population. (Data from Nevada did not meet U.S. Cancer Statistics publication criteria for 2010-2014.)

I Ethnicity is not mutually exclusive from race.

** Only includes microscopically confirmed cases; excludes cases identified only through death certificate or autopsy report.

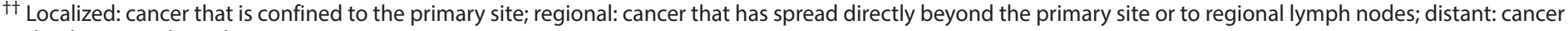
that has spread to other organs. 
TABLE 10. Incidence rates* and percentages ${ }^{\dagger}$ of invasive urinary bladder cancer, by demographic and tumor characteristics — United States, $\$$ 2010-2014

\begin{tabular}{|c|c|c|c|c|c|c|}
\hline \multirow[b]{2}{*}{ Demographic characteristic } & \multicolumn{2}{|c|}{ Total } & \multicolumn{2}{|c|}{ Male } & \multicolumn{2}{|c|}{ Female } \\
\hline & No. & Rate $(95 \% \mathrm{Cl})$ & No. & Rate $(95 \% \mathrm{Cl})$ & No. & Rate $(95 \% \mathrm{Cl})$ \\
\hline Total & 354,478 & $20.5(20.4-20.6)$ & 268,872 & $35.8(35.7-35.9)$ & 85,606 & $8.8(8.8-8.9)$ \\
\hline \multicolumn{7}{|l|}{ Age group at diagnosis (yrs) } \\
\hline$<40$ & 3,145 & $0.4(0.4-0.4)$ & 2,170 & $0.6(0.5-0.6)$ & 975 & $0.3(0.2-0.3)$ \\
\hline $40-49$ & 10,369 & $4.8(4.7-4.9)$ & 7,491 & $6.9(6.8-7.1)$ & 2,878 & $2.6(2.5-2.7)$ \\
\hline $50-59$ & 42,345 & $19.2(19.1-19.4)$ & 31,916 & $29.7(29.4-30.1)$ & 10,429 & $9.3(9.1-9.5)$ \\
\hline $60-69$ & 90,204 & $58.4(58.0-58.8)$ & 69,828 & $95.2(94.5-95.9)$ & 20,376 & $25.1(24.7-25.4)$ \\
\hline $70-79$ & 108,913 & $125.4(124.6-126.1)$ & 84,699 & 217.5 (216.0-218.9) & 24,214 & $50.6(49.9-51.2)$ \\
\hline$\geq 80$ & 99,502 & $172.4(171.3-173.5)$ & 72,768 & $340.8(338.3-343.2)$ & 26,734 & $73.2(72.3-74.1)$ \\
\hline \multicolumn{7}{|l|}{ Race } \\
\hline White & 322,431 & $21.8(21.7-21.9)$ & 246,446 & $38.0(37.8-38.1)$ & 75,985 & $9.3(9.2-9.3)$ \\
\hline Black & 19,647 & $11.7(11.5-11.9)$ & 13,174 & 19.5 (19.1-19.9) & 6,473 & $6.6(6.4-6.8)$ \\
\hline American Indian/Alaska Native & 1,155 & $9.0(8.4-9.5)$ & 849 & $15.3(14.1-16.4)$ & 306 & $4.2(3.7-4.7)$ \\
\hline Asian/Pacific Islander & 6,084 & $8.5(8.3-8.7)$ & 4,558 & $14.9(14.5-15.4)$ & 1,526 & $3.8(3.6-4.0)$ \\
\hline \multicolumn{7}{|l|}{ Ethnicity } \\
\hline Hispanic & 15,308 & $11.2(11.0-11.3)$ & 11,365 & 19.5 (19.1-19.9) & 3,943 & $5.0(4.9-5.2)$ \\
\hline Non-Hispanic & 339,122 & $21.3(21.3-21.4)$ & 257,478 & $37.2(37.1-37.4)$ & 81,644 & $9.2(9.1-9.2)$ \\
\hline \multicolumn{7}{|l|}{ County classification } \\
\hline Metropolitan & 284,262 & $20.4(20.3-20.4)$ & 214,733 & 35.7 (35.5-35.9) & 69,529 & $8.8(8.8-8.9)$ \\
\hline Nonmetropolitan & 53,332 & $21.0(20.8-21.1)$ & 41,193 & $36.2(35.8-36.6)$ & 12,139 & $8.8(8.6-9.0)$ \\
\hline \multicolumn{7}{|l|}{ Census region } \\
\hline Northeast & 81,032 & $24.3(24.2-24.5)$ & 60,232 & $42.5(42.2-42.9)$ & 20,800 & $11.0(10.8-11.1)$ \\
\hline Midwest & 84,088 & 21.7 (21.6-21.9) & 63,670 & $37.9(37.6-38.2)$ & 20,418 & $9.4(9.3-9.5)$ \\
\hline South & 121,179 & $18.8(18.7-18.9)$ & 92,425 & $33.0(32.8-33.2)$ & 28,754 & $8.0(7.9-8.1)$ \\
\hline West & 68,179 & $18.7(18.6-18.9)$ & 52,545 & $32.5(32.3-32.8)$ & 15,634 & $7.8(7.6-7.9)$ \\
\hline Tumor characteristic** & No. & $\%$ & No. & $\%$ & No. & $\%$ \\
\hline Total & 346,522 & 100.0 & 263,415 & 100.0 & 83,107 & 100.0 \\
\hline \multicolumn{7}{|l|}{ Histology } \\
\hline Transitional cell carcinoma & 328,814 & 94.9 & 251,579 & 95.5 & 77,235 & 92.9 \\
\hline Squamous cell carcinoma & 5,506 & 1.6 & 3,170 & 1.2 & 2,336 & 2.8 \\
\hline Adenocarcinoma & 3,829 & 1.1 & 2,551 & 1.0 & 1,278 & 1.5 \\
\hline Epithelial carcinoma, NOS & 6,249 & 1.8 & 4,645 & 1.8 & 1,604 & 1.9 \\
\hline All other histologies & 2,124 & 0.6 & 1,470 & 0.6 & 654 & 0.8 \\
\hline \multicolumn{7}{|l|}{ Stage $^{\dagger \dagger}$} \\
\hline Localized & 296,493 & 85.6 & 227,058 & 86.2 & 69,435 & 83.5 \\
\hline Regional & 25,399 & 7.3 & 18,696 & 7.1 & 6,703 & 8.1 \\
\hline Distant & 14,366 & 4.1 & 10,047 & 3.8 & 4,319 & 5.2 \\
\hline Unknown & 10,264 & 3.0 & 7,614 & 2.9 & 2,650 & 3.2 \\
\hline
\end{tabular}

Abbreviations: $\mathrm{Cl}=$ confidence interval; $\mathrm{NOS}=$ not otherwise specified.

* New cases diagnosed per 100,000 persons, age adjusted to the 2000 U.S. standard population.

+ New cases diagnosed.

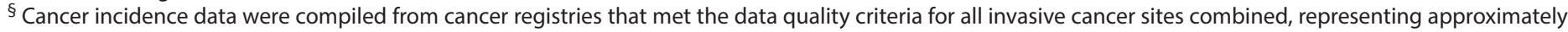
99\% of the U.S. population. (Data from Nevada did not meet U.S. Cancer Statistics publication criteria for 2010-2014.)

" Ethnicity is not mutually exclusive from race.

** Only includes microscopically confirmed cases; excludes cases identified only through death certificate or autopsy report.

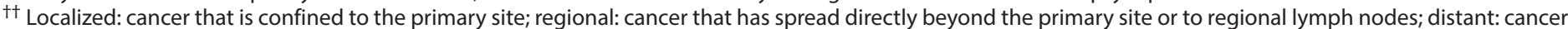
that has spread to other organs. 
TABLE 11. Incidence rates* and percentages ${ }^{\dagger}$ of invasive cervical $^{*}$ cancer, by demographic and tumor characteristics - United States, $\$$ 2010-2014

\begin{tabular}{|c|c|c|}
\hline Demographic characteristic & No. & Rate $(95 \% \mathrm{Cl})$ \\
\hline Total & 61,499 & $7.5(7.5-7.6)$ \\
\hline \multicolumn{3}{|l|}{ Age group at diagnosis (yrs) } \\
\hline$<40$ & 15,061 & $3.9(3.8-3.9)$ \\
\hline $40-49$ & 15,242 & $14.3(14.1-14.6)$ \\
\hline $50-59$ & 13,551 & $12.3(12.1-12.6)$ \\
\hline $60-69$ & 9,538 & $11.6(11.3-11.8)$ \\
\hline $70-79$ & 5,003 & $10.4(10.1-10.7)$ \\
\hline$\geq 80$ & 3,104 & $8.6(8.3-8.9)$ \\
\hline \multicolumn{3}{|l|}{ Race } \\
\hline White & 47,007 & $7.3(7.2-7.4)$ \\
\hline Black & 9,837 & $9.3(9.1-9.5)$ \\
\hline American Indian/Alaska Native & 609 & $6.5(6.0-7.1)$ \\
\hline Asian/Pacific Islander & 2,900 & $6.1(5.9-6.3)$ \\
\hline \multicolumn{3}{|l|}{ Ethnicity } \\
\hline Hispanic & 10,236 & $9.7(9.5-9.9)$ \\
\hline Non-Hispanic & 51,259 & $7.3(7.2-7.3)$ \\
\hline \multicolumn{3}{|l|}{ County classification } \\
\hline Metropolitan & 50,808 & $7.4(7.4-7.5)$ \\
\hline Nonmetropolitan & 8,440 & $8.4(8.2-8.6)$ \\
\hline \multicolumn{3}{|l|}{ Census region } \\
\hline Northeast & 10,935 & $7.1(6.9-7.2)$ \\
\hline Midwest & 12,530 & $7.1(7.0-7.3)$ \\
\hline South & 25,587 & $8.3(8.2-8.4)$ \\
\hline West & 12,447 & $6.9(6.8-7.0)$ \\
\hline Tumor characteristic ${ }^{* *}$ & No. & $\%$ \\
\hline Total & 59,726 & 100.0 \\
\hline \multicolumn{3}{|l|}{ Histology } \\
\hline Squamous cell carcinoma & 39,480 & 66.1 \\
\hline Adenocarcinoma & 16,456 & 27.6 \\
\hline Epithelial carcinoma, NOS & 2,235 & 3.7 \\
\hline All other histologies & 1,555 & 2.6 \\
\hline \multicolumn{3}{|l|}{ Stage ${ }^{\dagger \dagger}$} \\
\hline Localized & 26,183 & 43.8 \\
\hline Regional & 21,650 & 36.2 \\
\hline Distant & 8,824 & 14.8 \\
\hline Unknown & 3,069 & 5.1 \\
\hline
\end{tabular}

Abbreviations: $\mathrm{Cl}=$ confidence interval; $\mathrm{NOS}=$ not otherwise specified.

* New cases diagnosed per 100,000 females, age adjusted to the 2000 U.S. standard population.

† New cases diagnosed.

$\S$ Cancer incidence data were compiled from cancer registries that met the data quality criteria for all invasive cancer sites combined, representing approximately $99 \%$ of the U.S. population. (Data from Nevada did not meet U.S. Cancer Statistics publication criteria for 2010-2014.)

I Ethnicity is not mutually exclusive from race.

** Only includes microscopically confirmed cases; excludes cases identified only through death certificate or autopsy report.

t+ Localized: cancer that is confined to the primary site; regional: cancer that has spread directly beyond the primary site or to regional lymph nodes; distant: cancer that has spread to other organs. 
TABLE 12. Incidence rates* and percentages ${ }^{\dagger}$ of acute myeloid leukemia, by demographic and tumor characteristics - United States, $\$$ 2010-2014

\begin{tabular}{|c|c|c|c|c|c|c|}
\hline \multirow[b]{2}{*}{ Demographic characteristic } & \multicolumn{2}{|c|}{ Total } & \multicolumn{2}{|c|}{ Male } & \multicolumn{2}{|c|}{ Female } \\
\hline & No. & Rate $(95 \% \mathrm{Cl})$ & No. & Rate $(95 \% \mathrm{CI})$ & No. & Rate $(95 \% \mathrm{Cl})$ \\
\hline Total & 70,960 & $4.2(4.2-4.2)$ & 39,024 & $5.2(5.1-5.2)$ & 31,936 & $3.5(3.5-3.6)$ \\
\hline \multicolumn{7}{|l|}{ Age group at diagnosis (yrs) } \\
\hline$<40$ & 8,576 & $1.0(1.0-1.1)$ & 4,254 & $1.0(1.0-1.1)$ & 4,322 & $1.1(1.0-1.1)$ \\
\hline $40-49$ & 4,967 & $2.3(2.3-2.4)$ & 2,512 & $2.4(2.3-2.5)$ & 2,455 & $2.3(2.2-2.4)$ \\
\hline $50-59$ & 9,408 & $4.3(4.2-4.4)$ & 5,099 & $4.8(4.7-4.9)$ & 4,309 & $3.9(3.8-4.0)$ \\
\hline $60-69$ & 15,497 & $10.0(9.8-10.2)$ & 9,068 & $12.3(12.1-12.6)$ & 6,429 & $7.9(7.7-8.1)$ \\
\hline 70-79 & 17,344 & $20.0(19.7-20.3)$ & 10,119 & $26.0(25.5-26.5)$ & 7,225 & $15.1(14.7-15.4)$ \\
\hline$\geq 80$ & 15,168 & $26.3(25.9-26.8)$ & 7,972 & $37.3(36.5-38.1)$ & 7,196 & $19.9(19.4-20.3)$ \\
\hline \multicolumn{7}{|l|}{ Race } \\
\hline White & 60,923 & $4.3(4.3-4.3)$ & 33,980 & $5.3(5.2-5.3)$ & 26,943 & $3.6(3.5-3.6)$ \\
\hline Black & 6,368 & $3.5(3.4-3.6)$ & 3,157 & $4.1(4.0-4.3)$ & 3,211 & $3.1(3.0-3.2)$ \\
\hline American Indian/Alaska Native & 432 & $2.7(2.5-3.0)$ & 214 & $3.1(2.6-3.6)$ & 218 & $2.5(2.2-2.9)$ \\
\hline Asian/Pacific Islander & 2,645 & $3.4(3.2-3.5)$ & 1,361 & $4.0(3.7-4.2)$ & 1,284 & $2.9(2.8-3.1)$ \\
\hline \multicolumn{7}{|l|}{ Ethnicity } \\
\hline Hispanic & 6,362 & $3.6(3.5-3.7)$ & 3,351 & $4.2(4.0-4.4)$ & 3,011 & $3.2(3.0-3.3)$ \\
\hline Non-Hispanic & 64,594 & $4.3(4.2-4.3)$ & 35,671 & $5.2(5.2-5.3)$ & 28,923 & $3.5(3.5-3.6)$ \\
\hline \multicolumn{7}{|l|}{ County classification } \\
\hline Metropolitan & 57,611 & $4.2(4.2-4.2)$ & 31,583 & $5.2(5.1-5.2)$ & 26,028 & $3.5(3.5-3.5)$ \\
\hline Nonmetropolitan & 10,050 & $4.2(4.1-4.3)$ & 5,611 & $5.1(4.9-5.2)$ & 4,439 & $3.6(3.5-3.7)$ \\
\hline \multicolumn{7}{|l|}{ Census region } \\
\hline Northeast & 14,211 & $4.5(4.4-4.5)$ & 7,763 & $5.5(5.4-5.6)$ & 6,448 & $3.7(3.6-3.8)$ \\
\hline Midwest & 16,751 & $4.5(4.4-4.5)$ & 9,143 & $5.5(5.3-5.6)$ & 7,608 & $3.7(3.7-3.8)$ \\
\hline South & 25,375 & $4.0(4.0-4.1)$ & 14,003 & $5.0(4.9-5.0)$ & 11,372 & $3.4(3.3-3.4)$ \\
\hline West & 14,623 & $4.0(4.0-4.1)$ & 8,115 & $4.9(4.8-5.0)$ & 6,508 & $3.4(3.3-3.5)$ \\
\hline
\end{tabular}

Abbreviation: $\mathrm{Cl}=$ confidence interval.

* New cases diagnosed per 100,000 persons, age adjusted to the 2000 U.S. standard population.

+ New cases diagnosed.

$\S$ Cancer incidence data were compiled from cancer registries that met the data quality criteria for all invasive cancer sites combined, representing approximately 99\% of the U.S. population. (Data from Nevada did not meet U.S. Cancer Statistics publication criteria for 2010-2014.)

" Ethnicity is not mutually exclusive from race.

TABLE 13. Annual percentage change* in incidence rates ${ }^{\dagger}$ of tobacco-associated cancers, by cancer site and sex - United States, $\$$ 2010-2014?

\begin{tabular}{|c|c|c|c|c|c|c|}
\hline \multirow[b]{2}{*}{ Cancer site } & \multicolumn{2}{|c|}{ Total } & \multicolumn{2}{|c|}{ Male } & \multicolumn{2}{|c|}{ Female } \\
\hline & APC & p value $e^{* *}$ & APC & $p$ value & APC & p value \\
\hline All tobacco-related cancer sites & -1.20 & $<0.001$ & -1.40 & 0.001 & -1.10 & $<0.001$ \\
\hline Oral cavity and pharynx & 0.63 & 0.09 & 0.79 & 0.18 & 0.06 & 0.81 \\
\hline Esophagus & -0.86 & 0.02 & -1.12 & 0.006 & -0.54 & 0.24 \\
\hline Stomach & -1.01 & $<0.001$ & -1.25 & 0.02 & -0.92 & 0.08 \\
\hline Colon and rectum & -2.07 & 0.002 & -2.19 & 0.001 & -2.04 & 0.005 \\
\hline Liver & 1.98 & 0.02 & 1.72 & 0.04 & 2.43 & 0.02 \\
\hline Pancreas & 0.53 & 0.08 & 0.70 & 0.05 & 0.36 & 0.10 \\
\hline Larynx & -3.00 & 0.004 & -3.18 & 0.008 & -2.81 & 0.004 \\
\hline Trachea, lung, and bronchus & -2.17 & $<0.001$ & -2.88 & $<0.001$ & -1.47 & 0.007 \\
\hline Cervix uteri & - & - & - & - & -0.87 & 0.15 \\
\hline Kidney and renal pelvis & 0.54 & 0.01 & 0.69 & 0.004 & 0.07 & 0.73 \\
\hline Urinary bladder & -1.28 & 0.02 & -1.51 & 0.02 & -1.29 & 0.04 \\
\hline Acute myeloid leukemia & 0.34 & 0.03 & 0.36 & 0.22 & 0.17 & 0.59 \\
\hline
\end{tabular}

Abbreviations: $\mathrm{APC}=$ annual percentage change.

* Calculated by least squares regression.

† New cases diagnosed per 100,000 persons, age adjusted to the 2000 U.S. standard population.

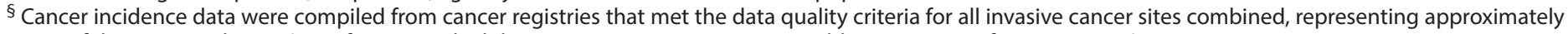

99\% of the U.S. population. (Data from Nevada did not meet U.S. Cancer Statistics publication criteria for 2010-2014.)

I See also Supplementary Table 1 (https://stacks.cdc.gov/view/cdc/59431) and Supplementary Table 2 (https://stacks.cdc.gov/view/cdc/59432).

** $\mathrm{p}<0.05$ was considered statistically significant. 
FIGURE 1. Incidence rates* for male lung, bronchial, and tracheal cancers, by state/area and U.S. census region ${ }^{\dagger}-$ United States, ${ }^{\S}$ 2010-2014

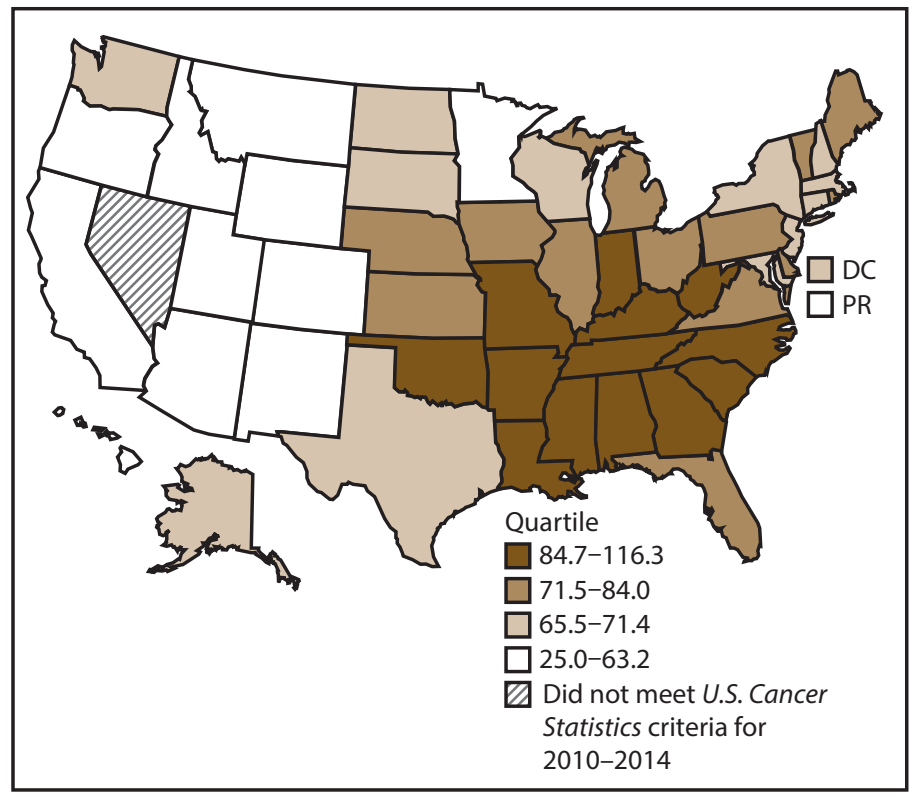

Abbreviations: $\mathrm{DC}=$ District of Columbia; $\mathrm{PR}=$ Puerto Rico

* New cases diagnosed per 100,000 males, age adjusted to the 2000 U.S. standard population.

† West: 53.5; Midwest: 78.6; Northeast: 72.0; South: 80.8. (West: Alaska, Arizona, California, Colorado, Hawaii, Idaho, Montana, Oregon, New Mexico, Utah, Washington, and Wyoming; Midwest: Illinois, Indiana, lowa, Kansas, Michigan, Minnesota, Missouri, Nebraska, North Dakota, Ohio, South Dakota, and Wisconsin; Northeast: Connecticut, Maine, Massachusetts, New Hampshire, New Jersey, New York, Pennsylvania, Rhode Island, and Vermont; South: Alabama, Arkansas, Delaware, District of Columbia, Florida, Georgia, Kentucky, Louisiana, Maryland, Mississippi, North Carolina, Oklahoma, South Carolina, Tennessee, Texas, Virginia, and West Virginia.)

$\S$ Cancer incidence data were compiled from cancer registries that met the data quality criteria for all invasive cancer sites combined, representing approximately $99 \%$ of the U.S. population. (Data from Nevada did not meet U.S. Cancer Statistics publication criteria for 2010-2014.) Data for Puerto Rico are included in state-specific analyses but not in U.S. census region analyses.
FIGURE 2. Incidence rates* for female lung, bronchial, and tracheal cancers, by state/area and U.S. census region ${ }^{\dagger}-$ United States, ${ }^{\S}$ 2010-2014

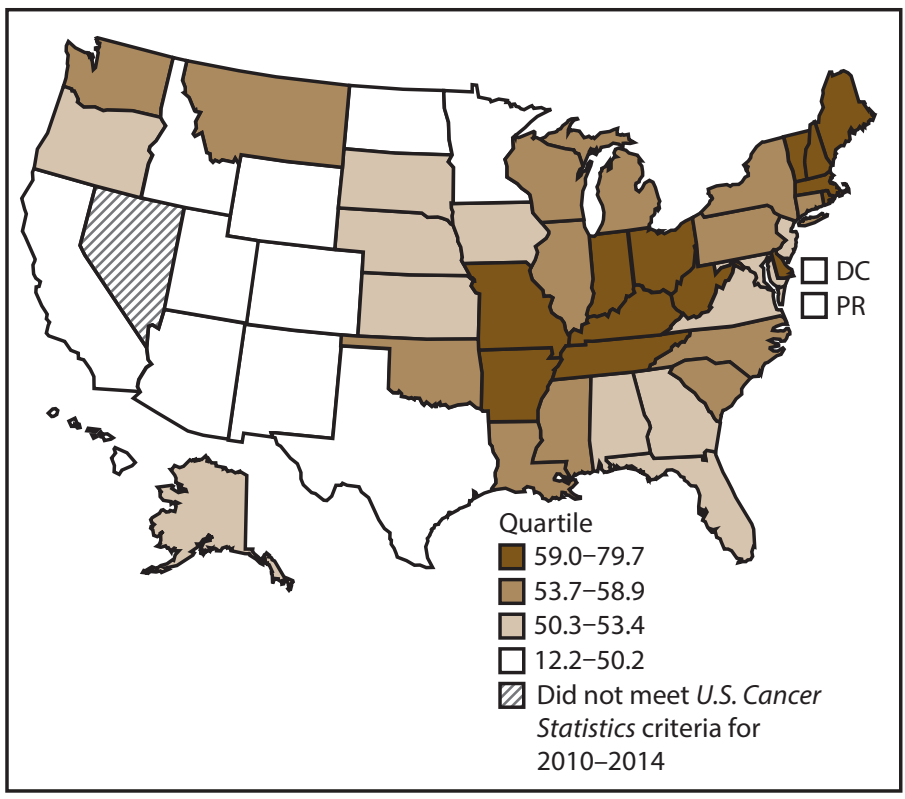

Abbreviations: $\mathrm{DC}=$ District of Columbia; $\mathrm{PR}=$ Puerto Rico.

* New cases diagnosed per 100,000 females, age adjusted to the 2000 U.S. standard population.

${ }^{\dagger}$ West: 42.7; Midwest: 57.4; Northeast: 56.0; South: 53.8. (West: Alaska, Arizona, California, Colorado, Hawaii, Idaho, Montana, Oregon, New Mexico, Utah, Washington, and Wyoming; Midwest: Illinois, Indiana, lowa, Kansas, Michigan, Minnesota, Missouri, Nebraska, North Dakota, Ohio, South Dakota, and Wisconsin; Northeast: Connecticut, Maine, Massachusetts, New Hampshire, New Jersey, New York, Pennsylvania, Rhode Island, and Vermont; South: Alabama, Arkansas, Delaware, District of Columbia, Florida, Georgia, Kentucky, Louisiana, Maryland, Mississippi, North Carolina, Oklahoma, South Carolina, Tennessee, Texas, Virginia, and West Virginia.)

$\S$ Cancer incidence data were compiled from cancer registries that met the data quality criteria for all invasive cancer sites combined, representing approximately $99 \%$ of the U.S. population. (Data from Nevada did not meet U.S. Cancer Statistics publication criteria for 2010-2014.) Data for Puerto Rico are included in state-specific analyses but not in U.S. census region analyses. 
FIGURE 3. Incidence rates* for male laryngeal cancer, by state/area and U.S. census region ${ }^{\dagger}$ — United States, $\$$ 2010-2014

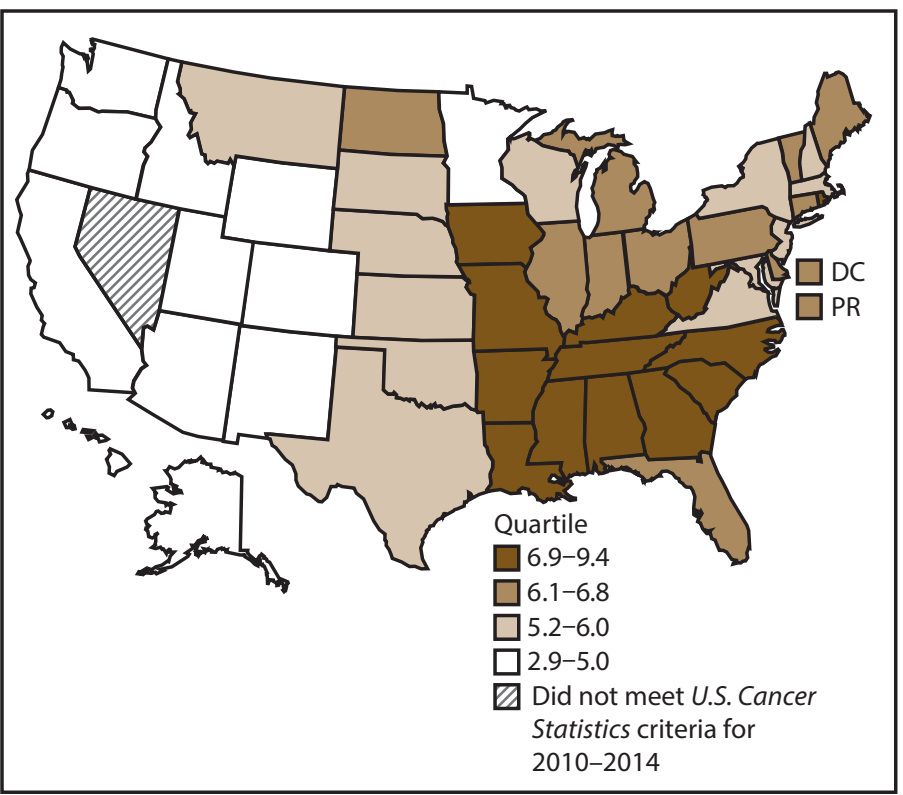

Abbreviations: $\mathrm{DC}=$ District of Columbia; $\mathrm{PR}=$ Puerto Rico.

* New cases diagnosed per 100,000 males, age adjusted to the 2000 U.S. standard population.

† West: 4.0; Midwest: 6.4; Northeast: 6.1; South: 6.8. (West: Alaska, Arizona, California, Colorado, Hawaii, Idaho, Montana, Oregon, New Mexico, Utah, Washington, and Wyoming; Midwest: Illinois, Indiana, lowa, Kansas, Michigan, Minnesota, Missouri, Nebraska, North Dakota, Ohio, South Dakota, and Wisconsin; Northeast: Connecticut, Maine, Massachusetts, New Hampshire, New Jersey, New York, Pennsylvania, Rhode Island, and Vermont; South: Alabama, Arkansas, Delaware, District of Columbia, Florida, Georgia, Kentucky, Louisiana, Maryland, Mississippi, North Carolina, Oklahoma, South Carolina, Tennessee, Texas, Virginia, and West Virginia.)

$\S$ Cancer incidence data were compiled from cancer registries that met the data quality criteria for all invasive cancer sites combined, representing approximately $99 \%$ of the U.S. population. (Data from Nevada did not meet U.S. Cancer Statistics publication criteria for 2010-2014.) Data for Puerto Rico are included in state-specific analyses but not in U.S. census region analyses.
FIGURE 4. Incidence rates* for female laryngeal cancer, by state/ area and U.S. census region ${ }^{\dagger} \_$United States, ${ }^{\S}$ 2010-2014

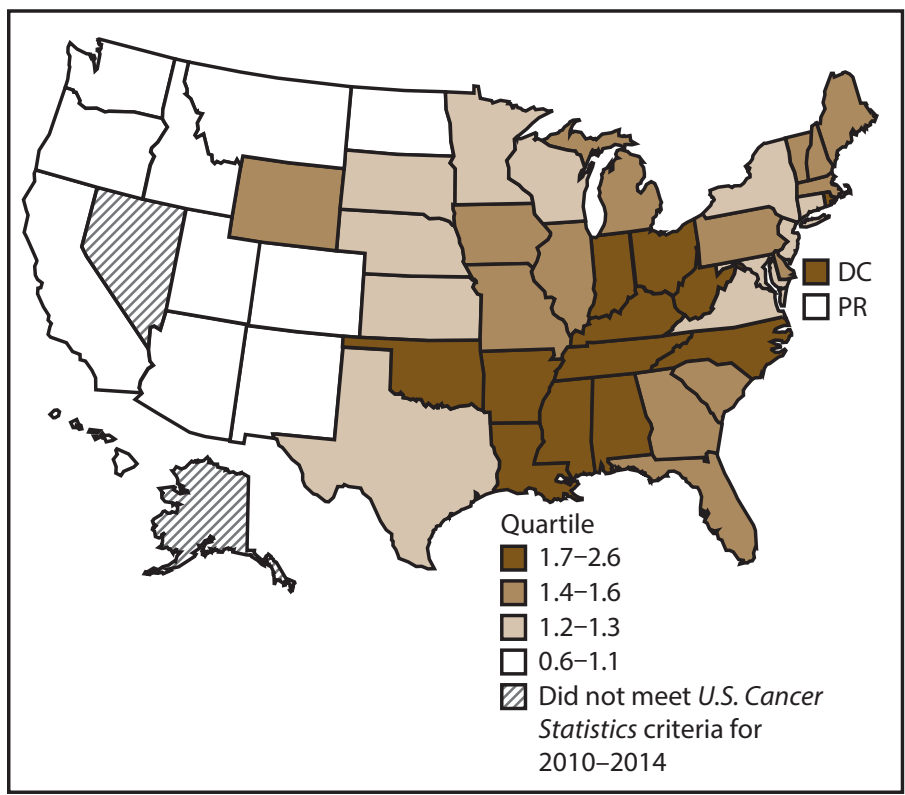

Abbreviations: $\mathrm{DC}=$ District of Columbia; $\mathrm{PR}=$ Puerto Rico.

* New cases diagnosed per 100,000 females, age adjusted to the 2000 U.S. standard population.

† West: 0.8; Midwest: 1.6; Northeast: 1.4; South: 1.5. (West: Alaska, Arizona, California, Colorado, Hawaii, Idaho, Montana, Oregon, New Mexico, Utah, Washington, and Wyoming; Midwest: Illinois, Indiana, lowa, Kansas, Michigan, Minnesota, Missouri, Nebraska, North Dakota, Ohio, South Dakota, and Wisconsin; Northeast: Connecticut, Maine, Massachusetts, New Hampshire, New Jersey, New York, Pennsylvania, Rhode Island, and Vermont; South: Alabama, Arkansas, Delaware, District of Columbia, Florida, Georgia, Kentucky, Louisiana, Maryland, Mississippi, North Carolina, Oklahoma, South Carolina, Tennessee, Texas, Virginia, and West Virginia.)

$\S$ Cancer incidence data were compiled from cancer registries that met the data quality criteria for all invasive cancer sites combined, representing approximately $99 \%$ of the U.S. population. (Data from Nevada did not meet U.S. Cancer Statistics publication criteria for 2010-2014.) Data for Puerto Rico are included in state-specific analyses but not in U.S. census region analyses. 
FIGURE 5. Incidence rates* for male oral cavity and pharyngeal cancers, by state/area and U.S. census region ${ }^{\dagger}$ - United States, ${ }^{\S}$ 2010-2014

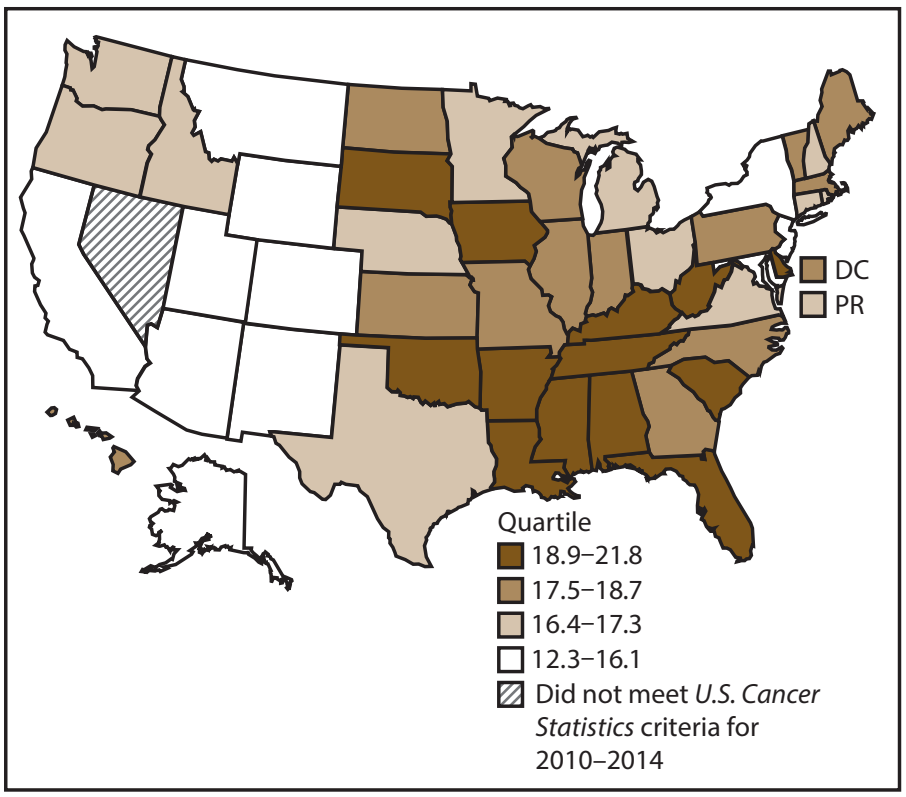

Abbreviations: $\mathrm{DC}=$ District of Columbia; $\mathrm{PR}=$ Puerto Rico.

* New cases diagnosed per 100,000 males, age adjusted to the 2000 U.S. standard population.

† West: 15.5; Midwest: 17.7; Northeast: 16.6; South: 18.6. (West: Alaska, Arizona, California, Colorado, Hawaii, Idaho, Montana, Oregon, New Mexico, Utah, Washington, and Wyoming; Midwest: Illinois, Indiana, lowa, Kansas, Michigan, Minnesota, Missouri, Nebraska, North Dakota, Ohio, South Dakota, and Wisconsin; Northeast: Connecticut, Maine, Massachusetts, New Hampshire, New Jersey, New York, Pennsylvania, Rhode Island, and Vermont; South: Alabama, Arkansas, Delaware, District of Columbia, Florida, Georgia, Kentucky, Louisiana, Maryland, Mississippi, North Carolina, Oklahoma, South Carolina, Tennessee, Texas, Virginia, and West Virginia.)

$\S$ Cancer incidence data were compiled from cancer registries that met the data quality criteria for all invasive cancer sites combined, representing approximately $99 \%$ of the U.S. population. (Data from Nevada did not meet U.S. Cancer Statistics publication criteria for 2010-2014.) Data for Puerto Rico are included in state-specific analyses but not in U.S. census region analyses.
FIGURE 6. Incidence rates* for female oral cavity and pharyngeal cancers, by state/area and U.S. census region ${ }^{\dagger}-$ United States, ${ }^{\S}$ 2010-2014

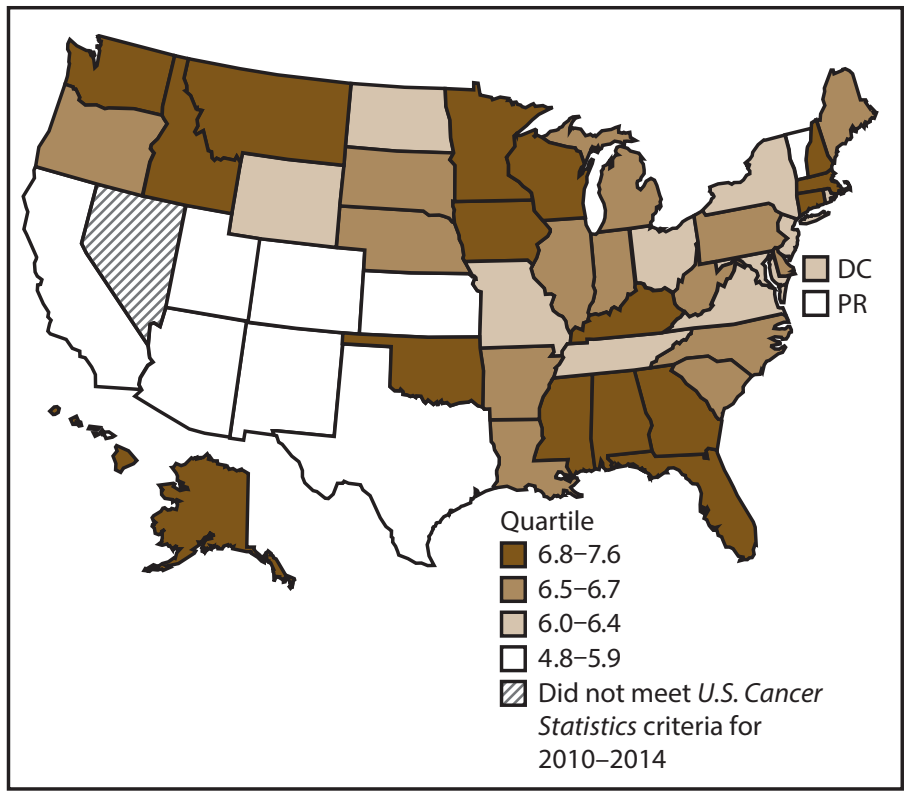

Abbreviations: $\mathrm{DC}=$ District of Columbia; $\mathrm{PR}=$ Puerto Rico.

* New cases diagnosed per 100,000 females, age adjusted to the 2000 U.S. standard population.

† West: 5.9; Midwest: 6.5; Northeast: 6.5; South: 6.5. (West: Alaska, Arizona, California, Colorado, Hawaii, Idaho, Montana, Oregon, New Mexico, Utah, Washington, and Wyoming; Midwest: Illinois, Indiana, lowa, Kansas, Michigan, Minnesota, Missouri, Nebraska, North Dakota, Ohio, South Dakota, and Wisconsin; Northeast: Connecticut, Maine, Massachusetts, New Hampshire, New Jersey, New York, Pennsylvania, Rhode Island, and Vermont; South: Alabama, Arkansas, Delaware, District of Columbia, Florida, Georgia, Kentucky, Louisiana, Maryland, Mississippi, North Carolina, Oklahoma, South Carolina, Tennessee, Texas, Virginia, and West Virginia.)

$\S$ Cancer incidence data were compiled from cancer registries that met the data quality criteria for all invasive cancer sites combined, representing approximately $99 \%$ of the U.S. population. (Data from Nevada did not meet U.S. Cancer Statistics publication criteria for 2010-2014.) Data for Puerto Rico are included in state-specific analyses but not in U.S. census region analyses. 
FIGURE 7. Incidence rates* for male esophageal cancer, by state/ area and U.S. census region ${ }^{\dagger}$ — United States, ${ }^{\S}$ 2010-2014

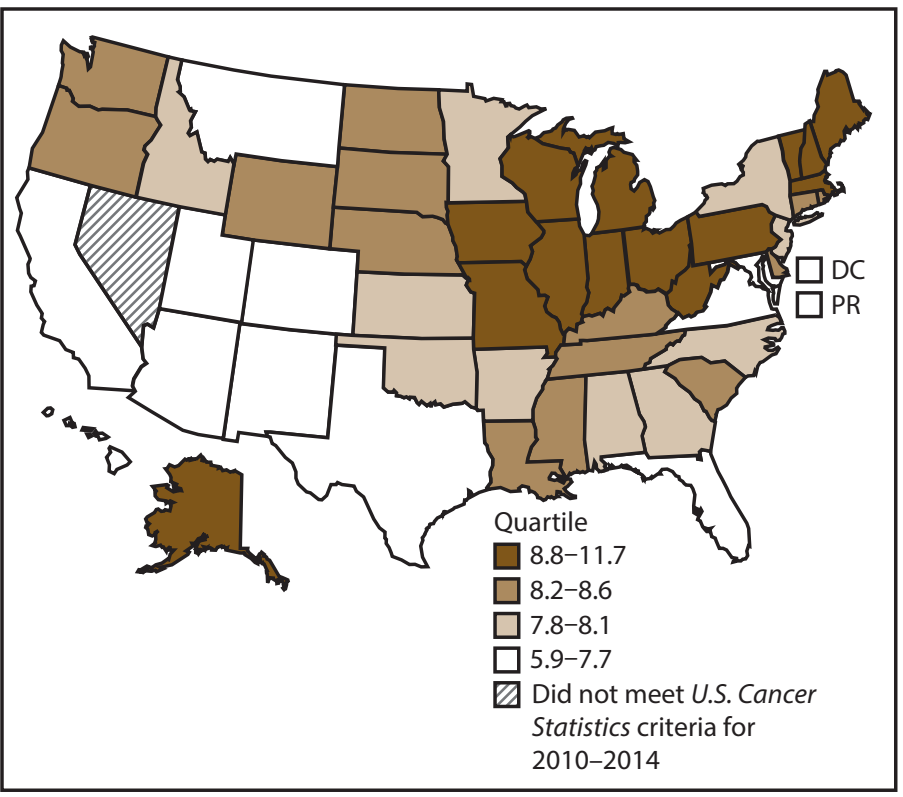

Abbreviations: $\mathrm{DC}=$ District of Columbia; $\mathrm{PR}=$ Puerto Rico.

* New cases diagnosed per 100,000 males, age adjusted to the 2000 U.S. standard population.

† West: 6.9; Midwest: 8.9; Northeast: 8.6; South: 7.7. (West: Alaska, Arizona, California, Colorado, Hawaii, Idaho, Montana, Oregon, New Mexico, Utah, Washington, and Wyoming; Midwest: Illinois, Indiana, lowa, Kansas, Michigan, Minnesota, Missouri, Nebraska, North Dakota, Ohio, South Dakota, and Wisconsin; Northeast: Connecticut, Maine, Massachusetts, New Hampshire, New Jersey, New York, Pennsylvania, Rhode Island, and Vermont; South: Alabama, Arkansas, Delaware, District of Columbia, Florida, Georgia, Kentucky, Louisiana, Maryland, Mississippi, North Carolina, Oklahoma, South Carolina, Tennessee, Texas, Virginia, and West Virginia.)

$\S$ Cancer incidence data were compiled from cancer registries that met the data quality criteria for all invasive cancer sites combined, representing approximately $99 \%$ of the U.S. population. (Data from Nevada did not meet U.S. Cancer Statistics publication criteria for 2010-2014.) Data for Puerto Rico are included in state-specific analyses but not in U.S. census region analyses.
FIGURE 8. Incidence rates* for female esophageal cancer, by state/ area and U.S. census region ${ }^{\dagger}$ — United States, ${ }^{\S}$ 2010-2014

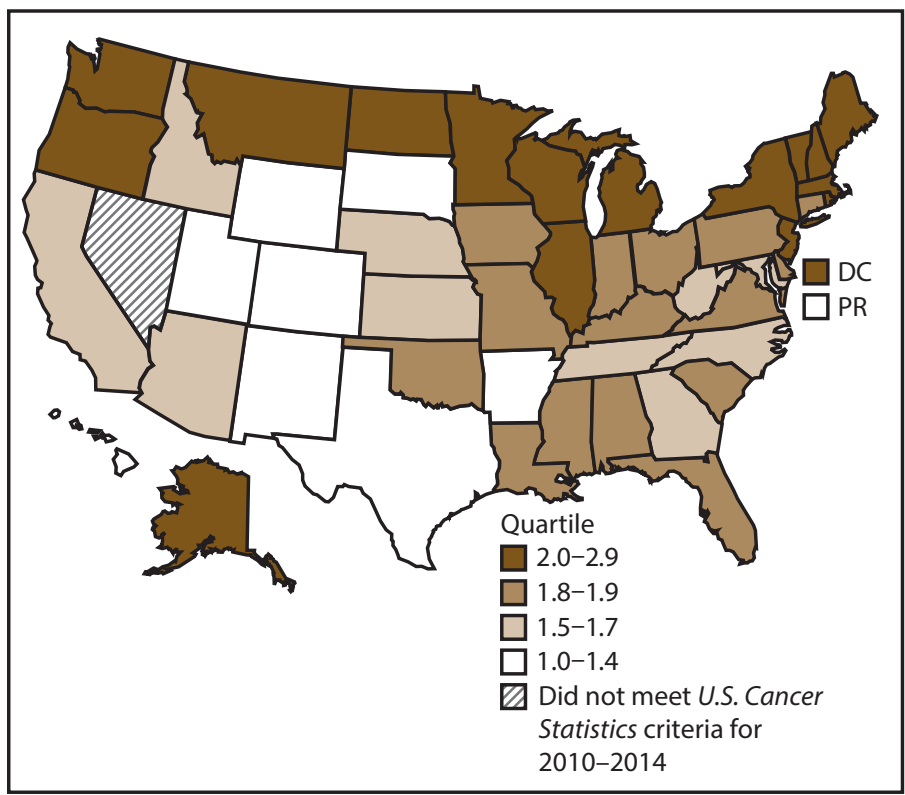

Abbreviations: $\mathrm{DC}=$ District of Columbia; $\mathrm{PR}=$ Puerto Rico.

* New cases diagnosed per 100,000 females, age adjusted to the 2000 U.S. standard population.

† West: 1.6; Midwest: 1.9; Northeast: 2.0; South: 1.7. (West: Alaska, Arizona, California, Colorado, Hawaii, Idaho, Montana, Oregon, New Mexico, Utah, Washington, and Wyoming; Midwest: Illinois, Indiana, lowa, Kansas, Michigan, Minnesota, Missouri, Nebraska, North Dakota, Ohio, South Dakota, and Wisconsin; Northeast: Connecticut, Maine, Massachusetts, New Hampshire, New Jersey, New York, Pennsylvania, Rhode Island, and Vermont; South: Alabama, Arkansas, Delaware, District of Columbia, Florida, Georgia, Kentucky, Louisiana, Maryland, Mississippi, North Carolina, Oklahoma, South Carolina, Tennessee, Texas, Virginia, and West Virginia.)

$\S$ Cancer incidence data were compiled from cancer registries that met the data quality criteria for all invasive cancer sites combined, representing approximately $99 \%$ of the U.S. population. (Data from Nevada did not meet U.S. Cancer Statistics publication criteria for 2010-2014.) Data for Puerto Rico are included in state-specific analyses but not in U.S. census region analyses. 
FIGURE 9. Incidence rates* for male stomach cancer, by state/area and U.S. census region ${ }^{\dagger}$ — United States, $\$$ 2010-2014

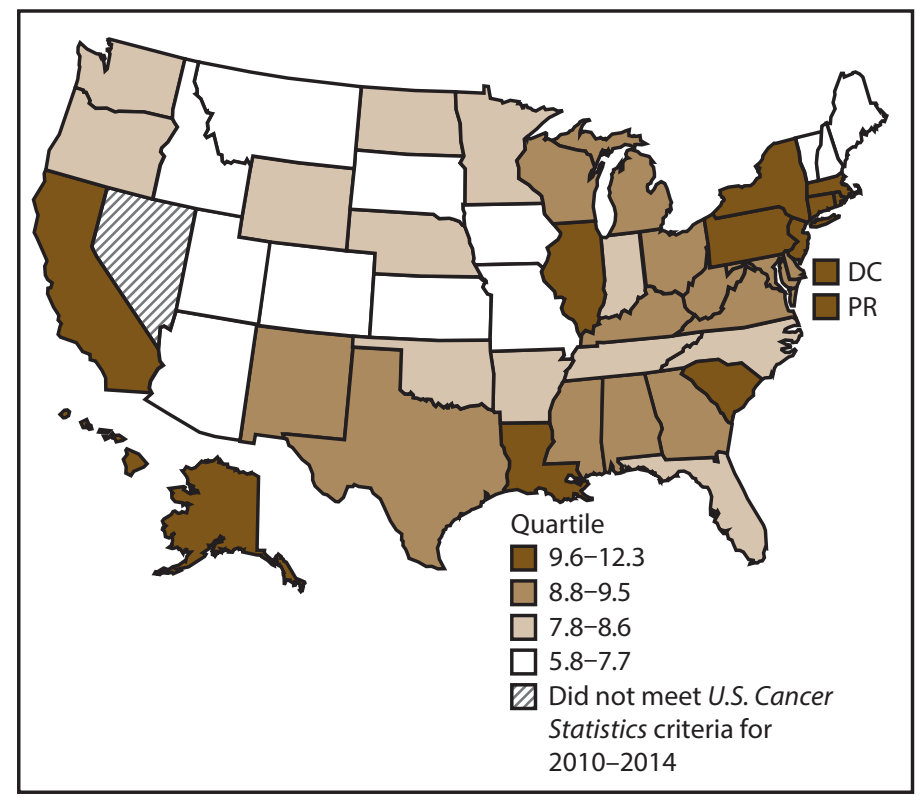

Abbreviations: $\mathrm{DC}=$ District of Columbia; $\mathrm{PR}=$ Puerto Rico.

* New cases diagnosed per 100,000 males, age adjusted to the 2000 U.S. standard population.

† West: 9.1; Midwest: 8.7; Northeast: 10.7; South: 8.7. (West: Alaska, Arizona, California, Colorado, Hawaii, Idaho, Montana, Oregon, New Mexico, Utah, Washington, and Wyoming; Midwest: Illinois, Indiana, lowa, Kansas, Michigan, Minnesota, Missouri, Nebraska, North Dakota, Ohio, South Dakota, and Wisconsin; Northeast: Connecticut, Maine, Massachusetts, New Hampshire, New Jersey, New York, Pennsylvania, Rhode Island, and Vermont; South: Alabama, Arkansas, Delaware, District of Columbia, Florida, Georgia, Kentucky, Louisiana, Maryland, Mississippi, North Carolina, Oklahoma, South Carolina, Tennessee, Texas, Virginia, and West Virginia.)

$\S$ Cancer incidence data were compiled from cancer registries that met the data quality criteria for all invasive cancer sites combined, representing approximately $99 \%$ of the U.S. population. (Data from Nevada did not meet U.S. Cancer Statistics publication criteria for 2010-2014.) Data for Puerto Rico are included in state-specific analyses but not in U.S. census region analyses.
FIGURE 10. Incidence rates* for female stomach cancer, by state/ area and U.S. census region ${ }^{\dagger} \_$United States, ${ }^{\S}$ 2010-2014

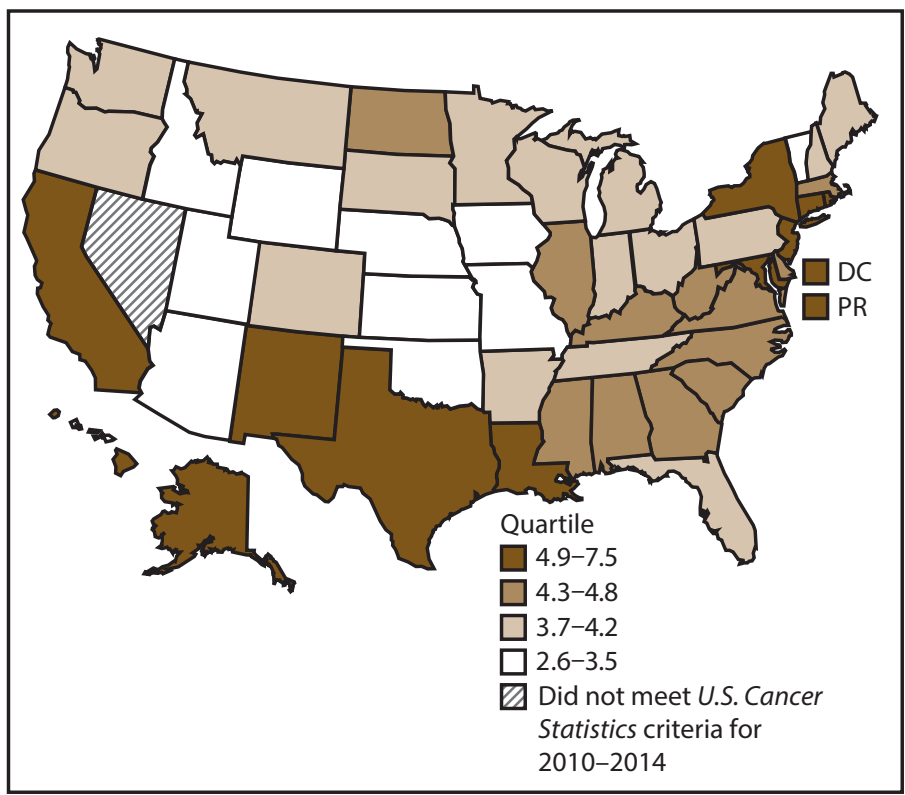

Abbreviations: $\mathrm{DC}=$ District of Columbia; $\mathrm{PR}=$ Puerto Rico.

* New cases diagnosed per 100,000 females, age adjusted to the 2000 U.S. standard population.

† West: 4.8; Midwest: 4.0; Northeast: 5.2; South: 4.6 (West: Alaska, Arizona, California, Colorado, Hawaii, Idaho, Montana, Oregon, New Mexico, Utah, Washington, and Wyoming; Midwest: Illinois, Indiana, lowa, Kansas, Michigan, Minnesota, Missouri, Nebraska, North Dakota, Ohio, South Dakota, and Wisconsin; Northeast: Connecticut, Maine, Massachusetts, New Hampshire, New Jersey, New York, Pennsylvania, Rhode Island, and Vermont; South: Alabama, Arkansas, Delaware, District of Columbia, Florida, Georgia, Kentucky, Louisiana, Maryland, Mississippi, North Carolina, Oklahoma, South Carolina, Tennessee, Texas, Virginia, and West Virginia.)

$\S$ Cancer incidence data were compiled from cancer registries that met the data quality criteria for all invasive cancer sites combined, representing approximately $99 \%$ of the U.S. population. (Data from Nevada did not meet U.S. Cancer Statistics publication criteria for 2010-2014.) Data for Puerto Rico are included in state-specific analyses but not in U.S. census region analyses. 
FIGURE 11. Incidence rates* for male colon and rectal cancers, by state/area and U.S. census region ${ }^{\dagger} \_$United States, ${ }^{\S}$ 2010-2014

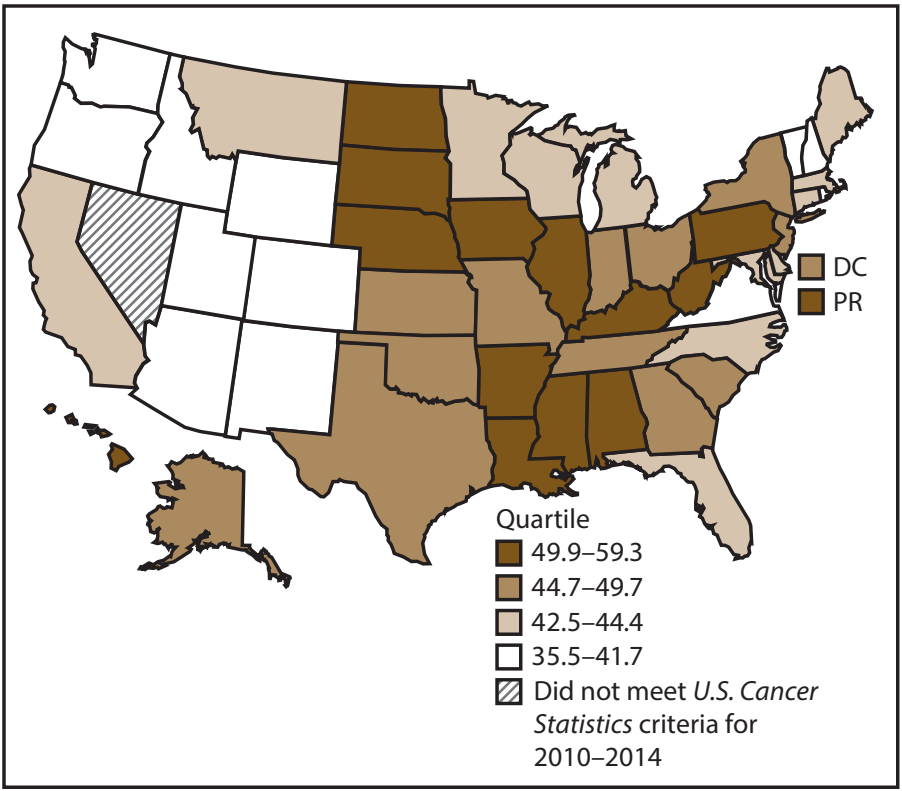

Abbreviations: $\mathrm{DC}=$ District of Columbia; $\mathrm{PR}=$ Puerto Rico.

* New cases diagnosed per 100,000 males, age adjusted to the 2000 U.S. standard population.

† West: 41.4; Midwest: 48.0; Northeast: 46.7; South: 46.6. (West: Alaska, Arizona, California, Colorado, Hawaii, Idaho, Montana, Oregon, New Mexico, Utah, Washington, and Wyoming; Midwest: Illinois, Indiana, lowa, Kansas, Michigan, Minnesota, Missouri, Nebraska, North Dakota, Ohio, South Dakota, and Wisconsin; Northeast: Connecticut, Maine, Massachusetts, New Hampshire, New Jersey, New York, Pennsylvania, Rhode Island, and Vermont; South: Alabama, Arkansas, Delaware, District of Columbia, Florida, Georgia, Kentucky, Louisiana, Maryland, Mississippi, North Carolina, Oklahoma, South Carolina, Tennessee, Texas, Virginia, and West Virginia.)

$\S$ Cancer incidence data were compiled from cancer registries that met the data quality criteria for all invasive cancer sites combined, representing approximately $99 \%$ of the U.S. population. (Data from Nevada did not meet U.S. Cancer Statistics publication criteria for 2010-2014.) Data for Puerto Rico are included in state-specific analyses but not in U.S. census region analyses.
FIGURE 12. Incidence rates* for female colon and rectal cancers, by state/area and U.S. census region ${ }^{\dagger} \_$United States, ${ }^{\S}$ 2010-2014

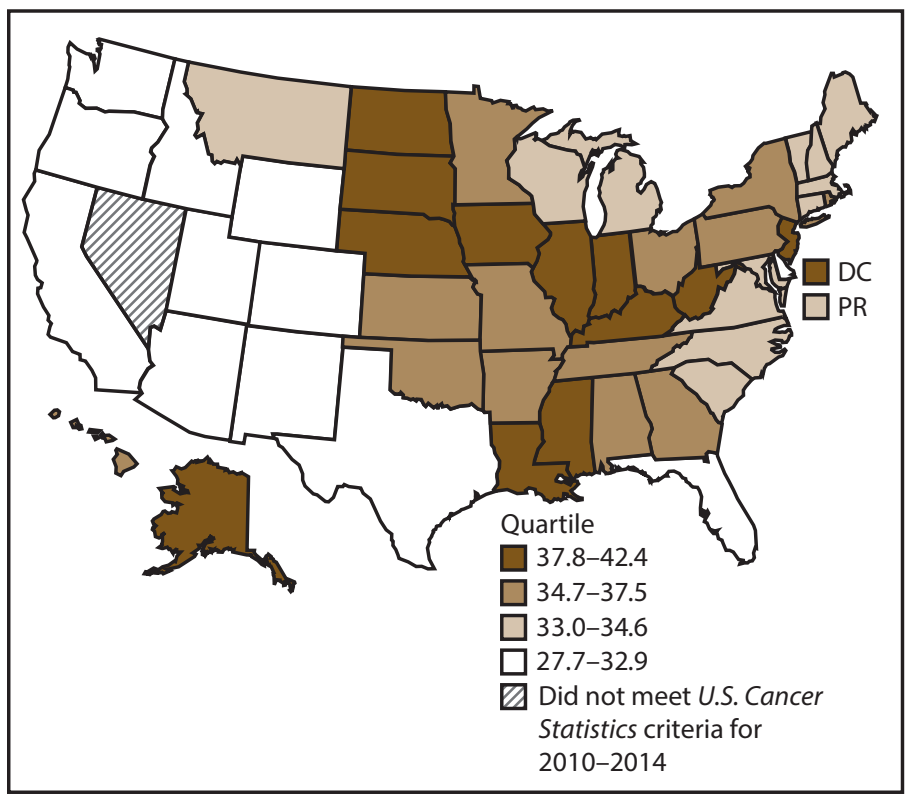

Abbreviations: $\mathrm{DC}=$ District of Columbia; $\mathrm{PR}=$ Puerto Rico.

* New cases diagnosed per 100,000 females, age adjusted to the 2000 U.S. standard population.

† West: 32.0; Midwest: 36.4; Northeast: 36.0; South: 34.7. (West: Alaska, Arizona, California, Colorado, Hawaii, Idaho, Montana, Oregon, New Mexico, Utah, Washington, and Wyoming; Midwest: Illinois, Indiana, lowa, Kansas, Michigan, Minnesota, Missouri, Nebraska, North Dakota, Ohio, South Dakota, and Wisconsin; Northeast: Connecticut, Maine, Massachusetts, New Hampshire, New Jersey, New York, Pennsylvania, Rhode Island, and Vermont; South: Alabama, Arkansas, Delaware, District of Columbia, Florida, Georgia, Kentucky, Louisiana, Maryland, Mississippi, North Carolina, Oklahoma, South Carolina, Tennessee, Texas, Virginia, and West Virginia.)

$\S$ Cancer incidence data were compiled from cancer registries that met the data quality criteria for all invasive cancer sites combined, representing approximately $99 \%$ of the U.S. population. (Data from Nevada did not meet U.S. Cancer Statistics publication criteria for 2010-2014.) Data for Puerto Rico are included in state-specific analyses but not in U.S. census region analyses. 
FIGURE 13. Incidence rates* for male liver cancer, by state/area and U.S. census region ${ }^{\dagger}$ — United States, $\$$ 2010-2014

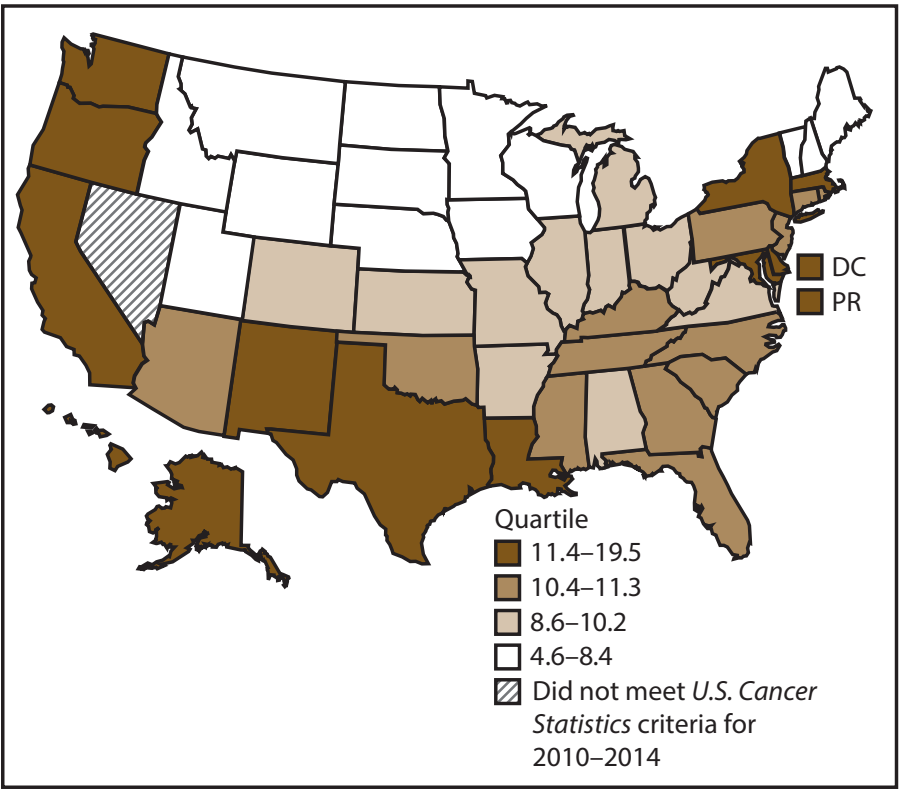

Abbreviations: $\mathrm{DC}=$ District of Columbia; $\mathrm{PR}=$ Puerto Rico

* New cases diagnosed per 100,000 males, age adjusted to the 2000 U.S. standard population.

+ West: 12.2; Midwest: 8.8; Northeast: 11.2; South: 11.5. (West: Alaska, Arizona, California, Colorado, Hawaii, Idaho, Montana, Oregon, New Mexico, Utah, Washington, and Wyoming; Midwest: Illinois, Indiana, lowa, Kansas, Michigan, Minnesota, Missouri, Nebraska, North Dakota, Ohio, South Dakota, and Wisconsin; Northeast: Connecticut, Maine, Massachusetts, New Hampshire, New Jersey, New York, Pennsylvania, Rhode Island, and Vermont; South: Alabama, Arkansas, Delaware, District of Columbia, Florida, Georgia, Kentucky, Louisiana, Maryland, Mississippi, North Carolina, Oklahoma, South Carolina, Tennessee, Texas, Virginia, and West Virginia.)

$\S$ Cancer incidence data were compiled from cancer registries that met the data quality criteria for all invasive cancer sites combined, representing approximately $99 \%$ of the U.S. population. (Data from Nevada did not meet U.S. Cancer Statistics publication criteria for 2010-2014.) Data for Puerto Rico are included in state-specific analyses but not in U.S. census region analyses.
FIGURE 14. Incidence rates* for female liver cancer, by state/area and U.S. census region ${ }^{\dagger}$ — United States, $\$$ 2010-2014

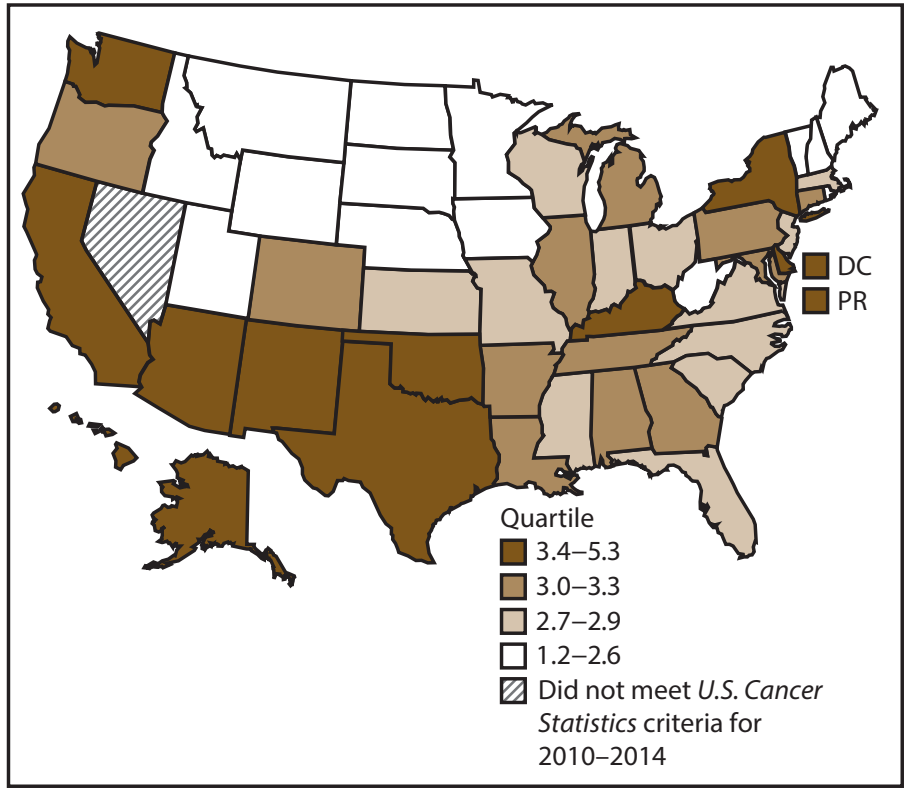

Abbreviations: $\mathrm{DC}=$ District of Columbia; $\mathrm{PR}=$ Puerto Rico.

* New cases diagnosed per 100,000 females, age adjusted to the 2000 U.S. standard population.

† West: 4.0; Midwest: 2.8; Northeast: 3.0; South: 3.3. (West: Alaska, Arizona, California, Colorado, Hawaii, Idaho, Montana, Oregon, New Mexico, Utah, Washington, and Wyoming; Midwest: Illinois, Indiana, lowa, Kansas, Michigan, Minnesota, Missouri, Nebraska, North Dakota, Ohio, South Dakota, and Wisconsin; Northeast: Connecticut, Maine, Massachusetts, New Hampshire, New Jersey, New York, Pennsylvania, Rhode Island, and Vermont; South: Alabama, Arkansas, Delaware, District of Columbia, Florida, Georgia, Kentucky, Louisiana, Maryland, Mississippi, North Carolina, Oklahoma, South Carolina, Tennessee, Texas, Virginia, and West Virginia.)

$\S$ Cancer incidence data were compiled from cancer registries that met the data quality criteria for all invasive cancer sites combined, representing approximately $99 \%$ of the U.S. population. (Data from Nevada did not meet U.S. Cancer Statistics publication criteria for 2010-2014.) Data for Puerto Rico are included in state-specific analyses but not in U.S. census region analyses. 
FIGURE 15. Incidence rates* for male pancreatic cancer, by state/ area and U.S. census region ${ }^{\dagger}$ — United States, ${ }^{\S} 2010-2014$

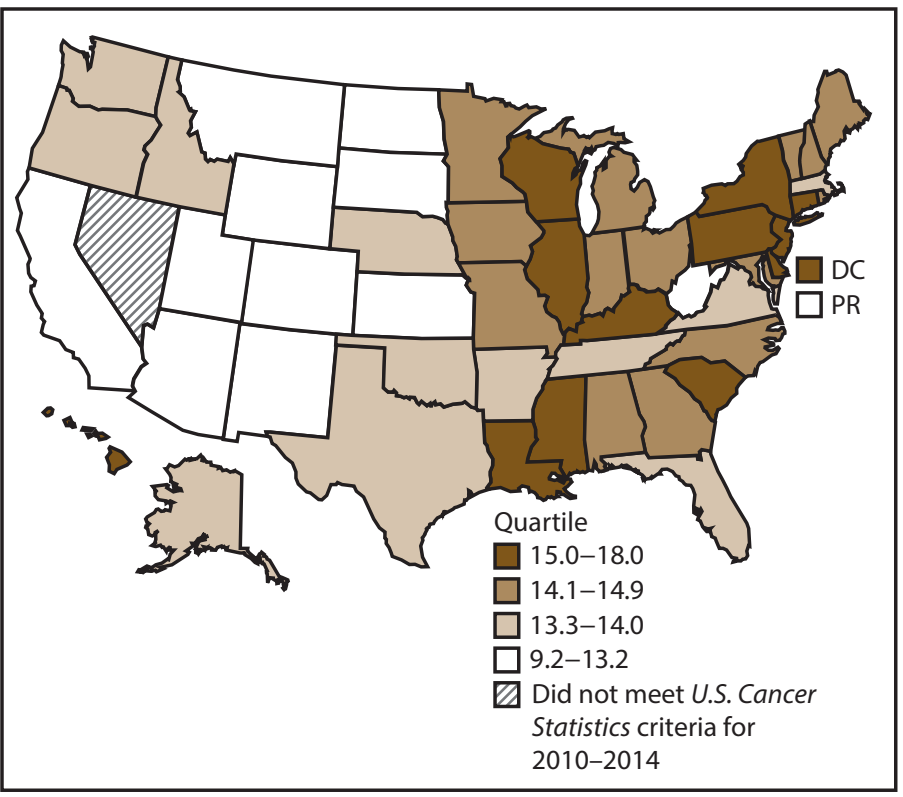

Abbreviations: $\mathrm{DC}=$ District of Columbia; $\mathrm{PR}=$ Puerto Rico.

* New cases diagnosed per 100,000 males, age adjusted to the 2000 U.S. standard population.

† West: 13.2; Midwest: 14.4; Northeast: 15.4; South: 14.1. (West: Alaska, Arizona, California, Colorado, Hawaii, Idaho, Montana, Oregon, New Mexico, Utah, Washington, and Wyoming; Midwest: Illinois, Indiana, lowa, Kansas, Michigan, Minnesota, Missouri, Nebraska, North Dakota, Ohio, South Dakota, and Wisconsin; Northeast: Connecticut, Maine, Massachusetts, New Hampshire, New Jersey, New York, Pennsylvania, Rhode Island, and Vermont; South: Alabama, Arkansas, Delaware, District of Columbia, Florida, Georgia, Kentucky, Louisiana, Maryland, Mississippi, North Carolina, Oklahoma, South Carolina, Tennessee, Texas, Virginia, and West Virginia.)

$\S$ Cancer incidence data were compiled from cancer registries that met the data quality criteria for all invasive cancer sites combined, representing approximately $99 \%$ of the U.S. population. (Data from Nevada did not meet U.S. Cancer Statistics publication criteria for 2010-2014.) Data for Puerto Rico are included in state-specific analyses but not in U.S. census region analyses.
FIGURE 16. Incidence rates* for female pancreatic cancer, by state/ area and U.S. census region ${ }^{\dagger} \_$United States, ${ }^{\S}$ 2010-2014

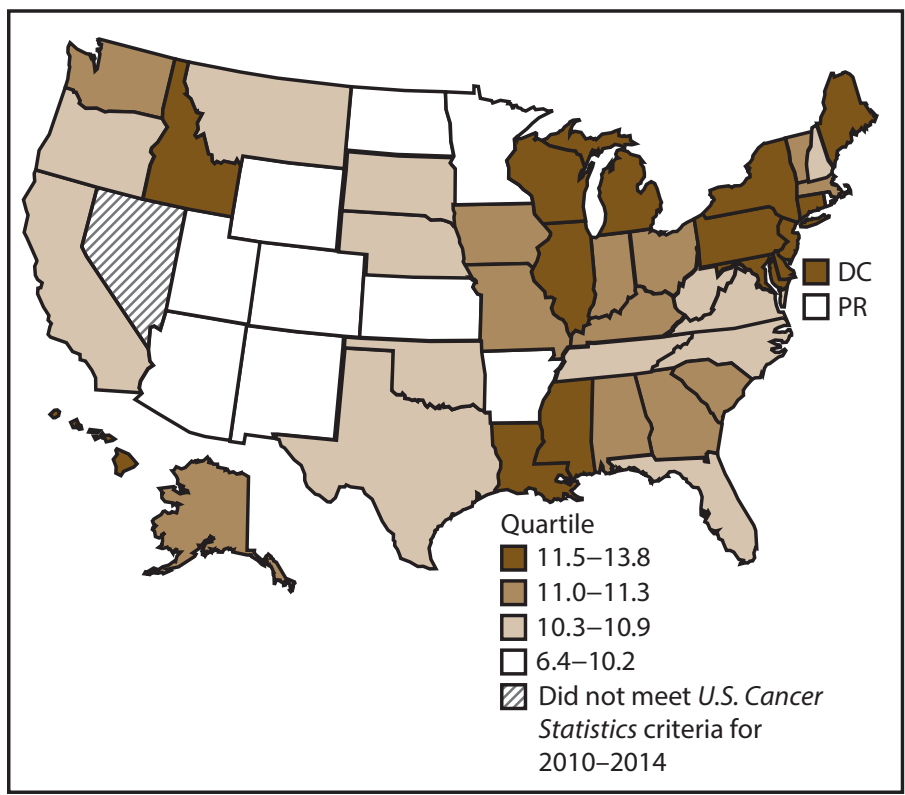

Abbreviations: $\mathrm{DC}=$ District of Columbia; $\mathrm{PR}=$ Puerto Rico.

* New cases diagnosed per 100,000 females, age adjusted to the 2000 U.S. standard population.

† West: 10.4; Midwest: 11.1; Northeast: 12.0; South: 10.9. (West: Alaska, Arizona, California, Colorado, Hawaii, Idaho, Montana, Oregon, New Mexico, Utah, Washington, and Wyoming; Midwest: Illinois, Indiana, lowa, Kansas, Michigan, Minnesota, Missouri, Nebraska, North Dakota, Ohio, South Dakota, and Wisconsin; Northeast: Connecticut, Maine, Massachusetts, New Hampshire, New Jersey, New York, Pennsylvania, Rhode Island, and Vermont; South: Alabama, Arkansas, Delaware, District of Columbia, Florida, Georgia, Kentucky, Louisiana, Maryland, Mississippi, North Carolina, Oklahoma, South Carolina, Tennessee, Texas, Virginia, and West Virginia.)

$\S$ Cancer incidence data were compiled from cancer registries that met the data quality criteria for all invasive cancer sites combined, representing approximately $99 \%$ of the U.S. population. (Data from Nevada did not meet U.S. Cancer Statistics publication criteria for 2010-2014.) Data for Puerto Rico are included in state-specific analyses but not in U.S. census region analyses. 
FIGURE 17. Incidence rates* for male kidney and renal pelvis cancers, by state/area and U.S. census region ${ }^{\dagger}$ - United States, ${ }^{\S}$ 2010-2014

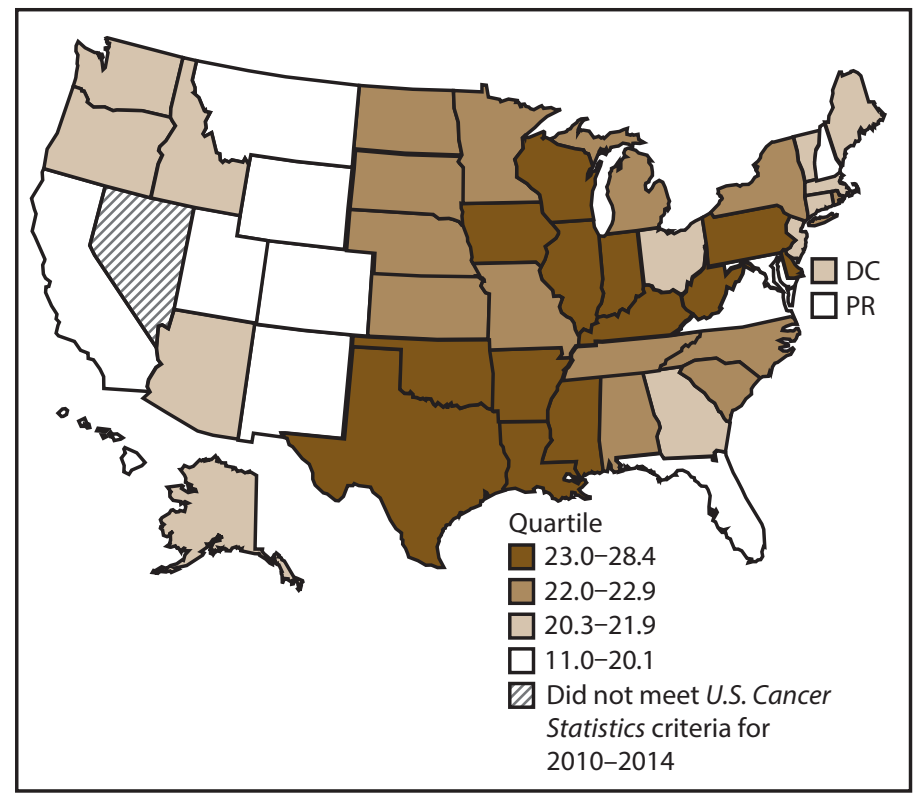

Abbreviations: DC = District of Columbia; PR = Puerto Rico.

* New cases diagnosed per 100,000 males, age adjusted to the 2000 U.S. standard population.

† West: 19.7; Midwest: 22.9; Northeast: 22.3; South: 22.2. (West: Alaska, Arizona, California, Colorado, Hawaii, Idaho, Montana, Oregon, New Mexico, Utah, Washington, and Wyoming; Midwest: Illinois, Indiana, lowa, Kansas, Michigan, Minnesota, Missouri, Nebraska, North Dakota, Ohio, South Dakota, and Wisconsin; Northeast: Connecticut, Maine, Massachusetts, New Hampshire, New Jersey, New York, Pennsylvania, Rhode Island, and Vermont; South: Alabama, Arkansas, Delaware, District of Columbia, Florida, Georgia, Kentucky, Louisiana, Maryland, Mississippi, North Carolina, Oklahoma, South Carolina, Tennessee, Texas, Virginia, and West Virginia.)

$\S$ Cancer incidence data were compiled from cancer registries that met the data quality criteria for all invasive cancer sites combined, representing approximately $99 \%$ of the U.S. population. (Data from Nevada did not meet U.S. Cancer Statistics publication criteria for 2010-2014.) Data for Puerto Rico are included in state-specific analyses but not in U.S. census region analyses.
FIGURE 18. Incidence rates* for female kidney and renal pelvis cancers, by state/area and U.S. census region ${ }^{\dagger}-$ United States, ${ }^{\S}$ 2010-2014

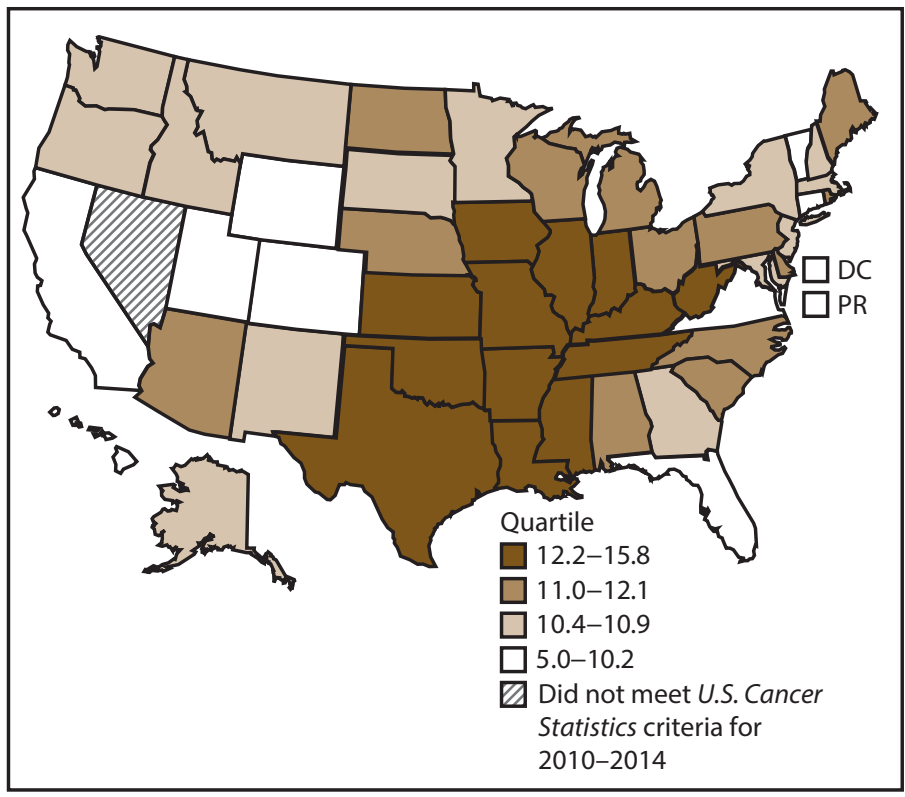

Abbreviations: $\mathrm{DC}=$ District of Columbia; $\mathrm{PR}=$ Puerto Rico.

* New cases diagnosed per 100,000 females, age adjusted to the 2000 U.S. standard population.

${ }^{\dagger}$ West: 9.9; Midwest: 12.1; Northeast: 10.9; South: 11.8. (West: Alaska, Arizona, California, Colorado, Hawaii, Idaho, Montana, Oregon, New Mexico, Utah, Washington, and Wyoming; Midwest: Illinois, Indiana, lowa, Kansas, Michigan, Minnesota, Missouri, Nebraska, North Dakota, Ohio, South Dakota, and Wisconsin; Northeast: Connecticut, Maine, Massachusetts, New Hampshire, New Jersey, New York, Pennsylvania, Rhode Island, and Vermont; South: Alabama, Arkansas, Delaware, District of Columbia, Florida, Georgia, Kentucky, Louisiana, Maryland, Mississippi, North Carolina, Oklahoma, South Carolina, Tennessee, Texas, Virginia, and West Virginia.)

$\S$ Cancer incidence data were compiled from cancer registries that met the data quality criteria for all invasive cancer sites combined, representing approximately $99 \%$ of the U.S. population. (Data from Nevada did not meet U.S. Cancer Statistics publication criteria for 2010-2014.) Data for Puerto Rico are included in state-specific analyses but not in U.S. census region analyses. 
FIGURE 19. Incidence rates* for male urinary bladder cancer, by state/area and U.S. census region ${ }^{\dagger} \_$United States, ${ }^{\S}$ 2010-2014

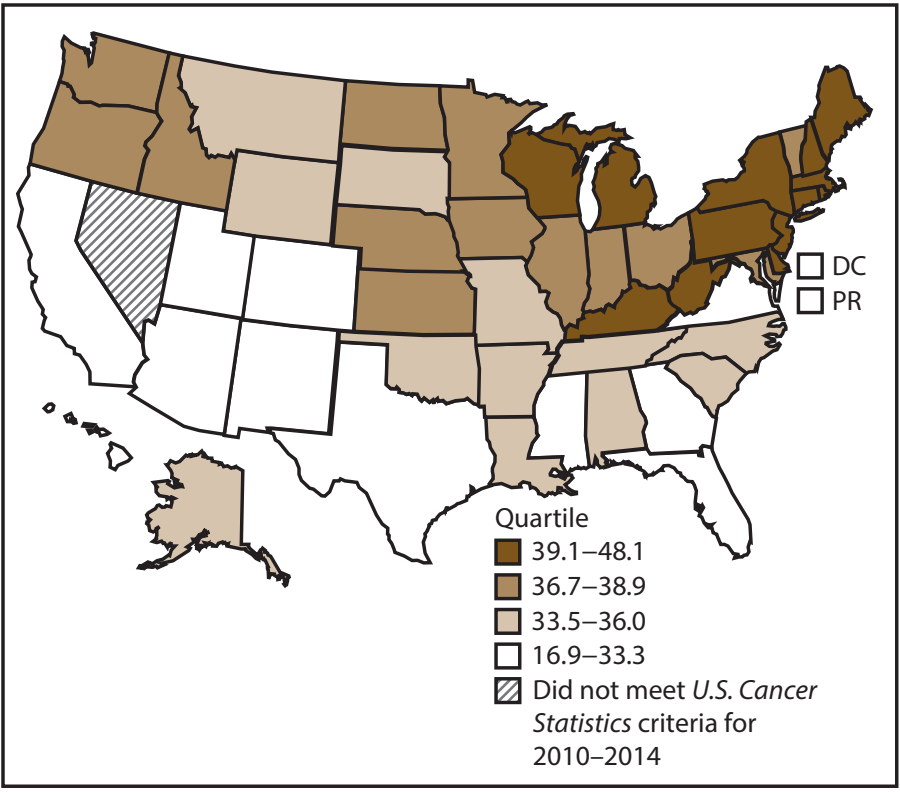

Abbreviations: $\mathrm{DC}=$ District of Columbia; $\mathrm{PR}=$ Puerto Rico.

* New cases diagnosed per 100,000 males, age adjusted to the 2000 U.S. standard population.

† West: 32.5; Midwest: 37.9; Northeast: 42.5; South: 33.0. (West: Alaska, Arizona, California, Colorado, Hawaii, Idaho, Montana, Oregon, New Mexico, Utah, Washington, and Wyoming; Midwest: Illinois, Indiana, lowa, Kansas, Michigan, Minnesota, Missouri, Nebraska, North Dakota, Ohio, South Dakota, and Wisconsin; Northeast: Connecticut, Maine, Massachusetts, New Hampshire, New Jersey, New York, Pennsylvania, Rhode Island, and Vermont; South: Alabama, Arkansas, Delaware, District of Columbia, Florida, Georgia, Kentucky, Louisiana, Maryland, Mississippi, North Carolina, Oklahoma, South Carolina, Tennessee, Texas, Virginia, and West Virginia.)

$\S$ Cancer incidence data were compiled from cancer registries that met the data quality criteria for all invasive cancer sites combined, representing approximately $99 \%$ of the U.S. population. (Data from Nevada did not meet U.S. Cancer Statistics publication criteria for 2010-2014.) Data for Puerto Rico are included in state-specific analyses but not in U.S. census region analyses.
FIGURE 20. Incidence rates* for female urinary bladder cancer, by state/area and U.S. census region ${ }^{\dagger} \_$United States, ${ }^{\S}$ 2010-2014

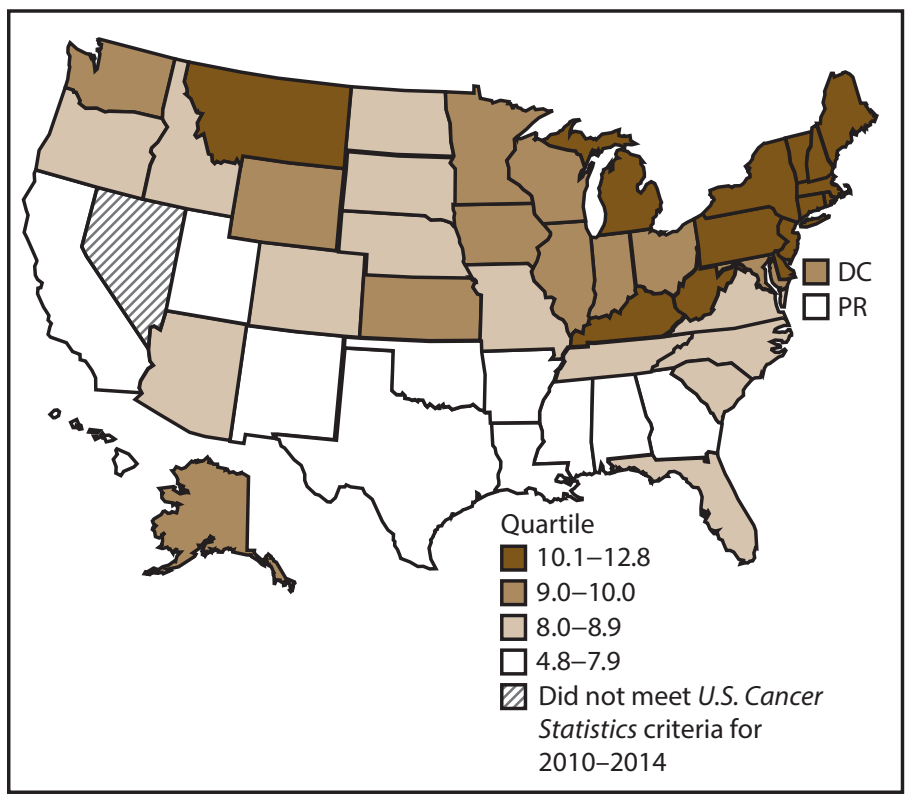

Abbreviations: $\mathrm{DC}=$ District of Columbia; $\mathrm{PR}=$ Puerto Rico

* New cases diagnosed per 100,000 females, age adjusted to the 2000 U.S. standard population.

† West: 7.8; Midwest: 9.4; Northeast: 11.0; South: 8.0. (West: Alaska, Arizona, California, Colorado, Hawaii, Idaho, Montana, Oregon, New Mexico, Utah, Washington, and Wyoming; Midwest: Illinois, Indiana, lowa, Kansas, Michigan, Minnesota, Missouri, Nebraska, North Dakota, Ohio, South Dakota, and Wisconsin; Northeast: Connecticut, Maine, Massachusetts, New Hampshire, New Jersey, New York, Pennsylvania, Rhode Island, and Vermont; South: Alabama, Arkansas, Delaware, District of Columbia, Florida, Georgia, Kentucky, Louisiana, Maryland, Mississippi, North Carolina, Oklahoma, South Carolina, Tennessee, Texas, Virginia, and West Virginia.)

$\S$ Cancer incidence data were compiled from cancer registries that met the data quality criteria for all invasive cancer sites combined, representing approximately $99 \%$ of the U.S. population. (Data from Nevada did not meet U.S. Cancer Statistics publication criteria for 2010-2014.) Data for Puerto Rico are included in state-specific analyses but not in U.S. census region analyses. 
FIGURE 21. Incidence rates* for cervical cancer, by state/area and U.S. census region ${ }^{\dagger}$ — United States, $\$$ 2010-2014

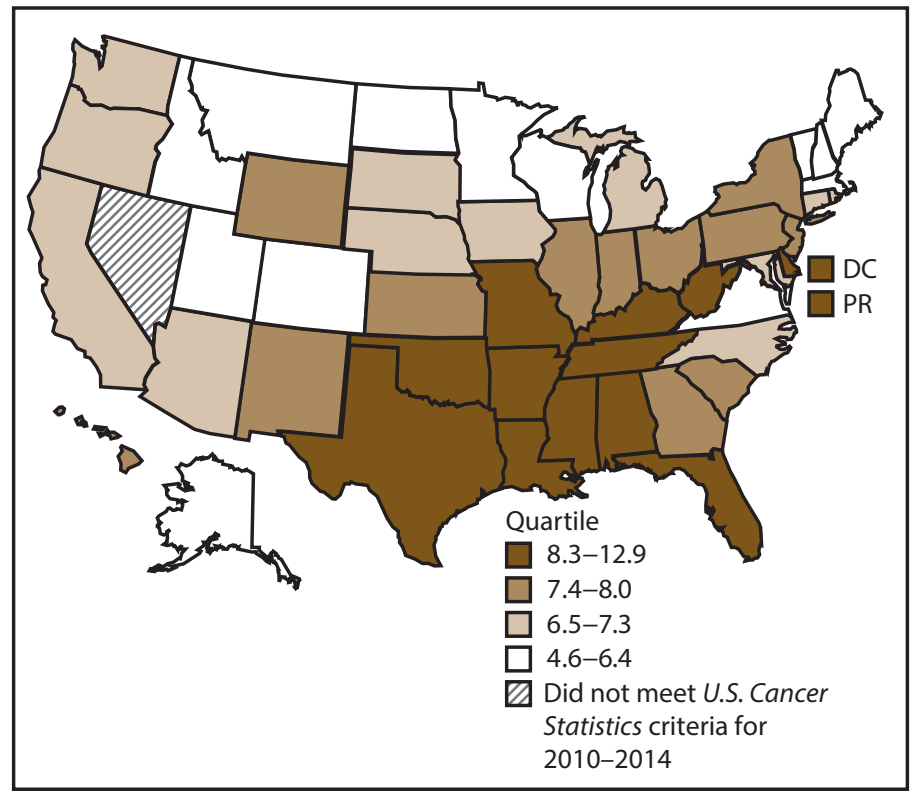

Abbreviations: $\mathrm{DC}=$ District of Columbia; $\mathrm{PR}=$ Puerto Rico.

* New cases diagnosed per 100,000 females, age adjusted to the 2000 U.S. standard population.

† West: 6.9; Midwest: 7.1; Northeast: 7.1; South: 8.3. (West: Alaska, Arizona, California, Colorado, Hawaii, Idaho, Montana, Oregon, New Mexico, Utah, Washington, and Wyoming; Midwest: Illinois, Indiana, lowa, Kansas, Michigan, Minnesota, Missouri, Nebraska, North Dakota, Ohio, South Dakota, and Wisconsin; Northeast: Connecticut, Maine, Massachusetts, New Hampshire, New Jersey, New York, Pennsylvania, Rhode Island, and Vermont; South: Alabama, Arkansas, Delaware, District of Columbia, Florida, Georgia, Kentucky, Louisiana, Maryland, Mississippi, North Carolina, Oklahoma, South Carolina, Tennessee, Texas, Virginia, and West Virginia.)

$\S$ Cancer incidence data were compiled from cancer registries that met the data quality criteria for all invasive cancer sites combined, representing approximately $99 \%$ of the U.S. population. (Data from Nevada did not meet U.S. Cancer Statistics publication criteria for 2010-2014.) Data for Puerto Rico are included in state-specific analyses but not in U.S. census region analyses. 
FIGURE 22. Incidence rates* for male acute myeloid leukemia, by state/area and U.S. census region ${ }^{\dagger}$ — United States, ${ }^{\S}$ 2010-2014

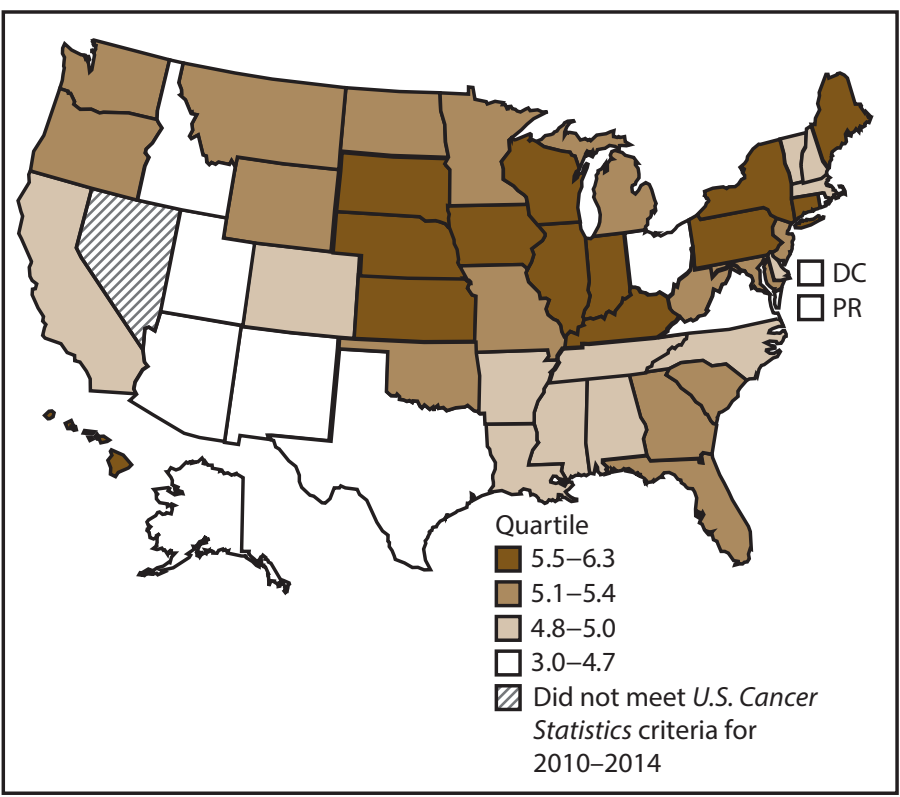

Abbreviations: $\mathrm{DC}=$ District of Columbia; $\mathrm{PR}=$ Puerto Rico.

* New cases diagnosed per 100,000 males, age adjusted to the 2000 U.S. standard population.

† West: 4.9; Midwest: 5.5; Northeast: 5.5; South: 5.0. (West: Alaska, Arizona, California, Colorado, Hawaii, Idaho, Montana, Oregon, New Mexico, Utah, Washington, and Wyoming; Midwest: Illinois, Indiana, lowa, Kansas, Michigan, Minnesota, Missouri, Nebraska, North Dakota, Ohio, South Dakota, and Wisconsin; Northeast: Connecticut, Maine, Massachusetts, New Hampshire, New Jersey, New York, Pennsylvania, Rhode Island, and Vermont; South: Alabama, Arkansas, Delaware, District of Columbia, Florida, Georgia, Kentucky, Louisiana, Maryland, Mississippi, North Carolina, Oklahoma, South Carolina, Tennessee, Texas, Virginia, and West Virginia.)

$\S$ Cancer incidence data were compiled from cancer registries that met the data quality criteria for all invasive cancer sites combined, representing approximately $99 \%$ of the U.S. population. (Data from Nevada did not meet U.S. Cancer Statistics publication criteria for 2010-2014.) Data for Puerto Rico are included in state-specific analyses but not in U.S. census region analyses.
FIGURE 23. Incidence rates* for female acute myeloid leukemia, by state/area and U.S. census region ${ }^{\dagger} \_$United States, ${ }^{\S}$ 2010-2014

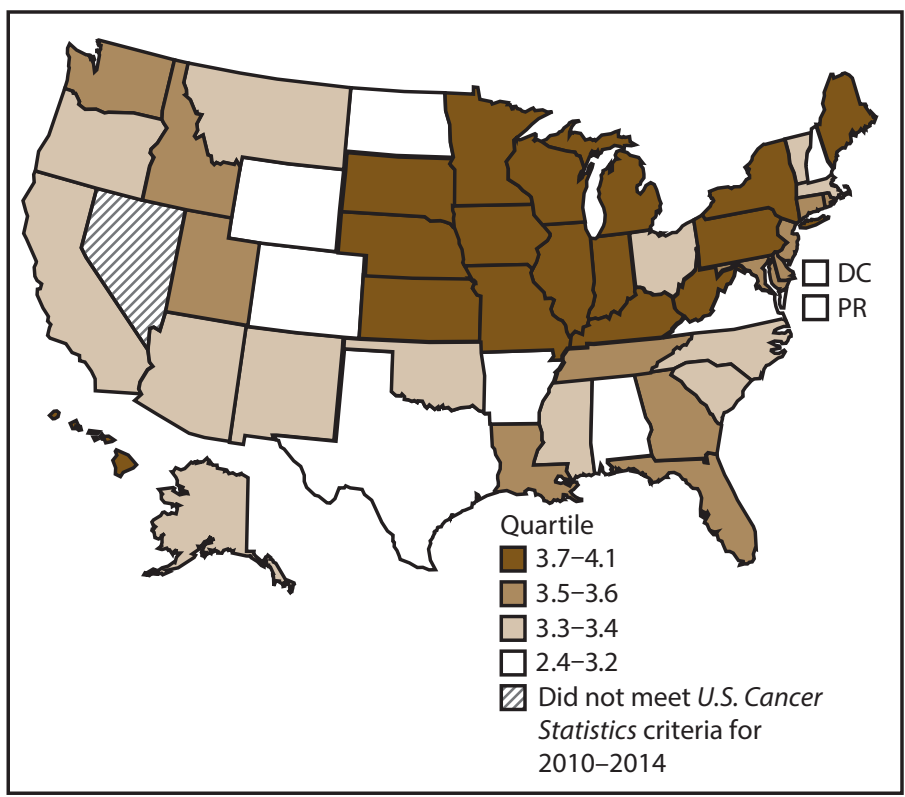

Abbreviations: $\mathrm{DC}=$ District of Columbia; $\mathrm{PR}=$ Puerto Rico.

* New cases diagnosed per 100,000 females, age adjusted to the 2000 U.S. standard population.

† West: 3.4; Midwest: 3.7; Northeast: 3.7; South: 3.4. (West: Alaska, Arizona, California, Colorado, Hawaii, Idaho, Montana, Oregon, New Mexico, Utah, Washington, and Wyoming; Midwest: Illinois, Indiana, lowa, Kansas, Michigan, Minnesota, Missouri, Nebraska, North Dakota, Ohio, South Dakota, and Wisconsin; Northeast: Connecticut, Maine, Massachusetts, New Hampshire, New Jersey, New York, Pennsylvania, Rhode Island, and Vermont; South: Alabama, Arkansas, Delaware, District of Columbia, Florida, Georgia, Kentucky, Louisiana, Maryland, Mississippi, North Carolina, Oklahoma, South Carolina, Tennessee, Texas, Virginia, and West Virginia.)

$\S$ Cancer incidence data were compiled from cancer registries that met the data quality criteria for all invasive cancer sites combined, representing approximately $99 \%$ of the U.S. population. (Data from Nevada did not meet U.S. Cancer Statistics publication criteria for 2010-2014.) Data for Puerto Rico are included in state-specific analyses but not in U.S. census region analyses. 



The Morbidity and Mortality Weekly Report (MMWR) Series is prepared by the Centers for Disease Control and Prevention (CDC) and is available free of charge in electronic format. To receive an electronic copy each week, visit MMWR at https://www.cdc.gov/mmwr/index.html.

Readers who have difficulty accessing this PDF file may access the HTML file at https://www.cdc.gov/mmwr/volumes/67/ss/ss6712a1.htm?s_ cid=ss6712a1_w. Address all inquiries about the $M M W R$ Series, including material to be considered for publication, to Executive Editor, $M M W R$ Series, Mailstop E-90, CDC, 1600 Clifton Rd., N.E., Atlanta, GA 30329-4027 or to mmwrq@cdc.gov.

All material in the MMWR Series is in the public domain and may be used and reprinted without permission; citation as to source, however, is appreciated. MMWR and Morbidity and Mortality Weekly Report are service marks of the U.S. Department of Health and Human Services.

Use of trade names and commercial sources is for identification only and does not imply endorsement by the U.S. Department of Health and Human Services.

References to non-CDC sites on the Internet are provided as a service to $M M W R$ readers and do not constitute or imply endorsement of these organizations or their programs by CDC or the U.S. Department of Health and Human Services. CDC is not responsible for the content of these sites. URL addresses listed in $M M W R$ were current as of the date of publication.

ISSN: 0149-2195 (Print) 